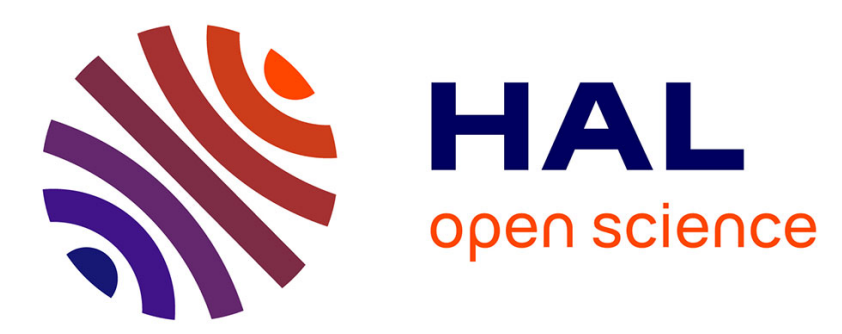

\title{
An approach to constructing a homogeneous time series of soil moisture using SMOS
}

D. Leroux, Yann H. Kerr, E. F. Wood, A.K. Sahoo, R. Bindlish, T.J. Jackson

\section{To cite this version:}

D. Leroux, Yann H. Kerr, E. F. Wood, A.K. Sahoo, R. Bindlish, et al.. An approach to constructing a homogeneous time series of soil moisture using SMOS. IEEE Transactions on Geoscience and Remote Sensing, 2013, 99, pp.1-13. 10.1109/TGRS.2013.2240691 • ird-00828699

\section{HAL Id: ird-00828699 \\ https://hal.ird.fr/ird-00828699}

Submitted on 31 May 2013

HAL is a multi-disciplinary open access archive for the deposit and dissemination of scientific research documents, whether they are published or not. The documents may come from teaching and research institutions in France or abroad, or from public or private research centers.
L'archive ouverte pluridisciplinaire HAL, est destinée au dépôt et à la diffusion de documents scientifiques de niveau recherche, publiés ou non, émanant des établissements d'enseignement et de recherche français ou étrangers, des laboratoires publics ou privés. 


\section{- An Approach to Constructing a Homogeneous Time Series of Soil Moisture Using SMOS}

\begin{abstract}
5 Abstract-Overlapping soil moisture time series derived 6 from two satellite microwave radiometers (the Soil Moisture 7 and Ocean Salinity and the Advanced Microwave Scanning 8 Radiometer-Earth Observing System) are used to generate a soil 9 moisture time series from 2003 to 2010 . Two statistical methodolo10 gies for generating long homogeneous time series of soil moisture 11 are considered. Generated soil moisture time series using only 12 morning satellite overpasses are compared to ground measure13 ments from four watersheds in the U.S.A. with different clima14 tologies. The two methods, cumulative density function (CDF) 15 matching and copulas, are based on the same statistical theory, but 16 the first makes the assumption that the two data sets are ordered 17 the same way, which is not needed by the second. Both methods 18 are calibrated in $\mathbf{2 0 1 0}$, and the calibrated parameters are applied 19 to the soil moisture data from 2003 to 2009 . Results from these 20 two methods compare well with ground measurements. However, 21 CDF matching improves the correlation, whereas copulas improve 22 the root-mean-square error.
\end{abstract}

23 Index Terms-Advanced Microwave Scanning Radiometer24 Earth Observing System (AMSR-E), cumulative density func25 tion (CDF) matching, copulas, Soil Moisture and Ocean Salinity 26 (SMOS), soil moisture, time series.

\section{INTRODUCTION}

28 OIL moisture is an important variable and is now consid29 ered as an essential climate variable by the World Meteo30 rological Organization [1]. It has a crucial role in the transfers 31 of water and energy between the soil and the atmosphere. Soil 32 moisture is also an input variable for land surface modeling 33 in determining the evaporative fraction at the surface and the 34 infiltration in the root zone. For both agriculture and water 35 resource management, soil moisture information is essential at 36 local and regional scales. At global scales, soil moisture is of

Manuscript received November 28, 2011; revised May 14, 2012 and October 22, 2012; accepted December 22, 2012. This work was supported in part by Telespazio France and in part by TOSCA.

D. J. Leroux is with the Centre d'Etudes Spatiales de la Biosphere, 31400 Toulouse, France, and also with Telespazio France, 31023 Toulouse Cedex 1, France (e-mail: delphine.j.leroux@gmail.com).

Y. H. Kerr is with the Centre d'Etudes Spatiales de la Biosphere, 31400 Toulouse, France (e-mail: yann.kerr@cesbio.cnes.fr).

E. F. Wood and A. K. Sahoo are with the Department of Civil and Environmental Engineering, Princeton University, Princeton, NJ 08544 USA (e-mail: efwood@princeton.edu; aksahoo2004@gmail.com).

R. Bindlish and T. J. Jackson are with the USDA ARS Hydrology and Remote Sensing Laboratory, Beltsville, MD 20705 USA (e-mail: rajat.bindlish@ ars.usda.gov; tom.jackson@ars.usda.gov).

Color versions of one or more of the figures in this paper are available online at http://ieeexplore.ieee.org.

Digital Object Identifier 10.1109/TGRS.2013.2240691 great value for weather forecasting [2], climate change [3], and 37 monitoring extreme events such as floods and droughts. $\quad 38$

Soil Moisture and Ocean Salinity (SMOS) [4] was success- 39 fully launched by the European Space Agency in November 40 2009 and since has been providing global maps of soil moisture 41 every three days at a nominal spatial resolution of $43 \mathrm{~km} 42$ with an accuracy of $0.04 \mathrm{~m}^{3} / \mathrm{m}^{3}$. SMOS is the first mission 43 specifically designed for soil moisture monitoring. The Soil 44 Moisture Active Passive (SMAP) mission [5] is scheduled 45 for launch in October 2014 by the National Aeronautics and 46 Space Administration. SMAP will continue the time series of 47 soil moisture based on $1.4-\mathrm{GHz}$ radiometer observations that 48 began with SMOS. The 1.4-GHz frequency channel is the most 49 suitable frequency for soil moisture retrieval [6].

50

Longer time series of satellite-based soil moisture would be 51 of value in climate-related analysis. Utilizing the data from the 52 previous generations of satellite sensors involves resolving nu- 53 merous issues. Some of the platforms and approaches have been 54 developed to retrieve soil moisture using the higher frequencies, 55 which has been the only option until now. These include the 56 Scanning Multichannel Microwave Radiometer (1978-1987) 57 [7], the Special Sensor Microwave/Imager (1987-current) 58 [7], the Advanced Microwave Scanning Radiometer-Earth 59 Observing System (AMSR-E) (2002-2011) [7], [8], Wind- 60 Sat (2003-current) [9], and the European Remote Sensing- 61 Advanced Scatterometer (1991-current) [10]. Although their 62 lowest frequencies $(5-20 \mathrm{GHz})$ are not the most suitable for 63 soil moisture retrievals (higher sensitivity to vegetation growth 64 and atmospheric conditions), they remain a valuable time series 65 from 1978 until now. Applications such as data assimilation 66 or climate change assessment require consistent products. The 67 products referenced earlier have been retrieved using different 68 sensors with different algorithms, and as a result, the time series 69 is not homogeneous. This heterogeneity can be interpreted as a 70 bias and is a problem in the data assimilation process. To avoid 71 this issue, these products need to be processed to correct for any 72 bias or amplitude variation between the data sets.

73

Many previous studies have developed various methods for 74 the homogenization of time series. Vincent et al. [11] developed 75 a method to harmonize temperature time series with gaps. The 76 first step was to determine if the series was homogeneous by 77 comparing its anomalies to those of a reference series. The 78 identification of the gaps and their magnitude was performed 79 by successively fitting a linear model with different magnitude 80 values with the best fit being indicated by the minimum sum 81 of square errors. Homogeneous temperature and precipitation 82 time series were developed by Begert et al. [12] using statistical 83 
84 methods to detect potential inhomogeneity. In that study, a 85 reference time series was necessary in order to detect and 86 compute the magnitude of the shifts. Picard and Fily [13] 87 proposed a method to simulate a homogeneous time series of 88 the cumulative melting surface in Antarctica. Using satellite 89 observations from different sensors and acquisition times was 90 the biggest challenge. Correcting for the effect of the observing 91 time was accomplished in two steps. First, a sinusoidal function 92 with a 24-h periodicity was fitted, and then, an optimal interpo93 lation to refine this first guess model to force it to be closer was 94 applied to the observations and to provide very low uncertainty 95 around observation time and larger uncertainty when there is no 96 available observation.

97 Matching the cumulative density functions (CDFs) of two 98 data sets has been used in several studies to merge time series. 99 Reichle and Koster [14] and Choi and Jacobs [15] merged 100 soil moisture derived from satellite observations with model 101 data, and Li et al. [16] corrected the bias of precipitation 102 and temperature products derived from different models. CDF 103 matching was also used as a preliminary step of the assimilation 104 process [17] and to produce long time series of soil moisture 105 [18], [19].

106 Over the last few years, a new method based on copula 107 functions has been developed. It allows the derivation of bi108 variate distributions without making the assumptions required 109 when dealing with multivariate frequency distributions, e.g., 110 the same type of marginal distribution for both variables, a 111 joint normal distribution, and independent variables. One of 112 the major advantages of the copula method is that the marginal 113 distributions can be of any form [20]. The first comprehensive 114 treatment of copulas was by Nelsen [21]. He presented methods 115 to construct copulas and discussed the role played by copulas 116 in modeling and dependence. Since then, copulas have been 117 applied in various applications with the majority of the liter118 ature dedicated to the financial sector [22], [23]. In the field of 119 hydrology, some applications have emerged. Genest and Favre 120 [24] summarized the existing methods to detect and evaluate 121 the dependence between the data sets through copulas (analyt122 ically and graphically) and enumerated the various methods to 123 choose the best copula family and estimate their parameters. 124 Favre et al. [25] applied copulas to peak flows and volumes 125 from two watersheds, Salvadori and De Michele [26] to storm 126 and rainfall time series, Dupuis [27] to the volume and duration 127 of low flows of two rivers, Zhang and Singh [28] to rainfall fre128 quency, Serinaldi and Grimaldi [29] to flood and sea frequency, 129 and Laux et al. [30] to precipitation data. Gao et al. [31] used 130 copulas as a preprocessing step for the assimilation process on 131 soil moisture data.

132 Joint statistical analysis has already been applied when the 133 sources of the soil moisture measurements come from different 134 observation systems (e.g., AMSR-E surface soil moisture and 135 10-cm soil moisture from a land surface model [14]). Similarly, 136 joint statistical methods form the basis for data assimilation of 137 satellite soil moisture into land surface models [31]. There are 138 many other studies related to joint probability, including where 139 the variables are physically different but where their statistical 140 relationships are useful (e.g., rainfall storm intensity and storm 141 duration [32]).
The goal of this paper is to estimate for all the AMSR-E 142 period (2003-2010) SMOS-equivalent observations that can be 143 used to develop a statistical representation of SMOS retrieval so 144 that current and future SMOS retrievals can be used in applica- 145 tions like drought monitoring based on percentiles. However, 146 matching 130 am C-/X-band (AMSR-E) observations with 147 600 am L-band (SMOS) observations presents some issues: 148 1) The crossing times are different, and rainfalls may occur be- 149 tween the two acquisitions; and 2) the frequencies are different, 150 so the sensing depths are not similar.

151

The statistical impact of the rainfalls that could occur be- 152 tween 130 am and 600 am is to lower the correlation. However, 153 if the correlation is sufficiently high, a statistical relationship 154 can be established to estimate an equivalent SMOS value from 155 an AMSR-E observation. This high correlation implies that the 156 occurrence of precipitation between the SMOS and AMSR-E 157 overpasses is rare. Moreover, it is well known that soil moisture 158 has a long temporal correlation time scale, so the overpass time 159 differences will have a minimal effect on the analysis.

160

The impact of the different frequencies between AMSR-E 161 and SMOS is, in most situations, not significant. The higher 162 AMSR-E frequency $(10.7 \mathrm{GHz})$ results in a more superficial 163 emission depth than the SMOS observations, so while the 164 retrieved values may be different, their relative values will be 165 similar (both dry or wet). The correlation between paired ob- 166 servations depends on their relative values (with their individual 167 time series) and not absolute values, and in the case of copula- 168 based joint distributions, the correlation is represented by the 169 Kendall tau whose calculation is based on ranks.

If the two sensing depths were to be reconciled physically, 171 given the soil property variability (spatially and with depth) 172 with different wetting and drying properties, a physical model 173 would introduce significant uncertainty that could be very 174 difficult to estimate afterward. If the SMOS (or AMSR-E) 175 data were adjusted to the AMSR-E (or SMOS) emission depth 176 through data assimilation into a land surface model for exam- 177 ple, then the complete record would have to be adjusted with 178 the added uncertainty of the data assimilation step. With any 179 of the suggested adjustments, there is a mismatch with the 180 past or with the future. Only by treating the original data sets 181 and determining the information content between them can a 182 consistent approach be represented.

Data assimilation could, however, deal with the precipitation 184 and the difference in sensing depth issues, but that would imply 185 other uncertainties such as the space-time variability of the 186 precipitation data sets, as well as other meteorological issues. 187 Building a homogeneous time series based on data assimila- 188 tion into a land surface model can be seen as a competing 189 approach.

In this paper, we show two statistical methods to obtain 191 this homogeneous time series. The satellite data and the four 192 watersheds where the time series are simulated are presented 193 in Section II. The two statistical methods for generating ho- 194 mogeneous time series are presented in Section III which 195 includes the general theory and how to apply them to real data. 196 Simulated time series over the four watersheds are presented in 197 Section IV. Conclusions and perspectives are described in the 198 last section. 


\section{A. SMOS}

202 With its L-band radiometer, SMOS [4] has been providing 203 soil moisture data for almost three years and global coverage 204 every three days with a 43-km resolution. The satellite is polar 205 orbiting with equator crossing times of 6 am (local solar time 206 (LST), ascending) and 6 pm (LST, descending). The signal at 207 L-band is mainly influenced by the water content at the surface 208 of the soil (around $5 \mathrm{~cm}$ ).

209 SMOS acquires brightness temperatures at multiple inci210 dence angles, from $0^{\circ}$ to $55^{\circ}$ with full polarization. The an211 gular signature is a key element of the retrieval algorithm 212 that provides soil moisture and the vegetation optical thickness 213 through the minimization of a cost function between modeled 214 and acquired brightness temperatures [33], [34]. This estimated 215 soil moisture is referred as the Level 2 product [34] and is AQ12 216 available on the Icosahedral Snyder Equal Area-4h9 grid [35]. 217 The nodes of this grid are equally spaced at about $15 \mathrm{~km}$. In 218 this paper, the 2010 SMOS Level 2 version 4 products have 219 been used.

220 Currently, numerous studies are underway on the validation 221 of SMOS soil moisture product with in situ measurements 222 and estimates of other sensors and models. Bitar et al. [36] 223 used the Soil Climate Analysis Network [37] and the Snow224 pack Telemetry sites in North America to compare SMOS 225 soil moisture retrievals and ground measurements. That study 226 showed that SMOS soil moisture had a very good dynamic 227 response but tended to underestimate the values. However, 228 the new version of the product (V4) significantly improved 229 the general results. Jackson et al. [38] studied SMOS soil 230 moisture and vegetation optical depth over four watersheds in 231 the U.S. They concluded that SMOS almost met the accuracy AQ13 232 requirement with root-mean-square errors (rmses) of 0.043 and $2330.047 \mathrm{~m}^{3} / \mathrm{m}^{3}$ in the morning and afternoon, respectively, 234 whereas the vegetation optical depth retrievals were not reliable AQ14 235 yet for use in vegetation analyses. Leroux et al. [39] compared 236 SMOS data with other satellite and model output products over 237 the same four watersheds for the year 2010. It showed that 238 SMOS soil moisture data were closer to the ground measure239 ments than the other data sets. Even though the correlation 240 coefficient was not the best, the bias was extremely small.

241 After the results of the validation activities, the European 242 Center for Medium-Range Weather Forecasts has decided and 243 is now ready to process SMOS data in near real time into their 244 Integrated Forecast System. It is expected to have an impact on 245 the weather forecast at short and medium ranges [40].

\section{B. AMSR-E}

247 The AMSR-E was launched in June 2002 on the Aqua 248 satellite. This radiometer acquires data with a single $55^{\circ}$ inci249 dence angle at six different frequencies: 6.9, 10.7, 18.7, 23.8, 25036.5 , and $89.0 \mathrm{GHz}$, all dual polarized. The crossing times are 251 respectively 1:30 am (LST, descending) and 1:30 pm (LST, 252 ascending).

253 There are several soil moisture products available that are 254 based on AMSR-E data. Many studies have already showed

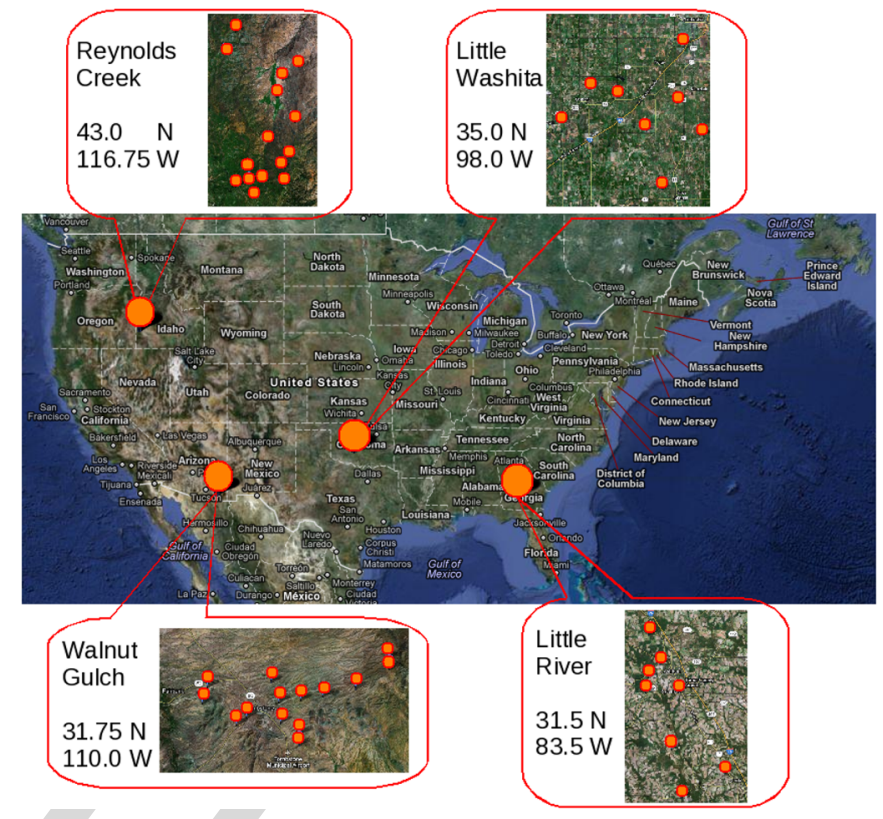

Fig. 1. Map of the four sites: WG, AZ; LW, OK; LR, GA; and RC, ID.

that the NASA product [41] is not able to reproduce low values 255 AQ15 of soil moisture and has low dynamic range [42]-[46]. The 256 soil moisture data produced by the joint collaboration of the 257 Vrije University of Amsterdam and NASA (whereafter called 258 the Land Parameter Retrieval Model (LPRM) [7]) were chosen 259 in this study.

260 AQ16

The LPRM [7] retrieves soil moisture and optical thickness 261 using the C- and X-band AMSR-E channels (combined prod- 262 uct) and $36.5 \mathrm{GHz}$ to estimate the surface temperature. This 263 algorithm is based on a microwave radiative transfer model with 264 a priori information about soil characteristics. The products are 265 available on a $0.25^{\circ} \times 0.25^{\circ}$ grid only for the descending orbit. 266 These data have been quality controlled, and the contaminated 267 estimates due to high topography and extreme weather condi- 268 tions such as snow have been flagged and not been considered 269 in this study.

\section{Study Areas}

Four watersheds located in the United States were selected 272 for this study: Walnut Gulch (WG) in Arizona, Little Washita 273 (LW) in Oklahoma, Little River (LR) in Georgia, and Reynolds 274 Creek (RC) in Idaho (see Fig. 1). They represent different 275 types of climate (from semiarid to humid) and land use patterns 276 [47]. These four watersheds have been used as calibration and 277 validation sites for comparison of AMSR-E satellite product 278 [47] and SMOS product [38], [39].

WG is located in the Southeast Arizona. Most of the water- 280 shed is covered by shrubs and grass, which is typical of the re- 281 gion. The annual mean temperature is $17.6{ }^{\circ} \mathrm{C}$ (at Tombstone), 282 and the annual mean precipitation is $320 \mathrm{~mm}$ (mainly from 283 high intensity convective thunderstorms in the late summer). 284 The uppermost $10 \mathrm{~cm}$ of the soil profile contains up to $60 \% 285$ gravel, and the underlying horizons usually contain less than 286 $40 \%$ gravel. 
TABLE I

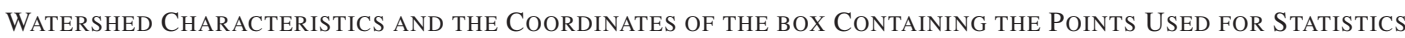

\begin{tabular}{|c|c|c|c|c|c|c|}
\hline Watershed & $\begin{array}{l}\text { Number of } \\
\text { stations }\end{array}$ & Climate & $\begin{array}{c}\text { Annual } \\
\text { rainfall }(\mathrm{mm})\end{array}$ & Topography & Land use & $\begin{array}{l}\text { Box for statistics } \\
\text { (corners coord.) }\end{array}$ \\
\hline $\begin{array}{l}\text { Walnut Gulch } \\
\text { AZ }\end{array}$ & 14 & semi-arid & 320 & rolling & range & $31.3 \mathrm{~N}-110.5 \mathrm{~W}$ \\
\hline $\begin{array}{l}\text { Little Washita } \\
\text { OK }\end{array}$ & 8 & sub-humid & 750 & rolling & range/wheat & $\begin{array}{l}34.4 \mathrm{~N}-98.5 \mathrm{~W} \\
35.4 \mathrm{~N}-97.5 \mathrm{~W}\end{array}$ \\
\hline $\begin{array}{l}\text { Little River } \\
\text { GA }\end{array}$ & 8 & humid & 1200 & flat & row crop/forest & $\begin{array}{l}31.0 \mathrm{~N}-84.0 \mathrm{~W} \\
32.0 \mathrm{~N}-83.0 \mathrm{~W}\end{array}$ \\
\hline $\begin{array}{l}\text { Reynolds Creek } \\
\text { ID }\end{array}$ & 15 & semi-arid & 500 & mountainous & range & $\begin{array}{l}34.7 \mathrm{~N}-98.7 \mathrm{~W} \\
35.7 \mathrm{~N}-97.7 \mathrm{~W}\end{array}$ \\
\hline
\end{tabular}

TABLE II

Correlation CoEFFicients (R) BETWEen THE IN SitU MEASUREMENTS AT 130 AM AND 600 AM FOR THE FOUR WATERSHEDS. N IS THE Number of AVAilable Dates, AND CI IS THE 95\% CONFIDENCE INTERVAL

\begin{tabular}{ccc|ccc}
\hline \multicolumn{3}{c|}{ WG } & \multicolumn{4}{c}{ LW } \\
\hline $\mathrm{R}$ & $\mathrm{N}$ & $\mathrm{CI}$ & $\mathrm{R}$ & $\mathrm{N}$ & $\mathrm{CI}$ \\
0.96 & 365 & {$[0.95-0.97]$} & 0.97 & 365 & {$[0.96-0.98]$} \\
\hline \multicolumn{3}{c|}{} & \multicolumn{4}{c}{$\mathrm{RC}$} \\
\multicolumn{3}{c}{$\mathrm{LR}$} \\
\hline $\mathrm{R}$ & $\mathrm{N}$ & $\mathrm{CI}$ & $\mathrm{R}$ & $\mathrm{N}$ & $\mathrm{CI}$ \\
0.95 & 365 & {$[0.94-0.96]$} & 0.99 & 328 & {$[0.99-0.99]$} \\
\hline
\end{tabular}

288 LW is located in Southwest Oklahoma in the Southern Great 289 Plains region of the U.S. The climate is subhumid with an 290 average annual rainfall of $750 \mathrm{~mm}$ (mainly during the spring 291 and fall seasons). Topography is moderately rolling with a 292 maximum relief of less than $200 \mathrm{~m}$. Land use is dominated by 293 rangeland and pasture $(63 \%)$.

294 LR is located in the Southern Georgia near Tifton. With 295 an average annual precipitation of $1200 \mathrm{~mm}$, the climate is 296 humid. The LR watershed is typical of the heavily vegetated 297 slow-moving stream systems in the Coastal Plain region of 298 the U.S. The topography over this watershed is relatively flat. 299 Approximately $40 \%$ of the watershed is forest with $40 \%$ crops 300 and $15 \%$ pasture.

$301 \mathrm{RC}$ is located in a mountainous area of Southwest Idaho. The 302 topography is high with a relief of over $1000 \mathrm{~m}$ that results in 303 diverse climates. Soils and vegetations are typical in this part 304 of the Rocky Mountains. The climate is considered as semiarid 305 with an annual precipitation of $500 \mathrm{~mm}$. Approximately $75 \%$ of 306 the annual precipitation at high elevation is snow, whereas only $30725 \%$ is snow at low elevation.

308 Surface soil moisture and temperature sensors $(0-5 \mathrm{~cm})$ have 309 been acquiring data since 2002 for the four watersheds. The 310 data used in this study are the means and standard deviations 311 of the soil moisture and surface temperature acquired every $31230 \mathrm{~min}$ from 2009 to 2010 (hourly for RC). The averages 313 are based on 14/8/8/15 sensors for WG/LW/LR/RC, respec314 tively, after eliminating sensors with poor and suspicious AQ19 315 performances. Weighting coefficients have been derived for 316 each sensor with a Thiessen polygon. Table I summarizes the 317 characteristics of each watershed [47].

318 In order to estimate the effect of the rainfalls that could 319 occur between $130 \mathrm{am}$ and $600 \mathrm{am}$, the correlation coefficients 320 between the measurements at 130 am and 600 am have been 321 computed for the four watersheds (see Table II and Fig. 2). They 322 range from 0.95 to 0.99 , and based on the fact that rainfalls 323 would lower the correlation, we can assess that precipitations 324 that do not affect significantly the analysis.

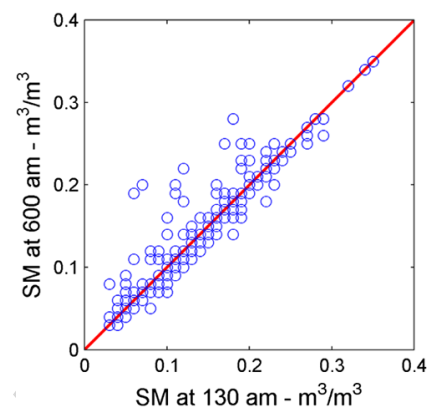

(a)

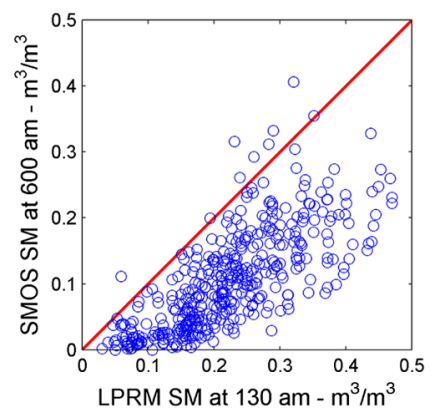

(b)
Fig. 2. Comparison between the 130 am and the 600 am soil moisture: In situ observations and satellite products for the four watersheds. (a) In situ soil moisture at $130 \mathrm{am}$ and $600 \mathrm{am}$. (b) LPRM (130 am) and SMOS (600 am) soil moisture.

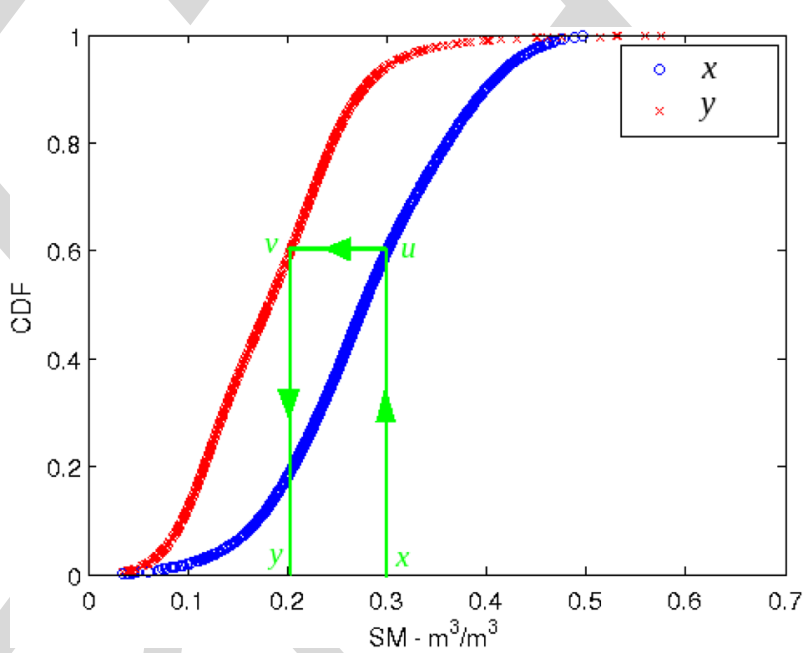

Fig. 3. Principle of CDF matching by setting the probabilities equal. For a given $x$, find $y$ such that $G_{Y}(y)=F_{X}(x)$.

\section{Two Statistical Methods for Generating HOMOGENEOUS TIME SERIES}

Two statistical methods were used to create a homogeneous 327 time series of soil moisture. CDF matching has been widely 328 used in previous studies to merge time series [14], [15], [18], 329 [19], whereas copulas have just started to be used recently for 330 environmental purposes.

\section{A. CDF Matching}

The $\mathrm{CDF}$ is the probability that a random variable $X$ takes a 333 value less than or equal to a given number $x$

$$
F_{X}(x)=\operatorname{Pr}[X \leq x]
$$




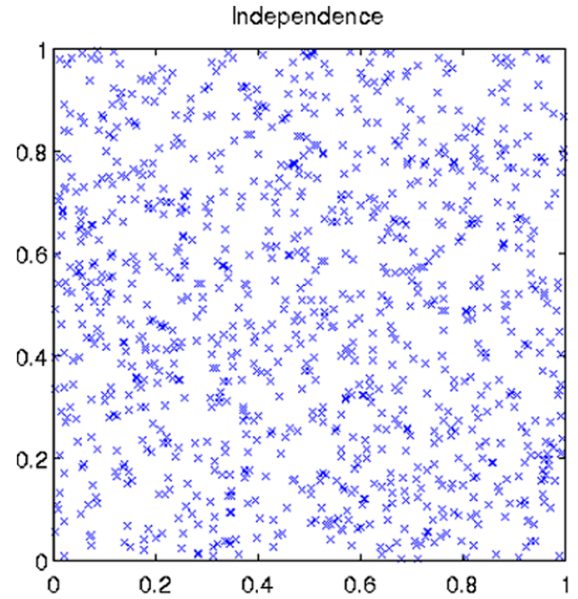

(a)

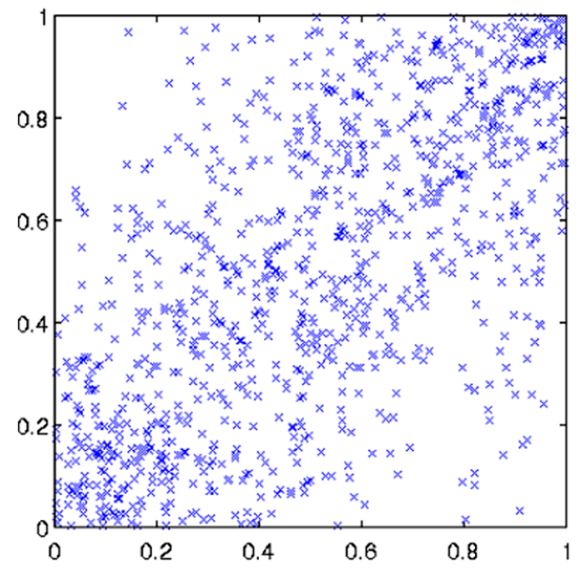

(d)

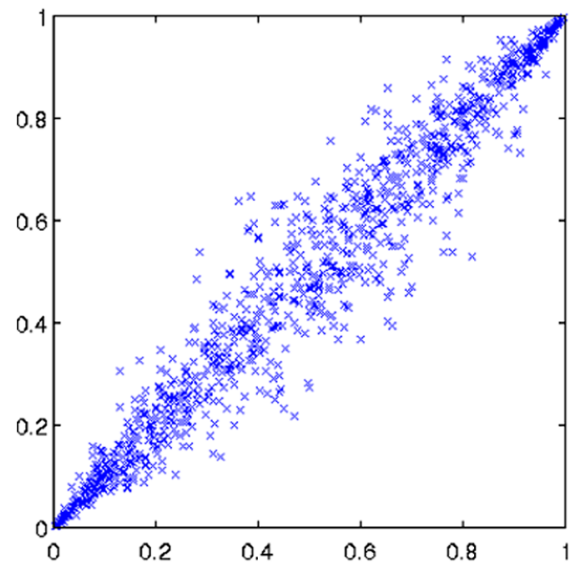

(g)

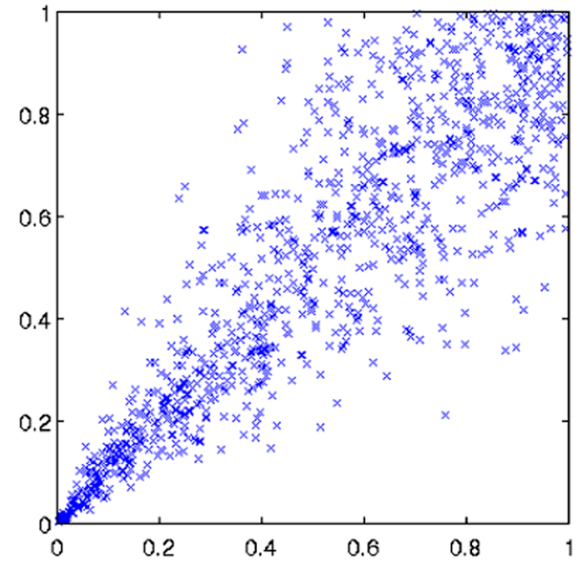

(b)

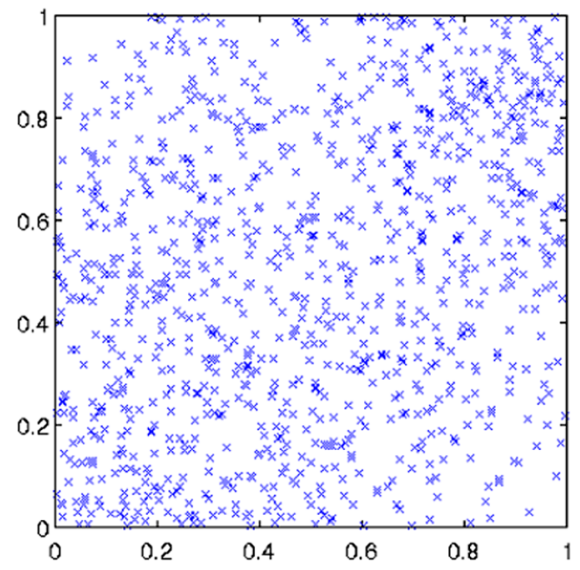

(e)

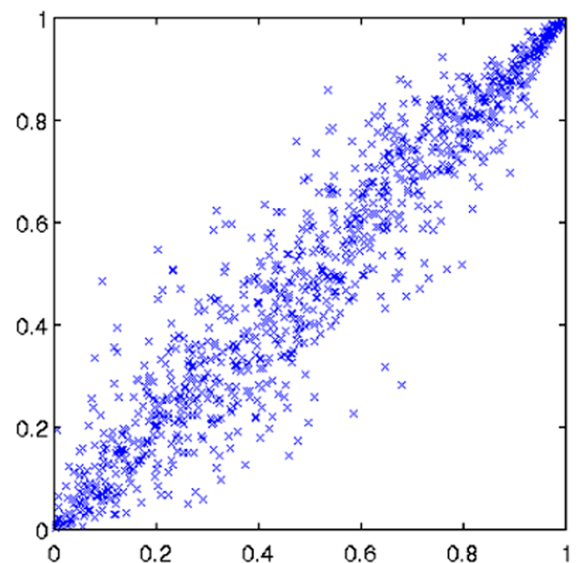

(h)

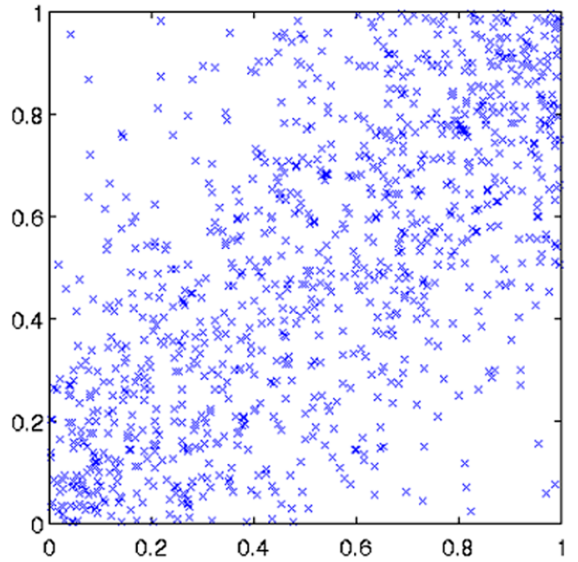

(c)

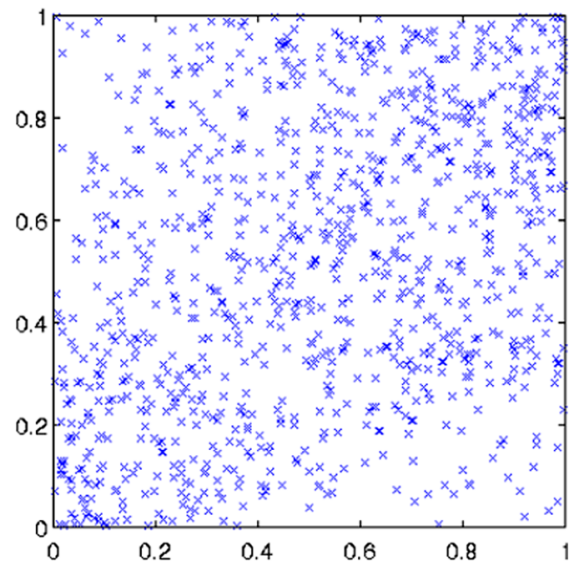

(f)

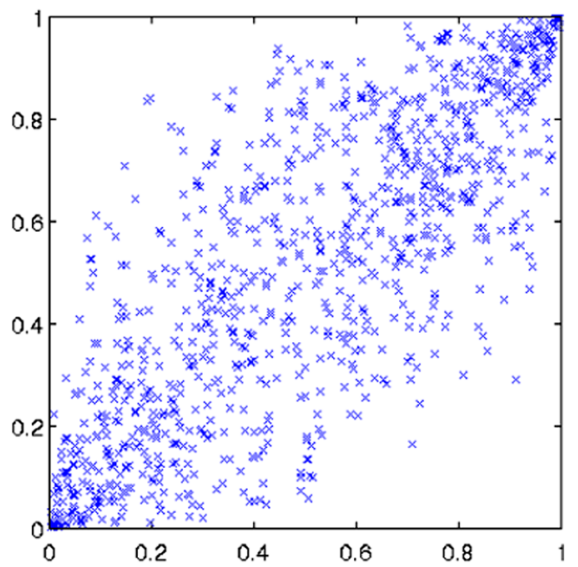

(i)

Fig. 4. Representations of the nine copulas showing their characteristics in the form of the point cloud ( $x$-axis: CDF of the first data set; $y$-axis: CDF of the second data set).

335 where $F_{X}$ is the $\mathrm{CDF}$ of the random variable $X$. If two time 336 series are considered, the CDF matching consists of matching 337 the CDF of each data set by setting their probabilities equal 338 (see Fig. 3). The following approach has been applied here to 339 the soil moisture data.

340 1) Compute the CDF of both data sets $X$ and $Y: F_{X}$ and $G_{Y}$.

341 2) Given a value $x$ of $X$, find $y$ such that $G_{Y}(y)=F_{X}(x)$.

342 However, the assumption that the probabilities $F_{X}(x)$ and $343 G_{Y}(y)$ are equal is never confirmed, and most of the time, they are scattered like in Fig. 4. The copula method models this 344 dependence between the probabilities.

345

For the rest of this paper, we use the variable $u$ to represent 346 $F_{X}(x)$ and $v$ for $G_{Y}(y) . U$ and $V$ are data sets, whereas $u$ and 347 $v$ are values of these data sets.

348

\section{B. Copulas}

349

The copula theory is a very useful and powerful tool to model 350 the dependence structure between two sets of random variables. 351 
TABLE III

Nine Copulas Tested in the Study: Definition, Parameter Range, and Family

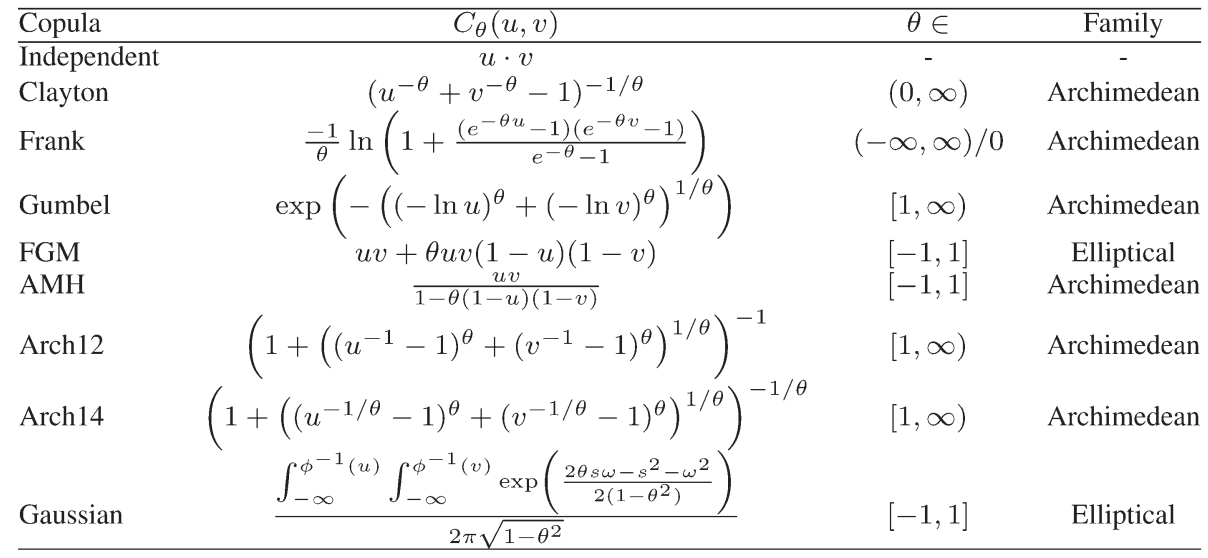

352 Like the CDF matching, copulas separate the marginal behavior 353 of variables from the dependence structure by using distribution 354 functions. Instead of setting the probabilities $u$ and $v$ equal, 355 the variables $U$ and $V$ are compared and analyzed. The copula 356 function binds the two variables together.

357 There are many families of copulas which exhibit very differ358 ent properties. The form of the scatter of $U$ and $V$ is controlled 359 by the family choice, and the width of the tail of this scatter 360 is controlled by the single parameter $\theta$. Most of the definitions 361 that follow in this section are based on [21].

362 1) General Theory: A copula is a function that generAQ20 363 ates a multivariate cumulative distribution function from 1-D 364 marginal CDFs. Given two random variables, $X$ and $Y$, with 365 marginal CDFs $F_{X}$ and $G_{Y}$, then, Sklar's theorem states

$$
H_{X Y}(x, y)=C_{X Y}\left(F_{X}(x), G_{Y}(y)\right)=\operatorname{Pr}[X \leq x, Y \leq y]
$$

366 where $H_{X Y}$ is the joint CDF of $X$ and $Y$ and $C_{X Y}$ is the asso367 ciated copula function. It is then possible to derive conditional 368 distributions, $H_{X Y}(y \mid x)$, i.e., the joint CDF knowing $x$. Let $369 u=F_{X}(x)$ and $v=G_{Y}(y)$. Then, $H_{X Y}(y \mid x)$ can be derived by

$$
C_{V \mid U}=\frac{\partial C(u, v)}{\partial u} .
$$

370 Schweizer and Wolff [48] established that the copula func371 tion accounts for all the dependence between the two variables. 372 They demonstrated that transformations of the variables $X$ and $373 Y$ do not affect their associated variables. Thus, the way that $X$ 374 and $Y$ evolve together is captured by the copula, regardless of 375 the scale in which each variable is measured.

376 2) Some Copula Families: The product copula corresponds 377 to the independence between $X$ and $Y$

$$
C(u, v)=u \cdot v .
$$

378 A copula of the Archimedean family takes the following 379 form:

$$
C(u, v)=\phi^{-1}(\phi(u)+\phi(v))
$$

380 where $\phi$ is the generator function that goes from $[0,1]$ to $381(0, \infty)$. It satisfies three conditions: $\phi(1)=0, \phi$ strictly de382 creasing, and $\phi$ convex.

383 Elliptical copulas have distributions with elliptic contours. 384 The main advantage of elliptical distributions is that the level of correlation between the variables $U$ and $V$ can be specified. 385 The disadvantages are that elliptical copulas do not have closed- 386 form expressions and are restricted to have radial symmetry. 387

In this paper, nine copulas were used: the product cop- 388 ula, Clayton, Frank, Gumbel, Farlie-Gumbel-Moregenstern 389 (FGM), Ali-Mikhail-Haq, Arch12 (the 12th copula presented 390 in [21]), Arch14 (the 14th copula presented in [21]), and the 391 Gaussian copula. The nine copulas are described in Table III 392 and Fig. 4 and have their own characteristics.

1) Clayton: Strong left tail dependence and relatively weak 394 right tail dependence (i.e., $u$ and $v$ are strongly linked for 395 low values, whereas they are not for high values). 396

2) Frank: Dependence is symmetric in both tails, weak in 397 both tails, and stronger in the center of the distribution. 398

3) Gumbel: Strong right tail dependence and relatively weak 399 left tail dependence (the opposite of Clayton).

400

4) FGM: Useful when the dependence between $U$ and $V$ is 401 modest in amplitude.

5) Gaussian: Flexible as it allows for positive and negative 403 dependences.

Hafner and Reznikova [23] and Wang and Pham [49] 405 developed a method that includes the time into the copula 406 formula to create a dynamic copula evolving with time. In 407 this paper, time was not included, but the year 2010 was 408 divided into four seasons as different statistical behaviors were 409 expected: December-January-February, March-April-May 410 (MAM), June-July-August (JJA), and September-October- 411 November (SON).

3) How to Select a Family: Since copulas separate marginal 413 distributions from dependence structures, the appropriate cop- 414 ula for a particular application is the one that best captures the 415 dependence features of the data [22]. Dupuis [27] examined the 416 effects of model misspecification and highlighted the dangers 417 of improper copula selection. Genest and Rivest [50] proposed 418 a method to select the most appropriate copula, but this method 419 is only relevant for Archimedean copulas. Other methods 420 were developed to compare any type of copulas [51]-[54]. 421 Genest et al. [55] and Berg [54] compared some of them 422 and concluded that there was no universal test and that some 423 procedures performed better in some situations but never in all 424 the situations. 
426 The method proposed by Huard et al. [56] is based on a 427 Bayesian approach where any type of copula can be tested. It 428 does not perform perfectly well in all the situations (with small 429 correlation coefficients or with small sample size) but has the 430 advantage to be a very fast method. This method was chosen 431 in this study to select the copula that provides the best fit to the 432 data.

433 4) Method Used for Simulations: The key to generating 434 simulations from a copula is to understand that a copula is a 435 joint distribution and that it obeys to the same rules. A con436 ditional copula $C_{V \mid U}(u, v)$ is the probability that the random 437 variable $V$ is less than or equal to a value $v$ knowing that the 438 random variable $U$ is equal to a value $u$

$$
C_{V \mid U}(u, v)=\operatorname{Pr}[V \leq v \mid U=u]=t \sim \mathcal{U}(0,1) .
$$

439 Simulating a uniform variable $t$ is necessary in order to 440 generate simulations from a copula. To retrieve $V \mid U$, the func441 tion $C_{V \mid U}$ needs to be inverted such that $v=C_{V \mid U}^{-1}(t)$, or the 442 equation $C_{V \mid U}(v)=t$ needs to be solved numerically. For each 443 value of $t$, a value for $v$ is retrieved. The following approach 444 was used here to simulate data with the copulas.

445 1) Compute $F_{X}$ and $G_{Y}$ from the two original data sets $X$ 446 and $Y$ with (1).

447 2) Choose the appropriate copula $C$ by applying Huard's 448 method and fitting the parameter $\theta$ to the original data.

4493 ) Derive the conditional copula $C_{V \mid U}$ with (3).

450 4) Generate 1000 simulations $t \sim \mathcal{U}(0,1)$.

451 5) Compute $v$ with $v=C_{V \mid U}^{-1}(t)$ and $y$ with $y=G_{Y}^{-1}(v)$.

452 6) The mean and standard deviation from the 1000 simula453 tions can be computed.

\section{Methodology}

455 For the CDF matching and the copula methods, 2010 data 456 were used for calibration. The CDFs of SMOS and LPRM were 457 calculated for the 2010 data sets. The two algorithms were then 458 applied to the data from previous years. It should be noted that 459 the consequence of using 2010 as a calibration year is that only 460 the soil moisture range from 2010 is taken into account. If an 461 extreme event occurred in the previous years, it might not be 462 well described with these methods as they are only based on 463 statistics and not on physical models. By looking at the in situ 464 soil moisture time series in Fig. 7, 2010 did not have enough 465 wet values over LR to estimate correctly the strong rainfalls 466 of 2004, 2005, and 2009, not enough wet values over LW for 467 rainfalls in 2007 and not enough dry values as well for 2003 468 and 2006, and again not enough dry values over RC for all the AQ23 469 previous years.

470 The two methods were applied to data contained in a $1^{\circ} \times 1^{\circ}$ 471 box around each watershed in order to have enough points for 472 computing reliable statistics. The coordinates of each box are 473 indicated in Table I. Only the satellite morning overpasses were 474 selected for this study (6:00 am for SMOS and 1:30 am for 475 AMSR-E, LST) since LPRM retrievals were only available for 476 this overpass.

477 The 2010 calibration year was divided into four seasons: 478 December-January-February, MAM, JJA, and SON. This
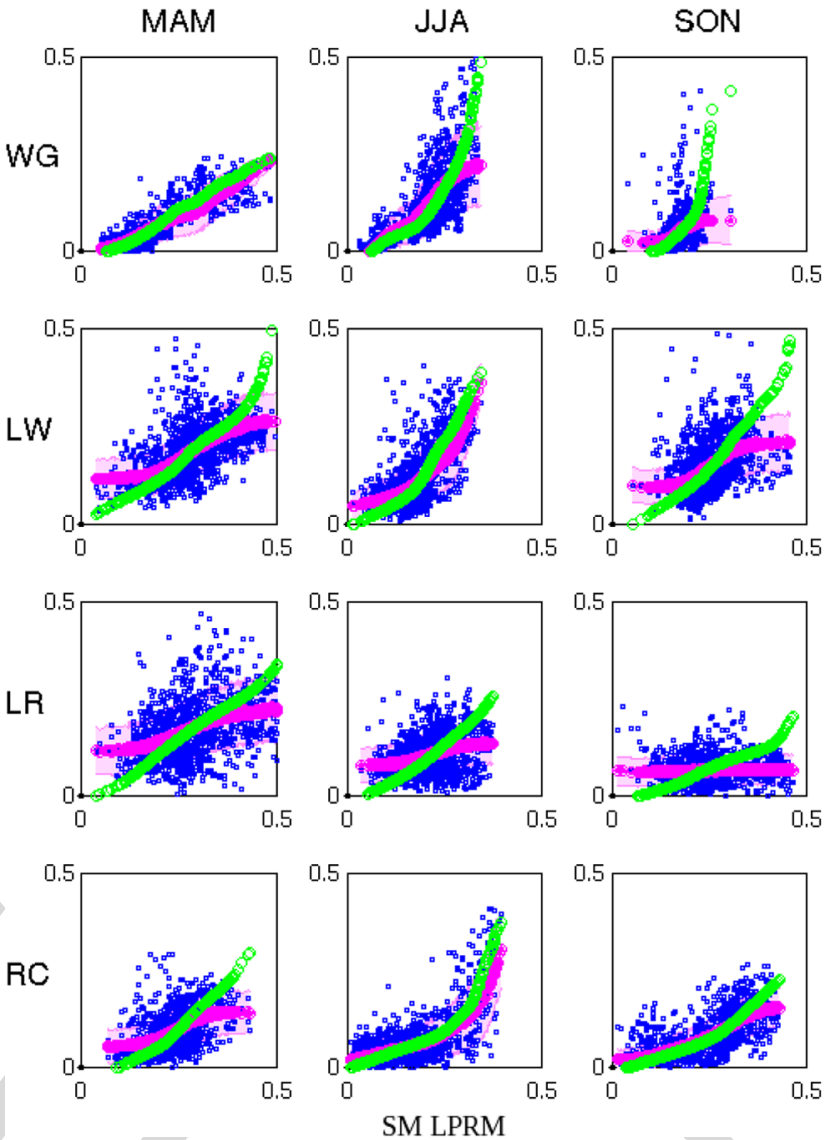

Fig. 5. Discrepancies in the simulations of soil moisture between CDF matching and copulas in 2010. Original soil moisture LPRM data are represented by blue points, and simulated data with CDF matching and copulas are in green and red, respectively. The standard deviation of the copula simulations is represented in shadowed red. Each row corresponds to a site, and each column corresponds to a season. $x$-axis: LPRM soil moisture. $y$-axis: SMOS soil moisture.

subdivision was done in order to better capture the sea- 479 sonal dynamic that can be very different depending on the 480 time of the year, particularly in vegetated areas. However, 481 not enough points were available during the winter period 482 (December-January-February) to compute reliable statistics, 483 so no estimation was performed for this season.

484

When comparing either two different remote sensing prod- 485 ucts or in situ data with remote sensing products, there is the 486 issue of the scale effect, as the products may have significantly 487 different spatial resolutions. Moreover, the spatial variability 488 varies with the seasons and the heterogeneity. So as to reduce 489 the problem, we used in this study averaged in situ data sets 490 ( 8 to 15 stations that were several miles away) which were 491 especially produced to be representative of 50-km spatial res- 492 olution or so [47]. Also, statistics were applied to all the points 493 contained in a $1^{\circ} \times 1^{\circ}$ box (more than 50 grid points).

\section{Generated Homogeneous Time Series}

The year 2010 was used to compute the CDFs of each 496 data set (SMOS and LPRM) for both methods and the joint 497 CDF based on fitting and selecting copula functions as de- 498 scribed previously. The soil moisture data were estimated using 499 
TABLE IV

Statistical Results of the Simulations From Copulas and CDF Matching. The Simulations Were Compared to Ground Measurements Over 2010 Divided Into Four Seasons: MAM, JJA, SON, but Not Enough Data Available for Winter Season. The Best Results Are Written in Bold, AND RMSES ARE IN $\mathrm{m}^{3} / \mathrm{m}^{3}$

\begin{tabular}{cc|cc|cc|ccc|cc|c}
\hline & & \multicolumn{2}{|c|}{ SMOS } & \multicolumn{2}{c|}{ LPRM } & \multicolumn{2}{|c|}{ Copula method } & \multicolumn{2}{c}{ CDF matching } & \# points \\
& & R & RMSE & R & RMSE & Fam $(\theta)$ & R & RMSE & R & RMSE & \\
\hline \multirow{4}{*}{ WG } & MAM & 0.80 & 0.032 & 0.82 & 0.125 & Gumbel $(2.18)$ & $\mathbf{0 . 8 9}$ & $\mathbf{0 . 0 2 0}$ & 0.87 & 0.031 & 43 \\
& JJA & 0.86 & 0.053 & 0.86 & 0.126 & Clayton(2.63) & 0.76 & $\mathbf{0 . 0 7 6}$ & $\mathbf{0 . 8 1}$ & 0.090 & 45 \\
& SON & 0.64 & 0.029 & 0.79 & 0.133 & Frank $(3.13)$ & $\mathbf{0 . 6 4}$ & $\mathbf{0 . 0 1 2}$ & 0.53 & 0.029 & 42 \\
& total & 0.84 & 0.040 & 0.79 & 0.139 & - & 0.79 & $\mathbf{0 . 0 4 3}$ & $\mathbf{0 . 8 2}$ & 0.054 & 159 \\
\hline \multirow{4}{*}{ LW } & MAM & 0.70 & 0.068 & 0.48 & 0.166 & Frank $(4.40)$ & 0.55 & $\mathbf{0 . 0 5 7}$ & $\mathbf{0 . 5 7}$ & 0.075 & 44 \\
& JJA & 0.85 & 0.037 & 0.58 & 0.085 & Gumbel $(1.66)$ & $\mathbf{0 . 7 7}$ & $\mathbf{0 . 0 4 2}$ & 0.76 & 0.050 & 44 \\
& SON & 0.80 & 0.041 & 0.80 & 0.122 & Frank $(3.61)$ & $\mathbf{0 . 7 5}$ & $\mathbf{0 . 0 2 3}$ & 0.72 & 0.048 & 46 \\
& total & 0.78 & 0.049 & 0.59 & 0.148 & - & $\mathbf{0 . 7 1}$ & $\mathbf{0 . 0 4 3}$ & $\mathbf{0 . 7 1}$ & 0.059 & 162 \\
\hline \multirow{4}{*}{ LR } & MAM & 0.77 & 0.080 & 0.54 & 0.175 & Frank $(2.82)$ & $\mathbf{0 . 5 9}$ & $\mathbf{0 . 0 6 3}$ & 0.58 & 0.067 & 39 \\
& JJA & 0.57 & 0.053 & 0.67 & 0.131 & Frank $(2.00)$ & 0.65 & 0.034 & $\mathbf{0 . 6 6}$ & $\mathbf{0 . 0 3 3}$ & 40 \\
& SON & 0.59 & 0.032 & 0.37 & 0.174 & FGM $(0.31)$ & $\mathbf{0 . 1 7}$ & $\mathbf{0 . 0 3 3}$ & 0.16 & 0.037 & 39 \\
& total & 0.74 & 0.060 & 0.65 & 0.178 & - & 0.51 & $\mathbf{0 . 0 4 5}$ & $\mathbf{0 . 5 9}$ & 0.048 & 147 \\
\hline \multirow{4}{*}{ RC } & MAM & 0.14 & 0.097 & 0.11 & 0.096 & Frank $(3.10)$ & 0.26 & $\mathbf{0 . 0 8 9}$ & $\mathbf{0 . 2 7}$ & 0.105 & 47 \\
& JJA & 0.63 & 0.055 & 0.81 & 0.070 & Gumbel $(1.81)$ & $\mathbf{0 . 8 4}$ & $\mathbf{0 . 0 4 7}$ & 0.83 & 0.052 & 42 \\
& SON & 0.14 & 0.070 & 0.52 & 0.144 & Frank $(6.30)$ & $\mathbf{0 . 3 4}$ & $\mathbf{0 . 0 5 6}$ & 0.29 & 0.066 & 39 \\
& total & 0.55 & 0.081 & 0.73 & 0.099 & - & $\mathbf{0 . 8 0}$ & $\mathbf{0 . 0 5 9}$ & 0.70 & 0.067 & 142 \\
\hline
\end{tabular}

500 the conditional distribution (conditional on LPRM retrievals). 501 While the copula procedure has the potential to generate an 502 ensemble of SMOS-like soil moisture estimates, given the 503 LPRM estimated soil moisture, we only use the mean estimate. 504 The ensembles could be used to provide uncertainty estimates. 505 It should be noted that CDF matching can only provide a 506 single SMOS estimate. The resulting time series will result in 507 a statistically homogeneous time series under the assumption 508 that 2010 LPRM retrievals and the underlying AMSR-E bright509 ness temperatures are temporally consistent. The resulting 510 SMOS-like estimated soil moisture is then compared to ground 511 measurements.

\section{A. Calibration Year 2010 and Comparison With 513 Ground Measurements}

5142010 is the year with both SMOS data and LPRM data. $515 \mathrm{CDFs}$ were computed for both variables. CDF matching and 516 copula methods were then applied, and these produced different 517 SMOS-like estimates. In Fig. 5, the original data (SMOS and 518 LPRM) are represented by the blue point cloud, CDF matching 519 and copula estimates are in green and red colors, respectively, 520 and standard deviations from copula simulations are in red AQ26 521 shadows. This standard deviation can be interpreted as the 522 uncertainty associated to the copula simulations, which can be 523 not produced by CDF matching estimation.

524 Over WG in the MAM season, there was no obvious differ525 ence between the two simulation methods. However, in the JJA 526 and SON seasons, there were differences for the high values 527 of soil moisture: The CDF matching method produced higher 528 simulated values than the copula method. Similar behavior can 529 also be seen for all seasons in the other three sites, i.e., LW, LR, 530 and RC. Discrepancies can also be observed for small values 531 of soil moisture over LW, LR, and RC (MAM) where copulas 532 generated higher values of soil moisture.

533 Standard deviations of soil moisture simulations from copu534 las were also computed (see Fig. 5). This standard deviation is 535 directly related to the width of the tail of the chosen copula 536 which is controlled by the $\theta$ parameter. A high value of the 537 standard deviation corresponds to a large tail, meaning that the two variables are weakly linked to each other, whereas a 538 small value corresponds to a strong link. The differences in 539 the simulations can also be observed in the 2010 time series 540 (see Table IV and Fig. 6). Compared to the original LPRM 541 data, the estimated soil moisture was close to the SMOS level 542 and comparable to the ground measurements. The bias between 543 LPRM and SMOS was corrected by both methods.

544

Over WG, CDF matching and copula simulations were not 545 very different except in the summer season when the CDF 546 matching simulations were higher than the copulas. Consid- 547 ering the entire year, both simulation methods improved the 548 original statistics from the LPRM data set. The correlation 549 coefficient did not change significantly ( $R=0.79$ for LPRM 550 and $R=0.79 / 0.82$ for copulas/CDF matching), but the rmse 551 was highly improved going from $0.139 \mathrm{~m}^{3} / \mathrm{m}^{3}$ (original LPRM 552 data) to $0.054 \mathrm{~m}^{3} / \mathrm{m}^{3}$ with CDF matching and $0.043 \mathrm{~m}^{3} / \mathrm{m}^{3} 553$ with copula, which represents an improvement of a factor of 3. 554

Over LW, simulations responded very well to the succes- 555 sive rain events throughout the year and exhibited a pattern 556 of decrease following a rain event. The first two months 557 (March-April) exhibited more noisy simulations, and the statis- 558 tics were impacted by this behavior $(R=0.55 / 0.57$ and 559 rmse $=0.057 / 0.075 \mathrm{~m}^{3} / \mathrm{m}^{3}$ for copulas/CDF matching). The 560 other two seasons gave good results in terms of statistics. For 561 the entire year, the $R$ value was highly improved ( $R=0.59562$ for LPRM and $R=0.71 / 0.71$ for copulas/CDF matching), and 563 the rmse was reduced by a factor of $3\left(\mathrm{rmse}=0.148 \mathrm{~m}^{3} / \mathrm{m}^{3} 564\right.$ for LPRM and rmse $=0.043 / 0.059 \mathrm{~m}^{3} / \mathrm{m}^{3}$ for copulas/CDF 565 matching).

The LR watershed is the site with the highest rainfall fre- 567 quency (events of small amplitude). The successive rainfall 568 events were not well captured by the simulations, particularly 569 during the fall season when both simulations exhibited only 570 small variations, which resulted in very poor statistics $(R=571$ $0.17 / 0.16$ for copulas/CDF matching). Unfortunately, even if 572 the rain events were captured by the original data sets, none 573 was captured by both data sets at the same time, so only the 574 nonraining periods were taken into account by the statistics. 575 Therefore, the simulations can only be representative of the dry 576 periods. It should be noted that the statistics of LPRM were 577 


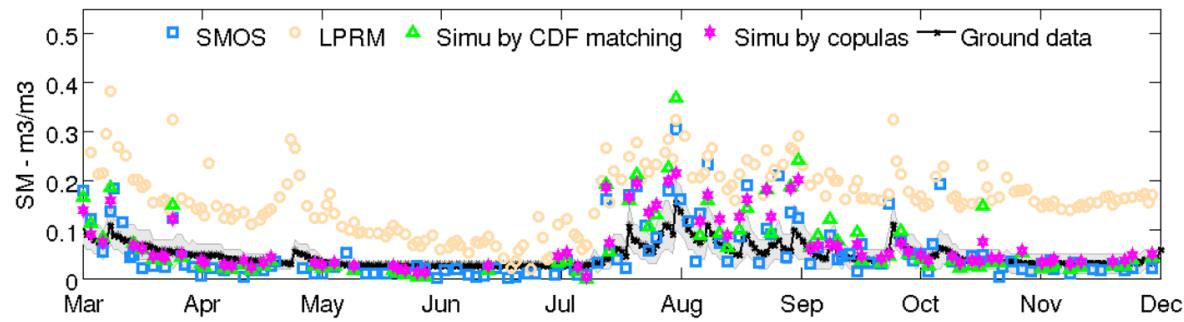

(a)

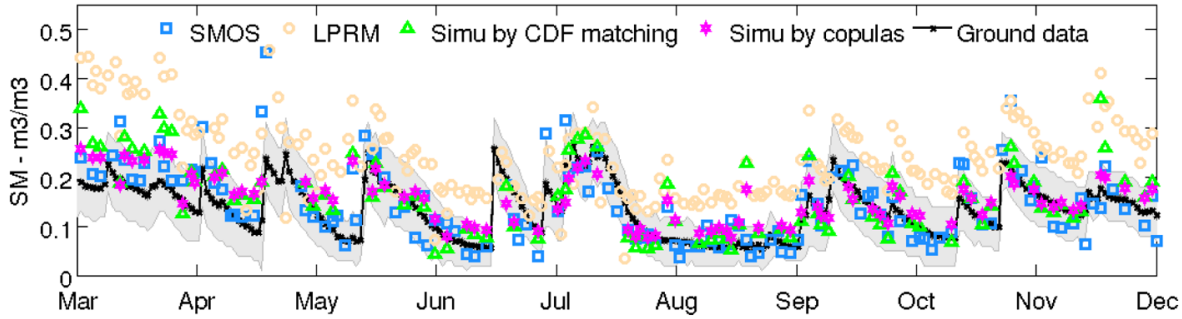

(b)

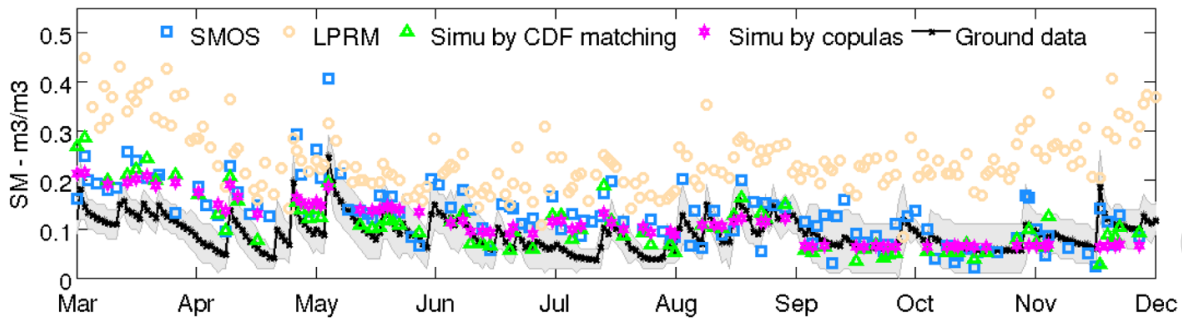

(c)

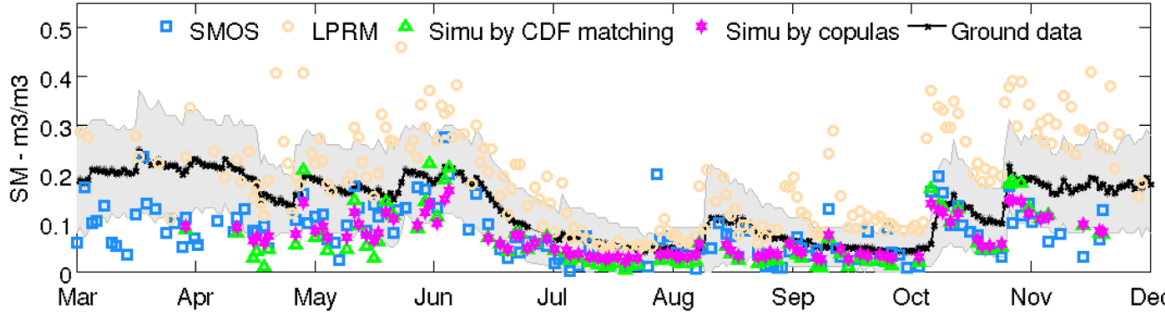

(d)

Fig. 6. Simulations for 2010: SMOS, LPRM, simulated soil moisture data from CDF matching and copulas, and ground measurements over the four watersheds. Since the in situ data are the mean of several ground measurements, their standard deviations are represented in gray shadows showing the spatial variability. (a) WG. (b) LW. (c) LR. (d) RC.

578 already not good during this season $(R=0.37$ and rmse $=$ $5790.174 \mathrm{~m}^{3} / \mathrm{m}^{3}$ ). During the spring season, SMOS overestimated 580 the in situ soil moisture measurements, so as a result, the 581 copulas and CDF matching estimates overestimated the in situ 582 measurements as well.

$583 \mathrm{RC}$ is located in a mountainous region and is subject to 584 frequent snow and frozen soil events. The satellite-based soil 585 moisture was not comparable to the ground measurements until 586 late May. After this winter period, the simulations captured 587 accurately the soil moisture evolution and improved the original 588 statistics and especially the rmse $\left(0.099 \mathrm{~m}^{3} / \mathrm{m}^{3}\right.$ for LPRM and $5890.059 / 0.067 \mathrm{~m}^{3} / \mathrm{m}^{3}$ for copulas/CDF matching).

\section{B. Times Series 2003-2010 and Comparison With}

\section{Ground Measurements}

592 Soil moisture from 2003 to 2010 was simulated from the 593 LPRM retrievals (2003-2010) using the copulas and CDF matching relationships developed for 2010. Fig. 7 and Table V 594 show the entire time series and the associated statistics ( $R$ and 595 rmse) between the original data, CDF matching simulations, 596 copula simulations, and ground measurements.

WG is the driest site and did not have a lot of rain events. 598 These rain events were well described by the simulated soil 599 moisture even though they were sometimes largely overesti- 600 mated, particularly by CDF matching simulations. Artifacts at 601 the extremities of the seasons can be seen at the beginning 602 of 2006 and 2008. The correlation coefficient was improved 603 using the CDF matching for each year, whereas the errors were 604 reduced by a factor larger than 2 with the copulas.

605

The overestimation of the soil moisture after the rain events 606 with CDF matching can be found as well over LW, but the 607 temporal evolution was well captured by both methods. For this 608 watershed, CDF matching overestimated the high soil moisture 609 values and underestimated the low values. CDF matching pro- 610 duced soil moisture with a higher dynamic range than copulas. 611 


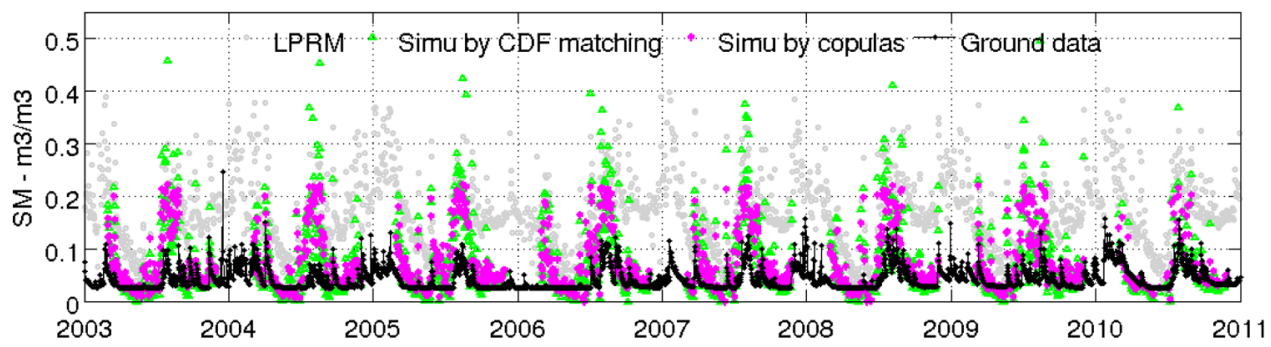

(a)

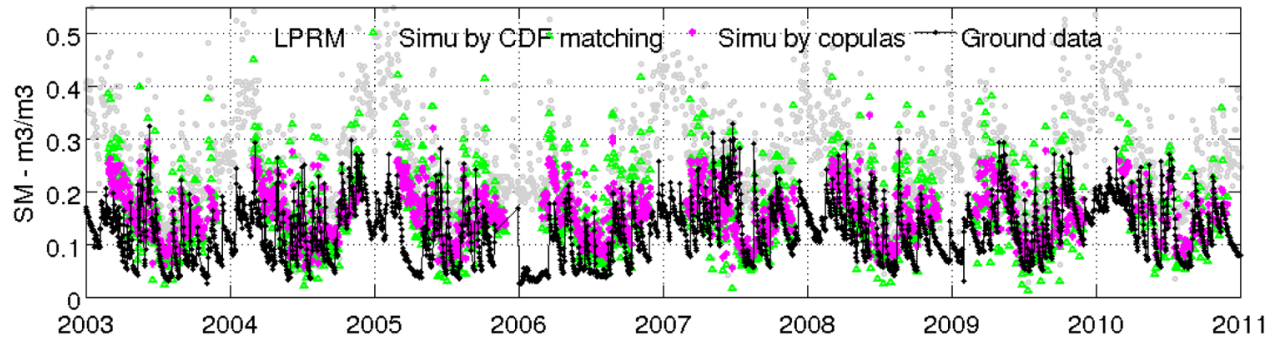

(b)

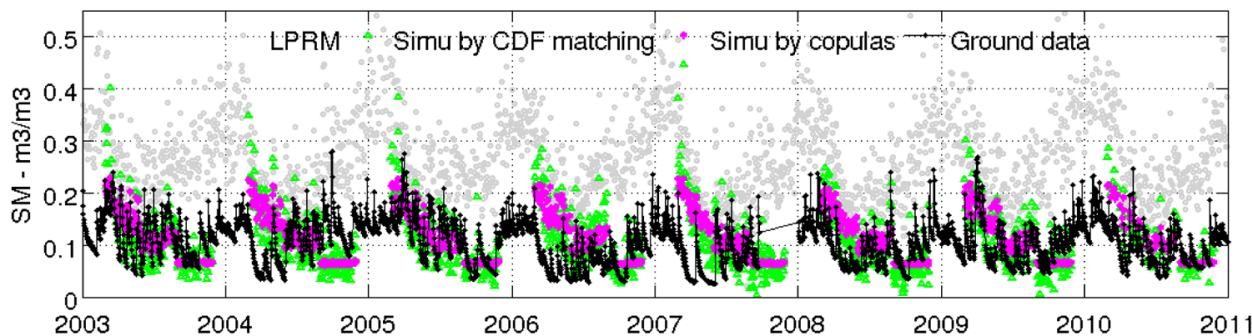

(c)

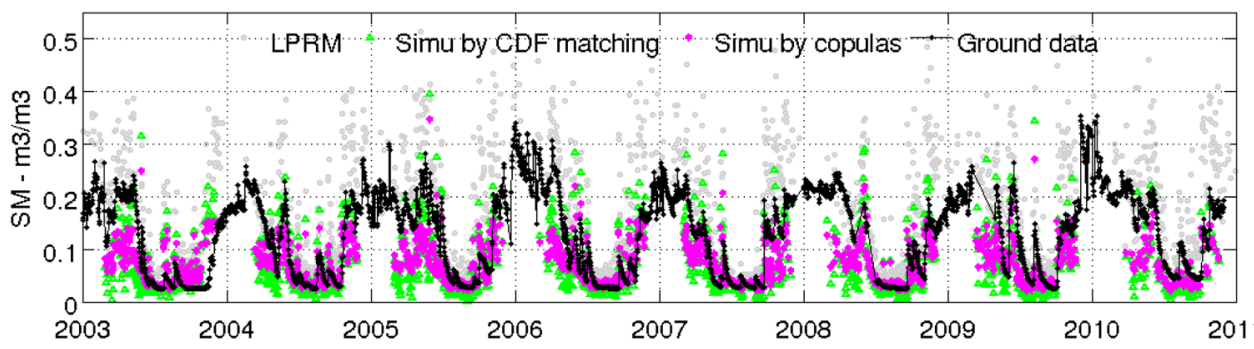

(d)

Fig. 7. Simulated time series from 2003 to 2010 with ground measurements for the four watersheds. (a) WG. (b) LW. (c) LR. (d) RC.

612 This was reflected in the total rmse value $\left(0.079 \mathrm{~m}^{3} / \mathrm{m}^{3}\right)$, 613 whereas the rmse of the copula simulations was of $0.066 \mathrm{~m}^{3} / \mathrm{m}^{3}$ 614 (original LPRM rmse: $0.160 \mathrm{~m}^{3} / \mathrm{m}^{3}$ ).

615 LR is the site with the largest number of rain events, and as 616 mentioned in the previous section, this high rain frequency was 617 not properly captured during the fall season of 2010; this can 618 be seen as well in the entire time series where all the copulas 619 and CDF matching estimates were flat during fall seasons. 620 Moreover, since SMOS was overestimating the soil moisture 621 during the spring season of 2010, both statistical estimates had 622 this behavior. Even though the tendency of the simulations was 623 correct, the dynamic behavior was not well represented, which 624 resulted in a very poor correlation coefficient (negative values 625 in 2004 and 2007).

$626 \mathrm{RC}$ is a very complicated site because of the frequent 627 snow and frozen soil events occurring during half of the year. 628 However, statistical results were improved for the entire year with copula simulations (rmse $=0.099 \mathrm{~m}^{3} / \mathrm{m}^{3}$ for LPRM and 629 rmse $=0.056 / 0.062 \mathrm{~m}^{3} / \mathrm{m}^{3}$ for copulas/CDF matching). $\quad 630$

\section{Conclusion And Perspectives}

The main goal of this study was to propose a new method to 632 generate a long homogeneous time series (2003-2010) of soil 633 moisture from two overlapping time series.

For that purpose, two statistical tools, the CDF matching and 635 the copulas, were tested over four watersheds in the U.S. By us- 636 ing CDF matching, the assumption that the two studied data sets 637 are ranked in the same way is made, which the copulas do not 638 require. The two analyzed data sets (SMOS and LPRM) were 639 jointly available only for 2010 , so data from 2010 were used to 640 estimate the CDFs that are used as references to estimate SMOS 641 soil moisture for previous years. The novelty of the approach is 642 its application: establishing the statistical relationship between 643 
TABLE V

Statistical Results From the Comparison Between the Simulated Time Series of Soil Moisture From 2003 to 2010. Original Soil Moisture Times ARE RePresented by LPRM. The Best Results ARE INDiCATED IN Bold, AND THE RMSE ARE IN $\mathrm{m}^{3} / \mathrm{m}^{3}$. (a) WG. (b) LW. (c) LR. (d) RC

(a)

\begin{tabular}{cc|c|c|c|c|c|c|c|c|c}
\hline & & 2003 & 2004 & 2005 & 2006 & 2007 & 2008 & 2009 & 2010 & Total \\
\hline \multirow{2}{*}{ LPRM } & $\mathrm{R}$ & 0.070 & 0.76 & 0.82 & 0.66 & 0.81 & 0.68 & 0.65 & 0.79 & 0.73 \\
& RMSE & 0.129 & 0.141 & 0.146 & 0.133 & 0.147 & 0.138 & 0.129 & 0.139 & 0.138 \\
\hline \multirow{2}{*}{ Copula } & $\mathrm{R}$ & 0.62 & 0.55 & 0.82 & 0.64 & 0.81 & $\mathbf{0 . 7 5}$ & 0.76 & 0.79 & 0.69 \\
& RMSE & $\mathbf{0 . 0 5 9}$ & $\mathbf{0 . 0 5 9}$ & $\mathbf{0 . 0 5 9}$ & $\mathbf{0 . 0 6 0}$ & $\mathbf{0 . 0 5 4}$ & $\mathbf{0 . 0 5 3}$ & $\mathbf{0 . 0 6 0}$ & $\mathbf{0 . 0 4 3}$ & $\mathbf{0 . 0 5 7}$ \\
\hline \multirow{2}{*}{ CDF m. } & $\mathrm{R}$ & $\mathbf{0 . 7 3}$ & $\mathbf{0 . 6 2}$ & $\mathbf{0 . 8 8}$ & $\mathbf{0 . 7 2}$ & $\mathbf{0 . 8 9}$ & $\mathbf{0 . 7 5}$ & $\mathbf{0 . 7 9}$ & $\mathbf{0 . 8 2}$ & $\mathbf{0 . 7 4}$ \\
& RMSE & 0.070 & 0.074 & 0.071 & 0.073 & 0.067 & 0.067 & 0.077 & 0.054 & 0.071 \\
\hline
\end{tabular}

(b)

\begin{tabular}{cc|c|c|c|c|c|c|c|c|c}
\hline & & 2003 & 2004 & 2005 & 2006 & 2007 & 2008 & 2009 & 2010 & Total \\
\multirow{2}{*}{ LPRM } & $\mathrm{R}$ & 0.56 & 0.71 & 0.48 & 0.67 & 0.32 & 0.42 & 0.52 & 0.58 & 0.55 \\
& RMSE & 0.163 & 0.149 & 0.187 & 0.149 & 0.173 & 0.158 & 0.149 & 0.149 & 0.160 \\
\multirow{2}{*}{ Copula } & $\mathrm{R}$ & 0.56 & 0.47 & 0.19 & 0.62 & 0.41 & $\mathbf{0 . 6 4}$ & $\mathbf{0 . 5 8}$ & $\mathbf{0 . 7 1}$ & 0.47 \\
& RMSE & $\mathbf{0 . 0 7 1}$ & $\mathbf{0 . 0 6 4}$ & $\mathbf{0 . 0 8 8}$ & $\mathbf{0 . 0 7 7}$ & $\mathbf{0 . 0 6 0}$ & $\mathbf{0 . 0 5 6}$ & $\mathbf{0 . 0 5 1}$ & $\mathbf{0 . 0 4 4}$ & $\mathbf{0 . 0 6 6}$ \\
\hline \multirow{2}{*}{ CDF m. } & $\mathrm{R}$ & $\mathbf{0 . 5 9}$ & $\mathbf{0 . 6 0}$ & $\mathbf{0 . 3 4}$ & $\mathbf{0 . 6 3}$ & $\mathbf{0 . 4 9}$ & 0.61 & 0.53 & $\mathbf{0 . 7 1}$ & $\mathbf{0 . 5 1}$ \\
& RMSE & 0.083 & 0.070 & 0.101 & 0.092 & 0.069 & 0.076 & 0.069 & 0.059 & 0.079 \\
\hline
\end{tabular}

(c)

\begin{tabular}{cc|c|c|c|c|c|c|c|c|c}
\hline & & 2003 & 2004 & 2005 & 2006 & 2007 & 2008 & 2009 & 2010 & Total \\
\hline \multirow{2}{*}{ LPRM } & $\mathrm{R}$ & 0.51 & 0.60 & 0.46 & 0.75 & 0.64 & 0.70 & 0.49 & 0.65 & 0.58 \\
& RMSE & 0.171 & 0.148 & 0.181 & 0.185 & 0.180 & 0.166 & 0.187 & 0.178 & 0.174 \\
\hline \multirow{2}{*}{ Copula } & $\mathrm{R}$ & 0.54 & -0.48 & $\mathbf{0 . 7 3}$ & 0.01 & -0.14 & 0.20 & 0.43 & 0.51 & 0.19 \\
& RMSE & $\mathbf{0 . 0 4 2}$ & $\mathbf{0 . 0 7 9}$ & $\mathbf{0 . 0 3 6}$ & $\mathbf{0 . 0 6 9}$ & $\mathbf{0 . 0 8 1}$ & 0.054 & $\mathbf{0 . 0 4 7}$ & $\mathbf{0 . 0 4 5}$ & $\mathbf{0 . 0 5 9}$ \\
\hline \multirow{2}{*}{ CDF m. } & $\mathrm{R}$ & $\mathbf{0 . 6 8}$ & $\mathbf{- 0 . 1 6}$ & 0.72 & $\mathbf{0 . 2 8}$ & $\mathbf{0 . 1 8}$ & $\mathbf{0 . 5 0}$ & $\mathbf{0 . 5 5}$ & $\mathbf{0 . 5 9}$ & $\mathbf{0 . 3 7}$ \\
& RMSE & 0.044 & 0.080 & 0.042 & 0.070 & 0.085 & $\mathbf{0 . 0 5 0}$ & 0.048 & 0.048 & 0.061 \\
\hline
\end{tabular}

(d)

\begin{tabular}{cc|c|c|c|c|c|c|c|c|c}
\hline & & 2003 & 2004 & 2005 & 2006 & 2007 & 2008 & 2009 & 2010 & Total \\
\hline \multirow{2}{*}{ LPRM } & $\mathrm{R}$ & 0.78 & 0.76 & 0.74 & 0.80 & 0.84 & 0.69 & 0.78 & 0.73 & 0.77 \\
& RMSE & 0.093 & 0.085 & 0.110 & 0.099 & 0.102 & 0.106 & 0.099 & 0.099 & 0.099 \\
\hline \multirow{2}{*}{ Copula } & $\mathrm{R}$ & $\mathbf{0 . 5 3}$ & $\mathbf{0 . 7 8}$ & $\mathbf{0 . 7 0}$ & $\mathbf{0 . 6 8}$ & $\mathbf{0 . 7 2}$ & 0.75 & $\mathbf{0 . 7 2}$ & $\mathbf{0 . 8 0}$ & $\mathbf{0 . 6 9}$ \\
& RMSE & $\mathbf{0 . 0 6 5}$ & $\mathbf{0 . 0 4 5}$ & $\mathbf{0 . 0 6 5}$ & $\mathbf{0 . 0 6 0}$ & $\mathbf{0 . 0 5 1}$ & $\mathbf{0 . 0 4 7}$ & $\mathbf{0 . 0 5 2}$ & $\mathbf{0 . 0 5 9}$ & $\mathbf{0 . 0 5 6}$ \\
\hline \multirow{2}{*}{ LDF m. } & $\mathrm{R}$ & 0.42 & 0.69 & 0.65 & 0.63 & 0.70 & $\mathbf{0 . 6 5}$ & 0.71 & 0.70 & 0.63 \\
& RMSE & 0.073 & 0.051 & 0.070 & 0.063 & 0.055 & 0.056 & 0.056 & 0.067 & 0.062 \\
\hline
\end{tabular}

644 AMSR-E and SMOS retrieved soil moisture values and using 645 this relationship to estimate the equivalent SMOS value for the 646 AMSR-E period prior to the SMOS launch.

647 The first analysis of these simulations over 2010 showed that 648 the simulated data sets were very similar to the SMOS estimates 649 and reproduced SMOS behavior accurately except over the LR 650 watershed where numerous rain events occurred. This high 651 rainfall frequency was interpreted statistically as noise, and 652 hence, the simulations did not describe the soil moisture evolu653 tion over this site very well. RC was also a very complicated site 654 due to the local topography and seasonal climate conditions. 655 Soil moisture derived from satellite observations was not able 656 to accurately reproduce the dynamics as found in the in situ 657 data, and as a result, the simulated soil moisture did not either. 658 However, the total rmse for the simulated soil moisture from 659 copulas was reduced by a factor of almost 2. The WG and $660 \mathrm{LW}$ sites were well represented by the simulations, and copulas 661 improved the error by a factor of 3, whereas CDF matching 662 improved the correlation.

663 The time series of soil moisture were estimated from 2003 to 6642010 and were compared to in situ measurements at all four 665 watersheds. Since simulated soil moisture data in 2010 over 666 the LR watershed had very little dynamic range, they remained 667 the same for the entire time series and showed very poor 668 statistical results. Even though the rmse values were improved by a factor of 3, the total correlation was not good. For the 669 three other sites, the correlation coefficient was a bit degraded 670 compared to the original LPRM data, but the rmse was highly 671 improved with copulas by a factor of 2 to 3. In general, CDF 672 matching gave better results in terms of correlation, and copulas 673 gave better results in terms of errors compared to the ground 674 measurements.

As a more general conclusion, CDF matching gives good 676 results but does not take into account the structure of the 677 dependence between the two data sets, whereas the copulas 678 allow to model this structure. Through the choice of the family 679 and the parameter $\theta$ (which controls the width of the tail of the 680 scatter), it is possible to model all kinds of structures, from the 681 perfect dependence (CDF matching), right or left dependence, 682 to complete independence. This is why copulas produce better 683 results for the extreme values (very low and very high values) 684 than CDF matching. Copulas can also estimate the uncertainty 685 of the soil moisture simulations given the LPRM value and 686 can be seen as a quality information in the simulation process. 687 However, the copula method is time consuming. It is quick 688 to choose the copula family and its associated parameter as 689 it is based on a Bayesian approach; however, it is very time 690 consuming to generate the 1000 simulations, particularly if the 691 chosen copula does not have an analytic inversion form. In the 692 latter case, 1000 equations need to be resolved numerically. 693 
694 Nevertheless, these simulations represent an advantage since it 695 is possible to compute a mean and a standard deviation. The 696 limitations are the same for both methods and even for any 697 general statistical methods using a specific year as a reference: 698 Only the variable range of this particular year can be well 699 represented. Therefore, if an event in a previous year occurs 700 and is out of the range found in the specific year of reference 701 (such as drought or flood events), then that event will not be 702 well represented in the simulated results.

703 In order to improve this methodology, applying a moving 704 window of three months would provide more accurate results 705 instead of dividing the year into four seasons. This would also 706 avoid the artifacts and gaps generally noticed at the transition 707 between the seasons. Another solution would be to introduce 708 the time in the copulas, but the level of complexity in the copula 709 manipulation would increase as well.

710 In this paper, the attempt to build a homogeneous soil mois711 ture time series has been based on statistical methods only. Of 712 course, other methods exist to reconcile different sensor ac713 quisitions, and because SMOS and AMSR-E do not operate at 714 the same frequencies and not at the same crossing times, using 715 physical models to tackle these discrepancies is an alternative to 716 statistical methods. Moreover, matching observations acquired 717 at 130 am and 600 am can trigger some questions, particularly 718 regarding the precipitations that could occur in between. The 719 present study is a first step toward a unified and homogeneous 720 soil moisture time series, and mixing physical and statisti721 cal models to do so would be a breakthrough for climate 722 studies.

723 The next step of this study is to build a homogeneous time 724 series of soil moisture at the global scale. Hence, the results of 725 this study will be extended in the future to build a global map 726 of the copula family choice and to study if there exists any rela727 tionship between the chosen copulas and the soil characteristics 728 or land use data. This would allow us to derive soil moisture 729 time series from LPRM data within SMOS soil moisture range 730 over the entire globe.

\section{ACKNOWLEDGMENT}

732 The authors would like to thank the USDA research team for 733 providing the in situ data and D. Huard from McGill University 734 for the helpful inputs on the copula method. USDA is an Equal 735 Employment Opportunity employer.

\section{REFERENCES}

1] "Implementation Plan for the Global Observing System for Climate in Support of the UNFCCC," World Meteorological Org., Geneva, Switzerland, Tech. Rep., 2010.

2] M. Drusch, "Initializing numerical weather predictions models with satellite derived surface soil moisture: Data assimilation experiments with ECMWF's integrated forecast system and the TMI soil moisture data set," J. Geophys. Res., vol. 113, no. D3, p. D03 102, Feb. 2007.

[3] H. Douville and F. Chauvin, "Relevance of soil moisture for seasonal climate predictions: A preliminary study," Climate Dyn., vol. 16, no. 10/11, pp. 719-736, Oct. 2000.

[4] Y. Kerr, P. Waldteufel, J. Wigneron, S. Delwart, F. Cabot, J. Boutin, M. Escorihuela, J. Font, N. Reul, C. Gruhier, S. Juglea, M. Drinkwater, A. Hahne, M. Martin-Neira, and S. Mecklenburg, "The SMOS mission: New tool for monitoring key elements of the global water cycle," Proc. IEEE, vol. 98, no. 5, pp. 666-687, May 2010.
[5] D. Entekhabi, E. Njoku, P. O’Neill, K. Kellogg, W. Crow, W. Edelstein, 752 J. Entin, S. Goodman, T. Jackson, J. Johnson, J. Kimball, J. Piepmeier, 753 R. Koster, N. Martin, K. McDonald, M. Moghaddam, S. Moran, 754 R. Reichle, J. Shi, M. Spencer, S. Thurman, L. Tsang, and J. Zyl, "The 755 soil moisture active passive (SMAP) mission," Proc. IEEE, vol. 98, no. 5, 756 pp. 704-716, May 2010.

[6] Y. Kerr, P. Waldteufel, J. Wigneron, J. Martinuzzi, J. Font, and M. Berger, 758 "Soil moisture retrieval from space: The soil moisture and ocean salinity 759 (SMOS) mission," IEEE Trans. Geosci. Remote Sens., vol. 39, no. 8, 760 pp. 1729-1735, Aug. 2001.

[7] M. Owe, R. de Jeu, and J. Walker, "A methodology for surface soil 762 moisture and vegetation optical depth retrieval using the microwave po- 763 larization difference index," IEEE Trans. Geosci. Remote Sens., vol. 39, 764 no. 8, pp. 1643-1654, Aug. 2001.

[8] E. Njoku, T. Jackson, V. Lakshmi, T. Chan, and S. Nghiem, "Soil moisture 766 retrieval from AMSR-E," IEEE Trans. Geosci. Remote Sens., vol. 41, 767 no. 2, pp. 215-229, Feb. 2003.

[9] L. Li, P. Gaiser, B. Gao, R. Bevilacqua, T. Jackson, E. Njoku, C. Rüdiger, 769 J. Calvet, and R. Bindlish, "Windsat global soil moisture retrieval and 770 validation," IEEE Trans. Geosci. Remote Sens., vol. 48, no. 5, pp. 2224- 771 2241, May 2010.

[10] V. Naeimi, K. Scipal, Z. Bartalis, and S. H. W. Wagner, "An improved soil 773 moisture retrieval algorithm for ERS and METOP scatterometer observa- 774 tions," IEEE Trans. Geosci. Remote Sens., vol. 47, no. 7, pp. 1999-2013, 775 Jul. 2009.

[11] L. Vincent, X. Zhang, B. Bonsal, and W. Hogg, "Homogeneization of 777 daily temperatures over Canada," J. Climate, vol. 15, no. 11, pp. 1322- 778 1334, Jun. 2002.

[12] M. Begert, T. Schlegel, and W. Kirchhofer, "Homogeneous temperature 780 and precipitation series of Switzerland from 1864 to 2000," Int. J. Clima- 781 tol., vol. 25, no. 1, pp. 65-80, Jan. 2005.

[13] G. Picard and M. Fily, "Surface melting observations in Antarctica by 783 microwave radiometers: Correcting 26-year time series from changes in 784 acquisition hours," Remote Sens. Environ., vol. 104, no. 3, pp. 325-336, 785 Oct. 2006.

[14] R. Reichle and R. Koster, "Bias reduction in short records of satellite soil 787 moisture," Geophys. Res. Lett., vol. 31, no. 19, p. L19501, Oct. 2004.788

[15] M. Choi and J. Jacobs, "Temporal variability corrections for advanced 789 microwave scanning radiometer E (AMSR-E) surface soil moisture: 790 Case study in little river region, Georgia, U.S.," Sensors, vol. 8, no. 4, 791 pp. 2617-2627, Apr. 2008.

[16] H. Li, J. Sheffield, and E. Wood, "Bias correction of monthly precipitation 793 and temperature fields from IPCC AR4 models using equidistant quantile 794 matching," J. Geophys. Res., Atmosp., vol. 115, no. D10, p. D10 101, 795 May 2010.

[17] M. Drusch, E. Wood, and H. Gao, "Observation operators for the di- 797 rect assimilation of TRMM microwave imager retrieved soil moisture," 798 Geophys. Res. Lett., vol. 32, no. 15, p. L15 403, Aug. 2005.

[18] Y. Liu, A. van Dijk, R. de Jeu, and T. Holmes, "An analysis of spatiotem- 800 poral variations of soil and vegetation moisture from a 29-year satellite- 801 derived data set over mainland Australia," Water Resour. Res., vol. 45, 802 no. 7, p. W07 405, Jul. 2009.

[19] Y. Liu, R. Parinussa, W. Dorigo, R. D. Jeu, W. Wagner, A. V. Dijk, 804 M. McCabe, and J. Evans, "Developing an improved soil moisture dataset 805 by blending passive and active microwave satellite-based retrievals," 806 Hydrol. Earth Syst. Sci., vol. 15, no. 2, pp. 425-436, Feb. 2011.

[20] V. Singh and W. Strupczewski, "Editorial," J. Hydrol. Eng., vol. 12, no. 4, 808 p. 345 , Jul. 2007.

[21] R. Nelsen, "An introduction to copulas," in Springer Series in Statistics. 810 New York, NY, USA: Springer-Verlag, 1998.

[22] P. Trivedi and D. Zimmer, Copula Modeling: An Introduction for Practi- 812 tioners, vol. 1, Foundations and Trends in Econometrics. Hanover, MA, 813 USA: Now Publ. Inc., 2005, pp. 1-111.

[23] C. Hafner and O. Reznikova, "Efficient estimation of a semiparamet- 815 ric synamic copula model," Comput. Stat. Data Anal., vol. 54, no. 11, 816 pp. 2609-2627, Nov. 2010.

[24] C. Genest and A. Favre, "Everything you always wanted to know about 818 copula modeling but were afraid to ask," J. Hydrol. Eng., vol. 12, no. 4, 819 pp. 347-368, Jul./Aug. 2007.

[25] A. Favre, S. E. Adlouni, L. Perreault, N. Thiémonge, and B. Bobée, "Mul- 821 tivariate hydrological frequency analysis using copulas," Water Resour. 822 Res., vol. 40, no. 1, p. W01 101, Jan. 2004.

[26] G. Salvadori and C. de Michele, "On the use of copulas in hydrology: 824 Theory and practice," J. Hydrol. Eng., vol. 12, no. 4, pp. 369-380, 825 Jul. 2007.

[27] D. Dupuis, "Using Copulas in hydrology: Benefits, cautions and issues," 827 J. Hydrol. Eng., vol. 12, no. 4, pp. 381-393, Jul. 2007. 
28] L. Zhang and V. Singh, "Trivariate flood frequency analysis using the Gumbel-Hougaard copula," J. Hydrol. Eng., vol. 12, no. 4, pp. 431-439, Jul. 2007.

29] F. Serinaldi and S. Grimaldi, "Fully nested 3-copula: Procedure and application on hydrological data," J. Hydrol. Eng., vol. 12, no. 4, pp. 420-430, Jul. 2007.

30] P. Laux, S. Vog1, W. Qiu, H. Knoche, and H. Kunstmann, "Copula-based statistical refinement of precipitation in RCM simulations over complex terrain," Hydrol. Earth Syst. Sci., vol. 15, no. 7, pp. 2401-2419, Jul. 2011. 1] H. Gao, E. Wood, M. Drusch, and M. McCabe, "Copula-derived observation operators for assimilating TMI and AMSR-E retrieved soil moisture into land surface models," J. Hydrometreol., vol. 8, no. 3, pp. 413-429, Jun. 2007.

32] C. de Michele and G. Salvadori, "A generalized pareto intensity-duration model of storm rainfall exploiting 2-copulas," J. Geophys. Res., vol. 108, no. D2, p. 4067, Jan. 2003.

3] J. Wigneron, Y. Kerr, P. Waldteufel, K. Saleh, M. Escorihuela, P. Richaume, P. Ferrazzoli, P. de Rosnay, R. Gurney, J. Calvet, J. Grant, M. Guglielmetti, B. Hornbuckle, C. Mätzler, T. Pellarin, and M. Schwank, "L-band microwave emission of the biosphere (L-MEB) model: Description and calibration against experimental data sets over crop fields," Remote Sens. Environ., vol. 107, no. 4, pp. 639-655, Apr. 2007.

34] Y. Kerr, P. Waldteufel, P. Richaume, J. Wigneron, P. Ferrazzoli, A. Mahmoodi, A. A. Bitar, F. Cabot, C. Gruhier, S. Juglea, D. Leroux, A. Mialon, and S. Delwart, "The SMOS soil moisture retrieval algorithm," IEEE Trans. Geosci. Remote Sens., vol. 50, no. 5, pp. 1384-1403, May 2012

35] D. Carr, R. Kahn, K. Sahr, and T. Olsen, "ISEA discrete global grids," Stat. Comput. Stat. Graph. Newl., vol. 8, no. 2/3, pp. 31-39, 1997.

36] A. A. Bitar, D. Leroux, Y. Kerr, O. Merlin, P. Richaume, A. Sahoo, and E. Wood, "Evaluation of SMOS soil moisture products over continental US using SCAN/SNOTEL network," IEEE Trans. Geosci. Remote Sens., vol. 50, no. 5, pp. 1572-1586, May 2012.

37] G. Schaefer, M. Cosh, and T. Jackson, "The USDA natural resources conservation service soil climate analysis network (SCAN)," J. Atmosp. Ocean. Technol., vol. 24, no. 12, pp. 2073-2077, Dec. 2007.

8] T. Jackson, R. Bindlish, M. Cosh, T. Zhao, P. Starks, D. Bosch, M. Seyfried, S. Moran, Y. Kerr, and D. Leroux, "Validation of soil moisture and ocean salinity (SMOS) soil moisture over watershed networks in the U.S.," IEEE Trans. Geosci. Remote Sens., vol. 50, no. 5, pp. 15301543, May 2012.

9] D. Leroux, Y. Kerr, A. A. Bitar, C. Gruhier, R. Bindlish, T. Jackson, B. Berthelot, and G. Portet, "Comparison between SMOS, VUA, ASCAT and ECMWF soil moisture products over four watersheds in the U.S.," IEEE Trans. Geosci. Remote Sens., submitted for publication.

40] J. Sabatier, A. Fouilloux, and P. de Rosnay, "Technical implementation of SMOS data in the ECMWF integrated forecast system," IEEE Geosci. Remote Sens. Lett., vol. 9, no. 2, pp. 252-256, Mar. 2012.

11] [Online]. Available: ftp://n4ftl01u.ecs.nasa.gov/SAN/AMSA/

42] C. Gruhier, P. de Rosnay, Y. Kerr, E. Mougin, E. Ceschia, J. Calvet, and P. Richaume, "Evaluation of AMSR-E soil moisture product based on ground measurements over temperate and semi-arid regions," Geophys. Res. Lett., vol. 35, no. 10, p. L10 405, May 2008.

43] C. Rudiger, J. C. Calvet, C. Gruhier, T. Holmes, R. de Jeu, and W. Wagner, "An intercomparison of ERS-SCAT and AMSR-E soil moisture observations with model simulations over France," Amer. Meteorol. Soc., vol. 10, no. 2, pp. 431-447, Apr. 2009.

44] C. Draper, J. Walker, P. Steinle, R. de Jeu, and T. Holmes, "An evaluation of AMSR-E derived soil moisture over Australia," Remote Sens. Environ., vol. 113, no. 4, pp. 703-710, Apr. 2009.

45] C. Gruhier, P. de Rosnay, S. Hasenauer, T. Holmes, R. de Jeu, Y. Kerr, E. Mougin, E. Njoku, F. Timouk, W. Wagner, and M. Zribi, "Soil moisture active and passive microwave products: Intercomparison and evaluation over a Sahelian site," Hydrol. Earth Syst. Sci., vol. 14, no. 1, pp. 141-156, Jan. 2010.

46] S. Chaurasia, D. Tung, P. Thapliyal, and P. Joshi, "Assessment of AMSRE soil moisture product over India," Int. J. Remote Sens., vol. 32, no. 23, pp. 7955-7970, Dec. 2011.

47] T. Jackson, M. Cosh, R. Bindlish, P. Starks, D. Bosch, M. Seyfried, D. Goodrich, M. Moran, and J. Du, "Validation of advanced microwave scanning radiometer soil moisture products," IEEE Trans. Geosci. Remote Sens., vol. 48, no. 12, pp. 4256-4272, Dec. 2010.

8] B. Schweizer and E. Wolff, "On nonparametric measures of dependence for random variables," Ann. Stat., vol. 9, no. 4, pp. 879-885, Jul. 1981. multiple degradation processes and random shock using time-varying copulas," IEEE Trans. Rel., vol. 61, no. 1, pp. 13-22, Mar. 2012

[50] C. Genest and L.-P. Rivest, "Statistical inference procedures for bivariate 906 Archimedean copulas," J. Amer. Stat. Assoc., vol. 88, no. 423, pp. 1034- 907 1043, Sep. 1993.

[51] J. Fermanian, "Goodness of fit tests for copulas," J. Multivariate Anal., 909 vol. 95, no. 1, pp. 119-152, Jul. 2005.

[52] C. Genest, J.-F. Quessy, and B. Rémillard, "Goodness-of-fit procedures 911 for copula models based on the probability integral transform," Scand. J. 912 Stat., vol. 33, no. 2, pp. 337-366, Jun. 2006.

[53] C. Genest and B. Rémillard, "Validity of the parametric bootstrap 914 for goodness-of-fit testing in semiparametric models," Annales Henri 915 Poincaré, vol. 44, no. 6, pp. 1096-1127, 2008.

[54] D. Berg, "Copula goodness-of-fit testing: An overview and power com- 917 parison," Eur. J. Finance, vol. 15, no. 7/8, pp. 675-701, 2009.

[55] C. Genest, B. Rémillard, and D. Beaudoin, "Goodness-of-fit tests for 919 copulas: A review and a power study," Insurance: Math. Econom., vol. 44, 920 no. 2, pp. 199-213, Apr. 2009.

[56] D. Huard, G. Evin, and A. Favre, "Bayesian copula selection," Comput. 922 Stat. Data Anal., vol. 51, no. 2, pp. 809-822, Nov. 2006.

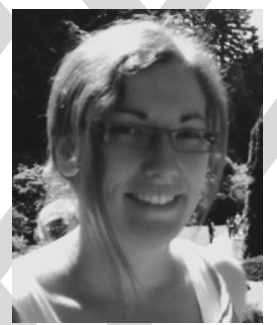

Delphine J. Leroux received the M.S. degree in 924 applied mathematics from Institut National des Sci- 925 ences Appliquees, Toulouse, France, in 2009 and the 926 $\mathrm{Ph} . \mathrm{D}$. degree in spatial hydrology from Universite 927 Paul Sabatier, Toulouse, in 2012.

From 2009 to 2012, she was with the Centre 929 d'Etudes Spatiales de la Biosphere, Toulouse, where 930 she worked on the validation of the Soil Moisture 931 and Ocean Salinity soil moisture product at the local 932 and global scales by using statistical and physical 933 methods. She is currently with the Jet Propulsion 934 Laboratory (JPL), Pasadena, CA, USA, on the Soil Moisture Active Passive 935 mission.
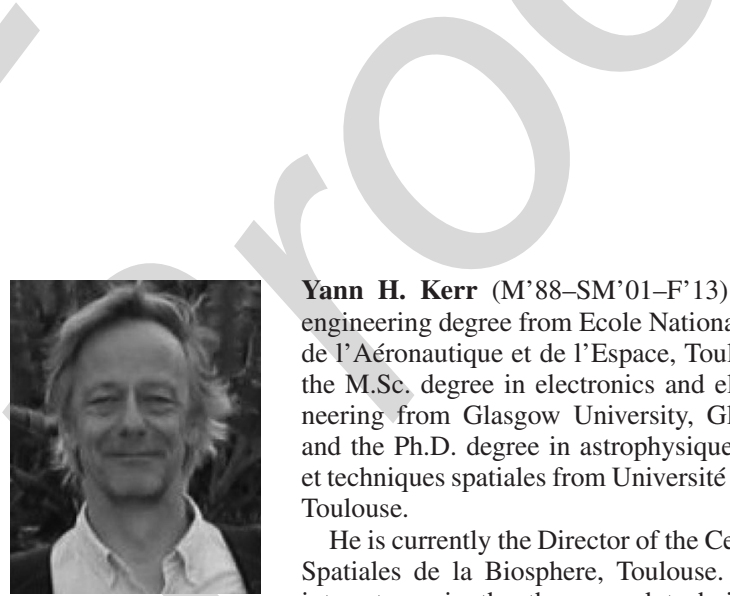

Yann H. Kerr (M'88-SM'01-F'13) received the 937 engineering degree from Ecole Nationale Supérieure 938 de l'Aéronautique et de l'Espace, Toulouse, France, 939 the M.Sc. degree in electronics and electrical engi- 940 neering from Glasgow University, Glasgow, U.K., 941 and the Ph.D. degree in astrophysique geophysique 942 et techniques spatiales from Université Paul Sabatier, 943 Toulouse.

He is currently the Director of the Centre d'Etudes 945 Spatiales de la Biosphere, Toulouse. His fields of 946 interest are in the theory and techniques for mi- 947 crowave and thermal infrared remote sensing of the Earth, with emphasis 948 on hydrology and water resource management. He was an EOS Principal 949 Investigator (interdisciplinary investigations) and PI and precursor of the use 950 of the SCAT over land. In 1990, he started to work on the interferometric 951 concept applied to passive microwave Earth observation and was subsequently 952 the Science Lead on the MIRAS project for ESA. In 1997, he proposed the 953 Soil Moisture and Ocean Salinity (SMOS) mission, the natural outcome of the 954 previous MIRAS work. He is currently involved in the exploitation of SMOS 955 data, in the Cal Val activities and related level 2 soil moisture and level 3 and 4956 developments. He is also working on the SMOS next concept.

Dr. Kerr received the World Meteorological Organization 1st prize (Norbert 958 Gerbier), the USDA Secretary's team award for excellence (Salsa Program), 959 and the GRSS certificate of recognition for leadership in the development of 960 the first synthetic aperture microwave radiometer in space and success of the 961 SMOS mission and is a Distinguished Lecturer for GRSS.
962 


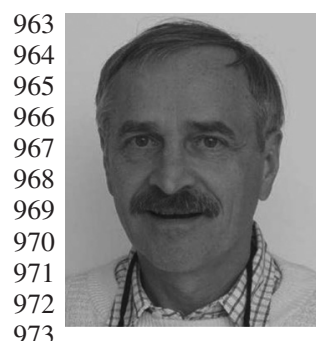

Eric F. Wood received the B.A.Sc. degree in civil engineering from the University of British Columbia, Vancouver, BC, Canada, in 1970 and the S.M., C.E., and Sc.D. degrees in civil engineering from the Massachusetts Institute of Technology, Cambridge, MA, USA, in 1972, 1973, and 1974, respectively.

$\mathrm{He}$ is currently a Professor in the Department of Civil and Environmental Engineering, Princeton University, NJ, USA. His recent contributions include the macroscale hydrologic prediction of the coupled water and energy balances of the land sur974 face, remote sensing as an integral tool for observation and modeling of 975 the hydrologic cycle, and developing and evaluating seasonal hydrological 976 forecasts based on coupled seasonal climate forecasts.

977 Dr. Wood is a fellow of the American Geophysical Union and the American 978 Meteorological Society. He received, among other honors, the Robert E. Horton 979 Award from the Hydrology Section of the American Geophysical Union (1977), 980 the John Dalton Medal from the European Geophysical Union (2007), and the 981 Jules G. Charney Award from the American Meteorological Society (2010).

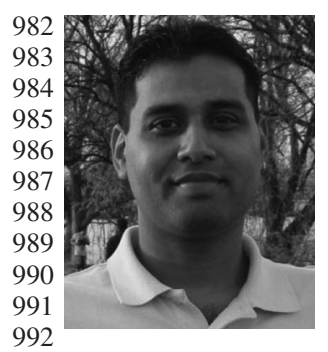

Alok K. Sahoo received the Ph.D. degree in computational sciences from George Mason University, Fairfax, VA, USA, in 2008.

After finishing his Ph.D., he worked as a Research Associate at the Institute of Global Environment and Society, Beltsville, MD, USA, from 2008 to 2009. $\mathrm{He}$ is currently an Associate Research Hydrologist with the Department of Civil and Environmental Engineering, Princeton University, Princeton, NJ, USA. His research interests involve the application of microwave remote sensing in hydrologic applications. 993 His current research projects include soil moisture estimation from microwave 994 sensors and checking consistency among hydrologic cycle variables for drought 995 monitoring.

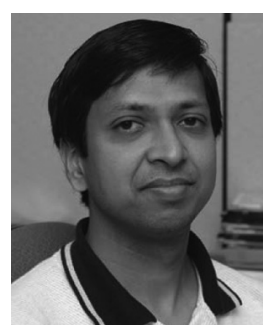

Rajat Bindlish (S'98-AM'99-M'03-SM'05) re- 996 ceived the B.S. degree in civil engineering from the 997 Indian Institute of Technology, Bombay in 1993 and 998 AQ40 the M.S. and Ph.D. degrees in civil engineering from 999 The Pennsylvania State University in 1996 and 2000, 1000 AQ41 respectively.

He is currently with SSAI, working at USDA 1002 AQ42 Agricultural Research Service, Hydrology and Re- 1003 mote Sensing Laboratory, Beltsville, MD, USA. His 1004 research interests involve the application of mi- 1005 crowave remote sensing in hydrology. He is currently 1006 working on soil moisture estimation from microwave sensors and their subse- 1007 quent application in land surface hydrology.

1008

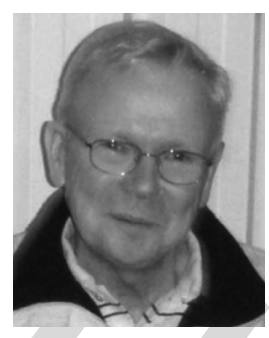

Thomas J.Jackson (SM'96-F'02) received the 1009 $\mathrm{Ph} . \mathrm{D}$. degree from the University of Maryland, 1010 College Park, MD, USA, in 1976.

1011

$\mathrm{He}$ is a Research Hydrologist with the U.S. De- 1012 partment of Agriculture, Agricultural Research Ser- 1013 vice, Hydrology and Remote Sensing Laboratory, 1014 Beltsville, MD, USA. His research involves the ap- 1015 plication and development of remote sensing tech- 1016 nology in hydrology and agriculture, primarily the 1017 microwave measurement of soil moisture.

1018

Dr. Jackson is or has been a member of the science 1019 and validation teams of the Aqua, ADEOS-II, Radarsat, Oceansat-1, Envisat, 1020 AQ43 ALOS, Soil Moisture and Ocean Salinity, Aquarius, GCOM-W, and Soil 1021 AO44 Moisture Active Passive remote sensing satellites. He is a fellow of the Society 1022 of Photo-Optical Instrumentation Engineers, the American Meteorological 1023 Society, and the American Geophysical Union. In 2003, he received the 1024 William T. Pecora Award (NASA and Department of Interior) for outstanding 1025 contributions toward understanding the Earth by means of remote sensing 1026 and the AGU Hydrologic Sciences Award for outstanding contributions to the $1027 \mathrm{AQ4}$ science of hydrology. He received the IEEE Geoscience and Remote Sensing 1028 Society Distinguished Achievement Award in 2011. 


\section{AUTHOR QUERIES}

\section{AUTHOR PLEASE ANSWER ALL QUERIES}

Please be aware that the authors are required to pay overlength page charges ( $\$ 200$ per page) if the paper is longer than 6 pages. If you cannot pay any or all of these charges please let us know.

This pdf contains 2 proofs. The first half is the version that will appear on Xplore. The second half is the version that will appear in print. If you have any figures to print in color, they will be in color in both proofs.

AQ1 = The sentence was restructured for clarity. Please check if the original thought was retained, and correct if necessary.

AQ2 = Please provide the expanded form of "USDA."

AQ3 = Please provide the expanded form of "ARS."

AQ4 = The sentence was restructured for clarity. Please check if the original thought was retained, and correct if necessary.

AQ5 = The sentence was restructured for clarity. Please check if the original thought was retained, and correct if necessary.

AQ6 = "AMSR-E" is defined as "Advanced Microwave Scanning Radiometer-Earth Observing System" for consistency. Please check if appropriate, and correct if necessary.

AQ7 = The sentence was restructured for clarity. Please check if the original thought was retained, and correct if necessary.

AQ8 = "Picard et al." was changed to "Picard and Fily." Please check if appropriate, and correct if necessary."

AQ9 = The sentence was rephrased for clarity. Please check if the original thought was retained, and correct if necessary.

AQ10 = The sentence was rephrased for clarity. Please check if the original thought was retained, and correct if necessary.

AQ11 = The sentence was rephrased for clarity. Please check if the original thought was retained, and correct if necessary.

AQ12 = The sentence was restructured for clarity. Please check if the original thought was retained, and correct if necessary.

AQ13 = "rmse" is defined as "root-mean-square error." Please check if appropriate, and correct if necessary."

AQ14 = The sentence was rephrased. Please check if the original thought was retained, and correct if necessary."

AQ15 = Please provide the expanded form of "NASA."

AQ16 = The sentence was rephrased for clarity. Please check if the original thought was retained, and correct if necessary.

AQ17 = The sentence was rephrased for clarity. Please check if the original thought was retained, and correct if necessary.

AQ18 = The caption was rephrased for clarity. Please check if the original thought was retained, and correct if necessary.

AQ19 = The sentence was rephrased for clarity. Please check if the original thought was retained, and correct if necessary.

AQ20 = "CDF" is defined as "cumulative density function" for consistency. Please check if appropriate, and correct if necessary.

AQ21 = The sentence was rephrased for clarity. Please check if the original thought was retained, and correct if necessary. 
AQ22 = The sentence was rephrased for clarity. Please check if the original thought was retained, and correct if necessary.

AQ23 = The sentence was rephrased for clarity. Please check if the original thought was retained, and correct if necessary.

AQ24 = The sentence was rephrased for clarity. Please check if the original thought was retained, and correct if necessary.

AQ25 = The sentence was rephrased for clarity. Please check if the original thought was retained, and correct if necessary.

AQ26 = The sentence was rephrased for clarity. Please check if the original thought was retained, and correct if necessary.

AQ27 = Please provide publication update in Ref. [39].

AQ28 = The author's current affiliation indicated in the footnote did not correspond to the current affiliation provided in the curriculum vitae. Please check.

AQ29 = The sentence was rephrased for clarity. Please check if the original thought was retained, and correct if necessary.

AQ30 = The sentence was rephrased for clarity. Please check if the original thought was retained, and correct if necessary.

AQ31 = Please provide the expanded form of "EOS."

AQ32 = Please provide the expanded form of "PI."

AQ33 = Please provide the expanded form of "SCAT."

AQ34 = Please provide the expanded form of "MIRAS."

AQ35 = Please provide the expanded form of "ESA."

AQ36 = Please provide the expanded form of "Cal Val."

AQ37 = "Dr." was inserted as the title for author Yann H. Kerr. Please check if appropriate, and correct if necessary.

AQ38 = Please provide the expanded form of "GRSS."

AQ39 = The sentence was rephrased for clarity. Please check if the original thought was retained, and correct if necessary.

AQ40 = Please provide the specific location of the Indian Institute of Technology, Bombay.

AQ41 = Please provide the specific location of The Pennsylvania State University.

AQ42 = Please provide the expanded form of "SSAI."

AQ43 = Please provide the expanded form of "ADEOS-II."

AQ44 = Please provide the expanded form of "ALOS."

AQ45 = Please provide the expanded form of "GCOM-W."

AQ46 = Please provide the expanded form of "AGU." 


\section{- An Approach to Constructing a Homogeneous Time Series of Soil Moisture Using SMOS}

\begin{abstract}
5 Abstract-Overlapping soil moisture time series derived 6 from two satellite microwave radiometers (the Soil Moisture 7 and Ocean Salinity and the Advanced Microwave Scanning 8 Radiometer-Earth Observing System) are used to generate a soil 9 moisture time series from 2003 to 2010 . Two statistical methodolo10 gies for generating long homogeneous time series of soil moisture 11 are considered. Generated soil moisture time series using only 12 morning satellite overpasses are compared to ground measure13 ments from four watersheds in the U.S.A. with different clima14 tologies. The two methods, cumulative density function (CDF) 15 matching and copulas, are based on the same statistical theory, but 16 the first makes the assumption that the two data sets are ordered 17 the same way, which is not needed by the second. Both methods 18 are calibrated in $\mathbf{2 0 1 0}$, and the calibrated parameters are applied 19 to the soil moisture data from 2003 to 2009 . Results from these 20 two methods compare well with ground measurements. However, 21 CDF matching improves the correlation, whereas copulas improve 22 the root-mean-square error.
\end{abstract}

23 Index Terms-Advanced Microwave Scanning Radiometer24 Earth Observing System (AMSR-E), cumulative density func25 tion (CDF) matching, copulas, Soil Moisture and Ocean Salinity 26 (SMOS), soil moisture, time series.

\section{INTRODUCTION}

28 OIL moisture is an important variable and is now consid29 ered as an essential climate variable by the World Meteo30 rological Organization [1]. It has a crucial role in the transfers 31 of water and energy between the soil and the atmosphere. Soil 32 moisture is also an input variable for land surface modeling 33 in determining the evaporative fraction at the surface and the 34 infiltration in the root zone. For both agriculture and water 35 resource management, soil moisture information is essential at 36 local and regional scales. At global scales, soil moisture is of

Manuscript received November 28, 2011; revised May 14, 2012 and October 22, 2012; accepted December 22, 2012. This work was supported in part by Telespazio France and in part by TOSCA.

D. J. Leroux is with the Centre d'Etudes Spatiales de la Biosphere, 31400 Toulouse, France, and also with Telespazio France, 31023 Toulouse Cedex 1, France (e-mail: delphine.j.leroux@gmail.com).

Y. H. Kerr is with the Centre d'Etudes Spatiales de la Biosphere, 31400 Toulouse, France (e-mail: yann.kerr@cesbio.cnes.fr).

E. F. Wood and A. K. Sahoo are with the Department of Civil and Environmental Engineering, Princeton University, Princeton, NJ 08544 USA (e-mail: efwood@princeton.edu; aksahoo2004@gmail.com).

R. Bindlish and T. J. Jackson are with the USDA ARS Hydrology and Remote Sensing Laboratory, Beltsville, MD 20705 USA (e-mail: rajat.bindlish@ ars.usda.gov; tom.jackson@ars.usda.gov).

Color versions of one or more of the figures in this paper are available online at http://ieeexplore.ieee.org.

Digital Object Identifier 10.1109/TGRS.2013.2240691 great value for weather forecasting [2], climate change [3], and 37 monitoring extreme events such as floods and droughts. $\quad 38$

Soil Moisture and Ocean Salinity (SMOS) [4] was success- 39 fully launched by the European Space Agency in November 40 2009 and since has been providing global maps of soil moisture 41 every three days at a nominal spatial resolution of $43 \mathrm{~km} 42$ with an accuracy of $0.04 \mathrm{~m}^{3} / \mathrm{m}^{3}$. SMOS is the first mission 43 specifically designed for soil moisture monitoring. The Soil 44 Moisture Active Passive (SMAP) mission [5] is scheduled 45 for launch in October 2014 by the National Aeronautics and 46 Space Administration. SMAP will continue the time series of 47 soil moisture based on $1.4-\mathrm{GHz}$ radiometer observations that 48 began with SMOS. The 1.4-GHz frequency channel is the most 49 suitable frequency for soil moisture retrieval [6].

50

Longer time series of satellite-based soil moisture would be 51 of value in climate-related analysis. Utilizing the data from the 52 previous generations of satellite sensors involves resolving nu- 53 merous issues. Some of the platforms and approaches have been 54 developed to retrieve soil moisture using the higher frequencies, 55 which has been the only option until now. These include the 56 Scanning Multichannel Microwave Radiometer (1978-1987) 57 [7], the Special Sensor Microwave/Imager (1987-current) 58 [7], the Advanced Microwave Scanning Radiometer-Earth 59 Observing System (AMSR-E) (2002-2011) [7], [8], Wind- 60 Sat (2003-current) [9], and the European Remote Sensing- 61 Advanced Scatterometer (1991-current) [10]. Although their 62 lowest frequencies $(5-20 \mathrm{GHz})$ are not the most suitable for 63 soil moisture retrievals (higher sensitivity to vegetation growth 64 and atmospheric conditions), they remain a valuable time series 65 from 1978 until now. Applications such as data assimilation 66 or climate change assessment require consistent products. The 67 products referenced earlier have been retrieved using different 68 sensors with different algorithms, and as a result, the time series 69 is not homogeneous. This heterogeneity can be interpreted as a 70 bias and is a problem in the data assimilation process. To avoid 71 this issue, these products need to be processed to correct for any 72 bias or amplitude variation between the data sets.

73

Many previous studies have developed various methods for 74 the homogenization of time series. Vincent et al. [11] developed 75 a method to harmonize temperature time series with gaps. The 76 first step was to determine if the series was homogeneous by 77 comparing its anomalies to those of a reference series. The 78 identification of the gaps and their magnitude was performed 79 by successively fitting a linear model with different magnitude 80 values with the best fit being indicated by the minimum sum 81 of square errors. Homogeneous temperature and precipitation 82 time series were developed by Begert et al. [12] using statistical 83 
84 methods to detect potential inhomogeneity. In that study, a 85 reference time series was necessary in order to detect and 86 compute the magnitude of the shifts. Picard and Fily [13] 87 proposed a method to simulate a homogeneous time series of 88 the cumulative melting surface in Antarctica. Using satellite 89 observations from different sensors and acquisition times was 90 the biggest challenge. Correcting for the effect of the observing 91 time was accomplished in two steps. First, a sinusoidal function 92 with a 24-h periodicity was fitted, and then, an optimal interpo93 lation to refine this first guess model to force it to be closer was 94 applied to the observations and to provide very low uncertainty 95 around observation time and larger uncertainty when there is no 96 available observation.

97 Matching the cumulative density functions (CDFs) of two 98 data sets has been used in several studies to merge time series. 99 Reichle and Koster [14] and Choi and Jacobs [15] merged 100 soil moisture derived from satellite observations with model 101 data, and Li et al. [16] corrected the bias of precipitation 102 and temperature products derived from different models. CDF 103 matching was also used as a preliminary step of the assimilation 104 process [17] and to produce long time series of soil moisture 105 [18], [19].

106 Over the last few years, a new method based on copula 107 functions has been developed. It allows the derivation of bi108 variate distributions without making the assumptions required 109 when dealing with multivariate frequency distributions, e.g., 110 the same type of marginal distribution for both variables, a 111 joint normal distribution, and independent variables. One of 112 the major advantages of the copula method is that the marginal 113 distributions can be of any form [20]. The first comprehensive 114 treatment of copulas was by Nelsen [21]. He presented methods 115 to construct copulas and discussed the role played by copulas 116 in modeling and dependence. Since then, copulas have been 117 applied in various applications with the majority of the liter118 ature dedicated to the financial sector [22], [23]. In the field of 119 hydrology, some applications have emerged. Genest and Favre 120 [24] summarized the existing methods to detect and evaluate 121 the dependence between the data sets through copulas (analyt122 ically and graphically) and enumerated the various methods to 123 choose the best copula family and estimate their parameters. 124 Favre et al. [25] applied copulas to peak flows and volumes 125 from two watersheds, Salvadori and De Michele [26] to storm 126 and rainfall time series, Dupuis [27] to the volume and duration 127 of low flows of two rivers, Zhang and Singh [28] to rainfall fre128 quency, Serinaldi and Grimaldi [29] to flood and sea frequency, 129 and Laux et al. [30] to precipitation data. Gao et al. [31] used 130 copulas as a preprocessing step for the assimilation process on 131 soil moisture data.

132 Joint statistical analysis has already been applied when the 133 sources of the soil moisture measurements come from different 134 observation systems (e.g., AMSR-E surface soil moisture and 135 10-cm soil moisture from a land surface model [14]). Similarly, 136 joint statistical methods form the basis for data assimilation of 137 satellite soil moisture into land surface models [31]. There are 138 many other studies related to joint probability, including where 139 the variables are physically different but where their statistical 140 relationships are useful (e.g., rainfall storm intensity and storm 141 duration [32]).
The goal of this paper is to estimate for all the AMSR-E 142 period (2003-2010) SMOS-equivalent observations that can be 143 used to develop a statistical representation of SMOS retrieval so 144 that current and future SMOS retrievals can be used in applica- 145 tions like drought monitoring based on percentiles. However, 146 matching 130 am C-/X-band (AMSR-E) observations with 147 600 am L-band (SMOS) observations presents some issues: 148 1) The crossing times are different, and rainfalls may occur be- 149 tween the two acquisitions; and 2) the frequencies are different, 150 so the sensing depths are not similar.

151

The statistical impact of the rainfalls that could occur be- 152 tween 130 am and 600 am is to lower the correlation. However, 153 if the correlation is sufficiently high, a statistical relationship 154 can be established to estimate an equivalent SMOS value from 155 an AMSR-E observation. This high correlation implies that the 156 occurrence of precipitation between the SMOS and AMSR-E 157 overpasses is rare. Moreover, it is well known that soil moisture 158 has a long temporal correlation time scale, so the overpass time 159 differences will have a minimal effect on the analysis.

160

The impact of the different frequencies between AMSR-E 161 and SMOS is, in most situations, not significant. The higher 162 AMSR-E frequency $(10.7 \mathrm{GHz})$ results in a more superficial 163 emission depth than the SMOS observations, so while the 164 retrieved values may be different, their relative values will be 165 similar (both dry or wet). The correlation between paired ob- 166 servations depends on their relative values (with their individual 167 time series) and not absolute values, and in the case of copula- 168 based joint distributions, the correlation is represented by the 169 Kendall tau whose calculation is based on ranks.

If the two sensing depths were to be reconciled physically, 171 given the soil property variability (spatially and with depth) 172 with different wetting and drying properties, a physical model 173 would introduce significant uncertainty that could be very 174 difficult to estimate afterward. If the SMOS (or AMSR-E) 175 data were adjusted to the AMSR-E (or SMOS) emission depth 176 through data assimilation into a land surface model for exam- 177 ple, then the complete record would have to be adjusted with 178 the added uncertainty of the data assimilation step. With any 179 of the suggested adjustments, there is a mismatch with the 180 past or with the future. Only by treating the original data sets 181 and determining the information content between them can a 182 consistent approach be represented.

Data assimilation could, however, deal with the precipitation 184 and the difference in sensing depth issues, but that would imply 185 other uncertainties such as the space-time variability of the 186 precipitation data sets, as well as other meteorological issues. 187 Building a homogeneous time series based on data assimila- 188 tion into a land surface model can be seen as a competing 189 approach.

In this paper, we show two statistical methods to obtain 191 this homogeneous time series. The satellite data and the four 192 watersheds where the time series are simulated are presented 193 in Section II. The two statistical methods for generating ho- 194 mogeneous time series are presented in Section III which 195 includes the general theory and how to apply them to real data. 196 Simulated time series over the four watersheds are presented in 197 Section IV. Conclusions and perspectives are described in the 198 last section. 


\section{A. SMOS}

202 With its L-band radiometer, SMOS [4] has been providing 203 soil moisture data for almost three years and global coverage 204 every three days with a 43-km resolution. The satellite is polar 205 orbiting with equator crossing times of 6 am (local solar time 206 (LST), ascending) and 6 pm (LST, descending). The signal at 207 L-band is mainly influenced by the water content at the surface 208 of the soil (around $5 \mathrm{~cm}$ ).

209 SMOS acquires brightness temperatures at multiple inci210 dence angles, from $0^{\circ}$ to $55^{\circ}$ with full polarization. The an211 gular signature is a key element of the retrieval algorithm 212 that provides soil moisture and the vegetation optical thickness 213 through the minimization of a cost function between modeled 214 and acquired brightness temperatures [33], [34]. This estimated 215 soil moisture is referred as the Level 2 product [34] and is AQ12 216 available on the Icosahedral Snyder Equal Area-4h9 grid [35]. 217 The nodes of this grid are equally spaced at about $15 \mathrm{~km}$. In 218 this paper, the 2010 SMOS Level 2 version 4 products have 219 been used.

220 Currently, numerous studies are underway on the validation 221 of SMOS soil moisture product with in situ measurements 222 and estimates of other sensors and models. Bitar et al. [36] 223 used the Soil Climate Analysis Network [37] and the Snow224 pack Telemetry sites in North America to compare SMOS 225 soil moisture retrievals and ground measurements. That study 226 showed that SMOS soil moisture had a very good dynamic 227 response but tended to underestimate the values. However, 228 the new version of the product (V4) significantly improved 229 the general results. Jackson et al. [38] studied SMOS soil 230 moisture and vegetation optical depth over four watersheds in 231 the U.S. They concluded that SMOS almost met the accuracy AQ13 232 requirement with root-mean-square errors (rmses) of 0.043 and $2330.047 \mathrm{~m}^{3} / \mathrm{m}^{3}$ in the morning and afternoon, respectively, 234 whereas the vegetation optical depth retrievals were not reliable AQ14 235 yet for use in vegetation analyses. Leroux et al. [39] compared 236 SMOS data with other satellite and model output products over 237 the same four watersheds for the year 2010. It showed that 238 SMOS soil moisture data were closer to the ground measure239 ments than the other data sets. Even though the correlation 240 coefficient was not the best, the bias was extremely small.

241 After the results of the validation activities, the European 242 Center for Medium-Range Weather Forecasts has decided and 243 is now ready to process SMOS data in near real time into their 244 Integrated Forecast System. It is expected to have an impact on 245 the weather forecast at short and medium ranges [40].

\section{B. AMSR-E}

247 The AMSR-E was launched in June 2002 on the Aqua 248 satellite. This radiometer acquires data with a single $55^{\circ}$ inci249 dence angle at six different frequencies: 6.9, 10.7, 18.7, 23.8, 25036.5 , and $89.0 \mathrm{GHz}$, all dual polarized. The crossing times are 251 respectively 1:30 am (LST, descending) and 1:30 pm (LST, 252 ascending).

253 There are several soil moisture products available that are 254 based on AMSR-E data. Many studies have already showed

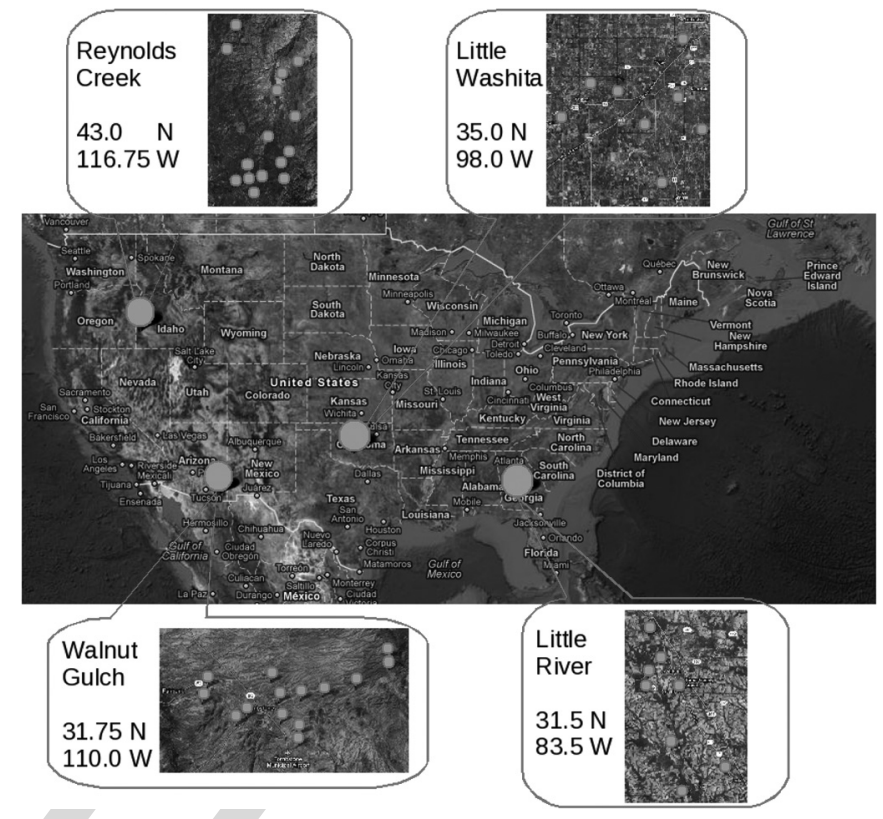

Fig. 1. Map of the four sites: WG, AZ; LW, OK; LR, GA; and RC, ID.

that the NASA product [41] is not able to reproduce low values 255 AQ15 of soil moisture and has low dynamic range [42]-[46]. The 256 soil moisture data produced by the joint collaboration of the 257 Vrije University of Amsterdam and NASA (whereafter called 258 the Land Parameter Retrieval Model (LPRM) [7]) were chosen 259 in this study.

260 AQ16

The LPRM [7] retrieves soil moisture and optical thickness 261 using the C- and X-band AMSR-E channels (combined prod- 262 uct) and $36.5 \mathrm{GHz}$ to estimate the surface temperature. This 263 algorithm is based on a microwave radiative transfer model with 264 a priori information about soil characteristics. The products are 265 available on a $0.25^{\circ} \times 0.25^{\circ}$ grid only for the descending orbit. 266 These data have been quality controlled, and the contaminated 267 estimates due to high topography and extreme weather condi- 268 tions such as snow have been flagged and not been considered 269 in this study.

\section{Study Areas}

Four watersheds located in the United States were selected 272 for this study: Walnut Gulch (WG) in Arizona, Little Washita 273 (LW) in Oklahoma, Little River (LR) in Georgia, and Reynolds 274 Creek (RC) in Idaho (see Fig. 1). They represent different 275 types of climate (from semiarid to humid) and land use patterns 276 [47]. These four watersheds have been used as calibration and 277 validation sites for comparison of AMSR-E satellite product 278 [47] and SMOS product [38], [39].

WG is located in the Southeast Arizona. Most of the water- 280 shed is covered by shrubs and grass, which is typical of the re- 281 gion. The annual mean temperature is $17.6{ }^{\circ} \mathrm{C}$ (at Tombstone), 282 and the annual mean precipitation is $320 \mathrm{~mm}$ (mainly from 283 high intensity convective thunderstorms in the late summer). 284 The uppermost $10 \mathrm{~cm}$ of the soil profile contains up to $60 \% 285$ gravel, and the underlying horizons usually contain less than 286 $40 \%$ gravel. 
TABLE I

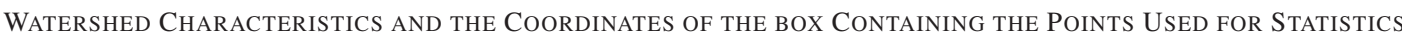

\begin{tabular}{|c|c|c|c|c|c|c|}
\hline Watershed & $\begin{array}{l}\text { Number of } \\
\text { stations }\end{array}$ & Climate & $\begin{array}{c}\text { Annual } \\
\text { rainfall }(\mathrm{mm})\end{array}$ & Topography & Land use & $\begin{array}{l}\text { Box for statistics } \\
\text { (corners coord.) }\end{array}$ \\
\hline $\begin{array}{l}\text { Walnut Gulch } \\
\text { AZ }\end{array}$ & 14 & semi-arid & 320 & rolling & range & $31.3 \mathrm{~N}-110.5 \mathrm{~W}$ \\
\hline $\begin{array}{l}\text { Little Washita } \\
\text { OK }\end{array}$ & 8 & sub-humid & 750 & rolling & range/wheat & $\begin{array}{l}34.4 \mathrm{~N}-98.5 \mathrm{~W} \\
35.4 \mathrm{~N}-97.5 \mathrm{~W}\end{array}$ \\
\hline $\begin{array}{l}\text { Little River } \\
\text { GA }\end{array}$ & 8 & humid & 1200 & flat & row crop/forest & $\begin{array}{l}31.0 \mathrm{~N}-84.0 \mathrm{~W} \\
32.0 \mathrm{~N}-83.0 \mathrm{~W}\end{array}$ \\
\hline $\begin{array}{l}\text { Reynolds Creek } \\
\text { ID }\end{array}$ & 15 & semi-arid & 500 & mountainous & range & $\begin{array}{l}34.7 \mathrm{~N}-98.7 \mathrm{~W} \\
35.7 \mathrm{~N}-97.7 \mathrm{~W}\end{array}$ \\
\hline
\end{tabular}

TABLE II

Correlation CoEFFicients (R) BETWEen THE IN SitU MEASUREMENTS AT 130 AM AND 600 AM FOR THE FOUR WATERSHEDS. N IS THE Number of AVAilable Dates, AND CI IS THE 95\% CONFIDENCE INTERVAL

\begin{tabular}{ccc|ccc}
\hline \multicolumn{3}{c|}{ WG } & \multicolumn{4}{c}{ LW } \\
\hline $\mathrm{R}$ & $\mathrm{N}$ & $\mathrm{CI}$ & $\mathrm{R}$ & $\mathrm{N}$ & $\mathrm{CI}$ \\
0.96 & 365 & {$[0.95-0.97]$} & 0.97 & 365 & {$[0.96-0.98]$} \\
\hline \multicolumn{3}{c|}{} & \multicolumn{4}{c}{$\mathrm{RC}$} \\
\multicolumn{3}{c}{$\mathrm{LR}$} \\
\hline $\mathrm{R}$ & $\mathrm{N}$ & $\mathrm{CI}$ & $\mathrm{R}$ & $\mathrm{N}$ & $\mathrm{CI}$ \\
0.95 & 365 & {$[0.94-0.96]$} & 0.99 & 328 & {$[0.99-0.99]$} \\
\hline
\end{tabular}

288 LW is located in Southwest Oklahoma in the Southern Great 289 Plains region of the U.S. The climate is subhumid with an 290 average annual rainfall of $750 \mathrm{~mm}$ (mainly during the spring 291 and fall seasons). Topography is moderately rolling with a 292 maximum relief of less than $200 \mathrm{~m}$. Land use is dominated by 293 rangeland and pasture $(63 \%)$.

294 LR is located in the Southern Georgia near Tifton. With 295 an average annual precipitation of $1200 \mathrm{~mm}$, the climate is 296 humid. The LR watershed is typical of the heavily vegetated 297 slow-moving stream systems in the Coastal Plain region of 298 the U.S. The topography over this watershed is relatively flat. 299 Approximately $40 \%$ of the watershed is forest with $40 \%$ crops 300 and $15 \%$ pasture.

$301 \mathrm{RC}$ is located in a mountainous area of Southwest Idaho. The 302 topography is high with a relief of over $1000 \mathrm{~m}$ that results in 303 diverse climates. Soils and vegetations are typical in this part 304 of the Rocky Mountains. The climate is considered as semiarid 305 with an annual precipitation of $500 \mathrm{~mm}$. Approximately $75 \%$ of 306 the annual precipitation at high elevation is snow, whereas only $30725 \%$ is snow at low elevation.

308 Surface soil moisture and temperature sensors $(0-5 \mathrm{~cm})$ have 309 been acquiring data since 2002 for the four watersheds. The 310 data used in this study are the means and standard deviations 311 of the soil moisture and surface temperature acquired every $31230 \mathrm{~min}$ from 2009 to 2010 (hourly for RC). The averages 313 are based on 14/8/8/15 sensors for WG/LW/LR/RC, respec314 tively, after eliminating sensors with poor and suspicious AQ19 315 performances. Weighting coefficients have been derived for 316 each sensor with a Thiessen polygon. Table I summarizes the 317 characteristics of each watershed [47].

318 In order to estimate the effect of the rainfalls that could 319 occur between $130 \mathrm{am}$ and $600 \mathrm{am}$, the correlation coefficients 320 between the measurements at 130 am and 600 am have been 321 computed for the four watersheds (see Table II and Fig. 2). They 322 range from 0.95 to 0.99 , and based on the fact that rainfalls 323 would lower the correlation, we can assess that precipitations 324 that do not affect significantly the analysis.

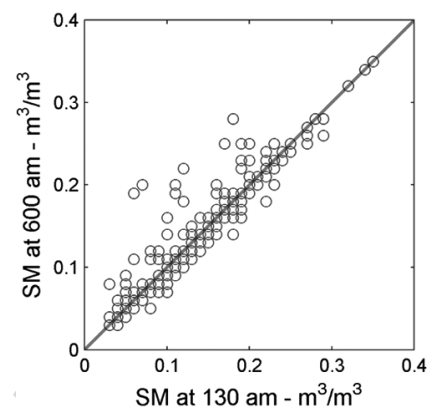

(a) (b)

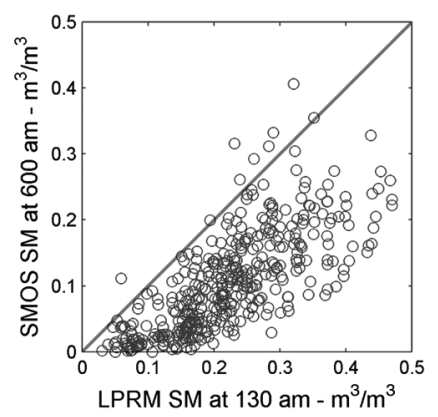

Fig. 2. Comparison between the 130 am and the 600 am soil moisture: In situ observations and satellite products for the four watersheds. (a) In situ soil moisture at $130 \mathrm{am}$ and $600 \mathrm{am}$. (b) LPRM (130 am) and SMOS (600 am) soil moisture.

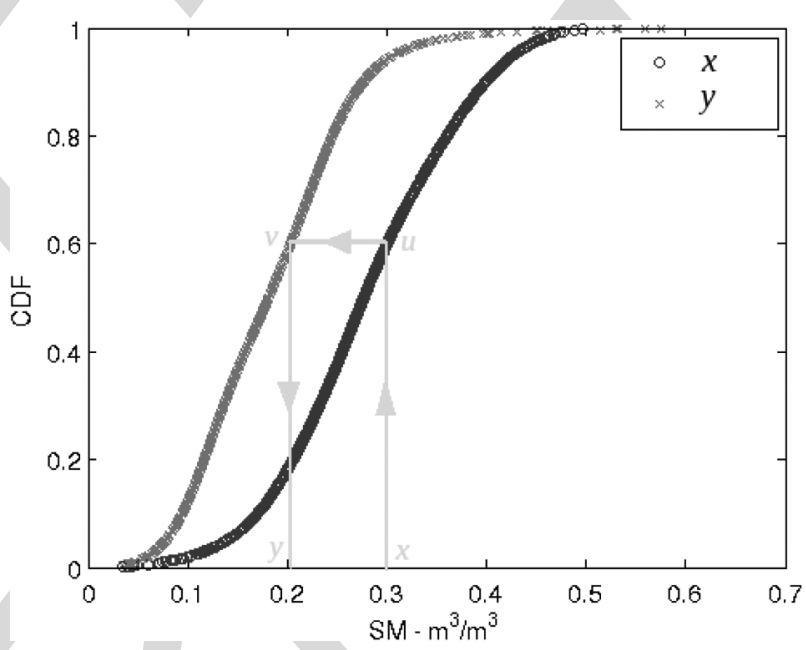

Fig. 3. Principle of CDF matching by setting the probabilities equal. For a given $x$, find $y$ such that $G_{Y}(y)=F_{X}(x)$.

\section{Two Statistical Methods for Generating HOMOGENEOUS TIME SERIES}

Two statistical methods were used to create a homogeneous 327 time series of soil moisture. CDF matching has been widely 328 used in previous studies to merge time series [14], [15], [18], 329 [19], whereas copulas have just started to be used recently for 330 environmental purposes.

\section{A. CDF Matching}

The $\mathrm{CDF}$ is the probability that a random variable $X$ takes a 333 value less than or equal to a given number $x$

$$
F_{X}(x)=\operatorname{Pr}[X \leq x]
$$




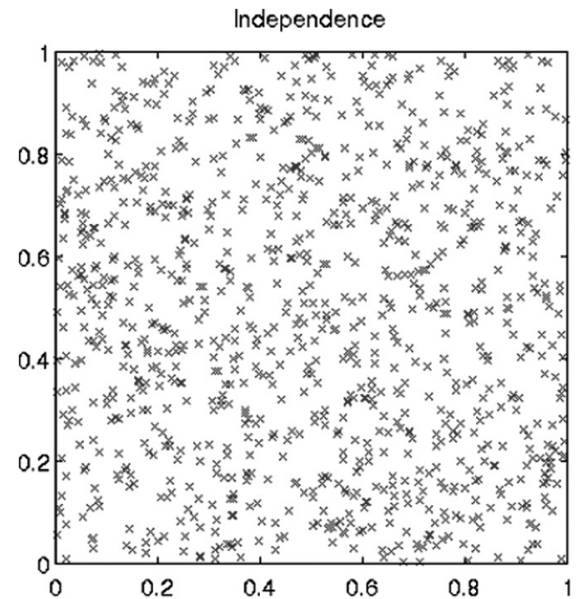

(a)

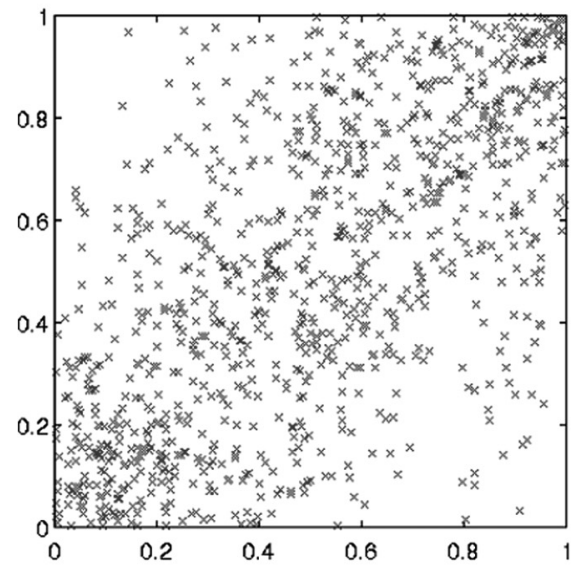

(d)

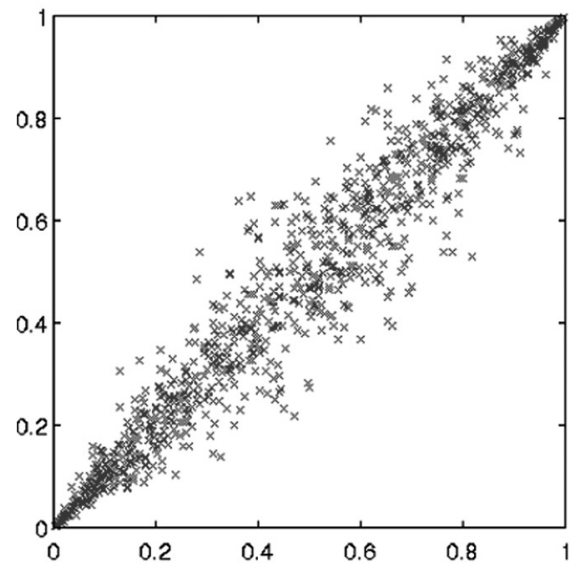

(g)

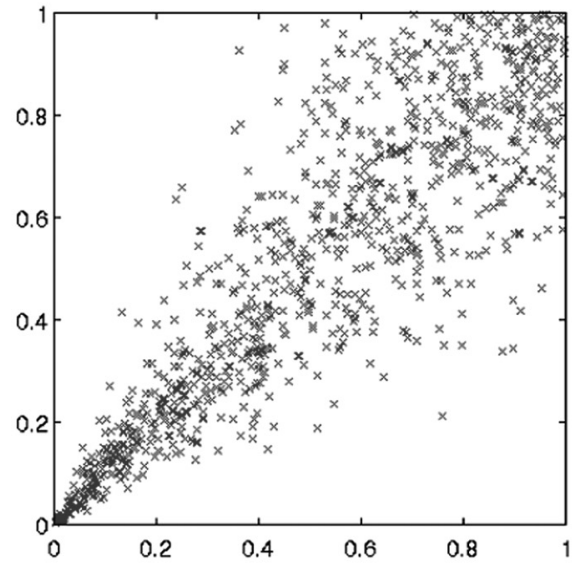

(b)

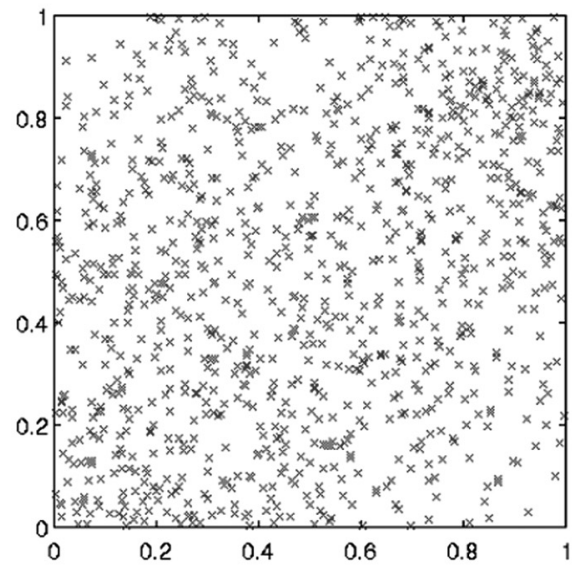

(e)

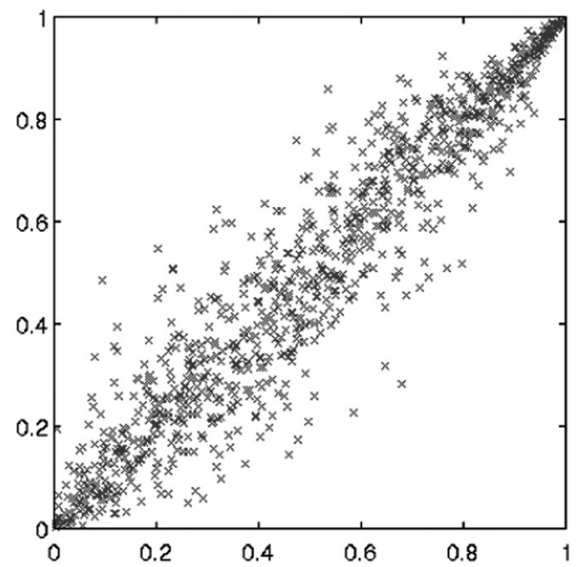

(h)

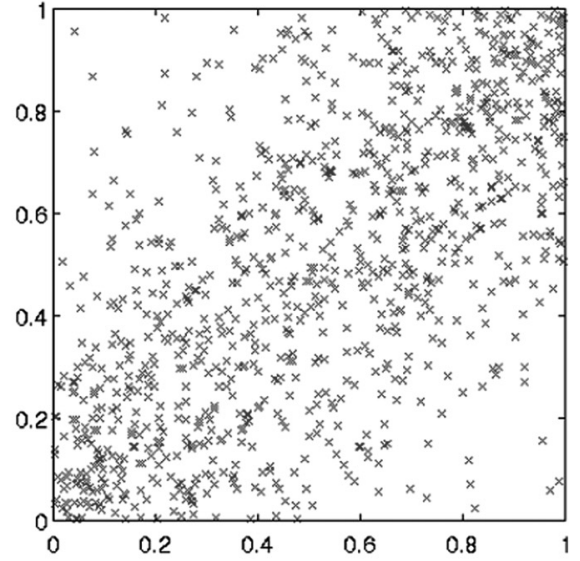

(c)

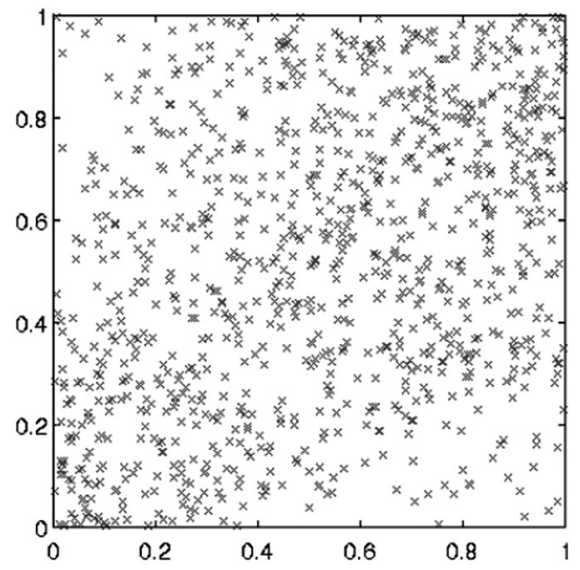

(f)

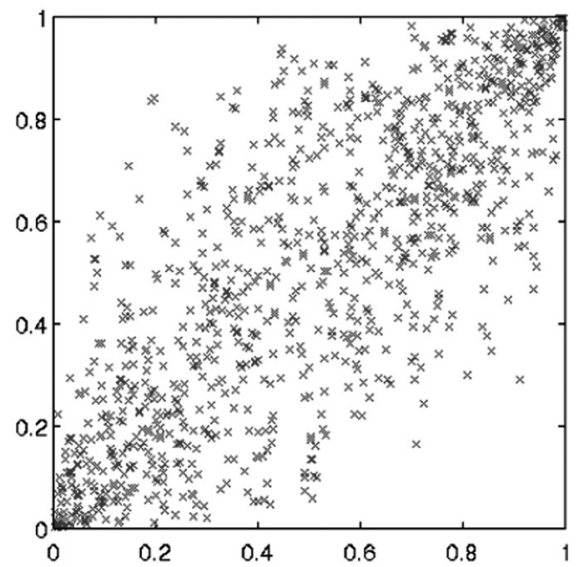

(i)

Fig. 4. Representations of the nine copulas showing their characteristics in the form of the point cloud ( $x$-axis: CDF of the first data set; $y$-axis: CDF of the second data set).

335 where $F_{X}$ is the $\mathrm{CDF}$ of the random variable $X$. If two time 336 series are considered, the CDF matching consists of matching 337 the CDF of each data set by setting their probabilities equal 338 (see Fig. 3). The following approach has been applied here to 339 the soil moisture data.

340 1) Compute the CDF of both data sets $X$ and $Y: F_{X}$ and $G_{Y}$.

341 2) Given a value $x$ of $X$, find $y$ such that $G_{Y}(y)=F_{X}(x)$.

342 However, the assumption that the probabilities $F_{X}(x)$ and $343 G_{Y}(y)$ are equal is never confirmed, and most of the time, they are scattered like in Fig. 4. The copula method models this 344 dependence between the probabilities.

345

For the rest of this paper, we use the variable $u$ to represent 346 $F_{X}(x)$ and $v$ for $G_{Y}(y) . U$ and $V$ are data sets, whereas $u$ and 347 $v$ are values of these data sets.

348

\section{B. Copulas}

The copula theory is a very useful and powerful tool to model 350 the dependence structure between two sets of random variables. 351 
TABLE III

Nine Copulas Tested in the Study: Definition, Parameter Range, and Family

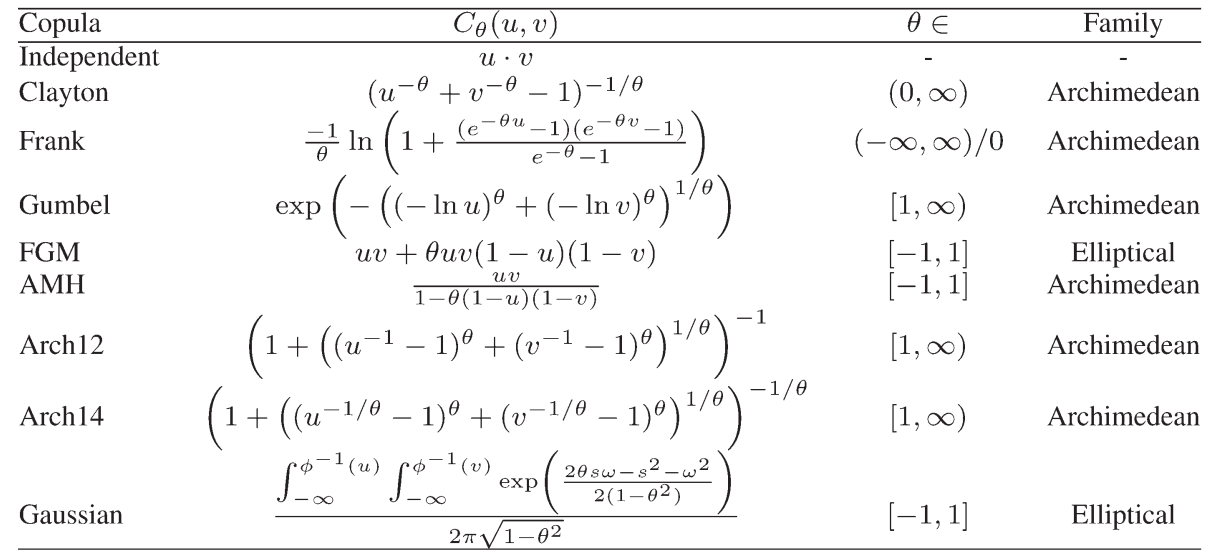

352 Like the CDF matching, copulas separate the marginal behavior 353 of variables from the dependence structure by using distribution 354 functions. Instead of setting the probabilities $u$ and $v$ equal, 355 the variables $U$ and $V$ are compared and analyzed. The copula 356 function binds the two variables together.

357 There are many families of copulas which exhibit very differ358 ent properties. The form of the scatter of $U$ and $V$ is controlled 359 by the family choice, and the width of the tail of this scatter 360 is controlled by the single parameter $\theta$. Most of the definitions 361 that follow in this section are based on [21].

362 1) General Theory: A copula is a function that generAQ20 363 ates a multivariate cumulative distribution function from 1-D 364 marginal CDFs. Given two random variables, $X$ and $Y$, with 365 marginal CDFs $F_{X}$ and $G_{Y}$, then, Sklar's theorem states

$$
H_{X Y}(x, y)=C_{X Y}\left(F_{X}(x), G_{Y}(y)\right)=\operatorname{Pr}[X \leq x, Y \leq y]
$$

366 where $H_{X Y}$ is the joint CDF of $X$ and $Y$ and $C_{X Y}$ is the asso367 ciated copula function. It is then possible to derive conditional 368 distributions, $H_{X Y}(y \mid x)$, i.e., the joint CDF knowing $x$. Let $369 u=F_{X}(x)$ and $v=G_{Y}(y)$. Then, $H_{X Y}(y \mid x)$ can be derived by

$$
C_{V \mid U}=\frac{\partial C(u, v)}{\partial u} .
$$

370 Schweizer and Wolff [48] established that the copula func371 tion accounts for all the dependence between the two variables. 372 They demonstrated that transformations of the variables $X$ and $373 Y$ do not affect their associated variables. Thus, the way that $X$ 374 and $Y$ evolve together is captured by the copula, regardless of 375 the scale in which each variable is measured.

376 2) Some Copula Families: The product copula corresponds 377 to the independence between $X$ and $Y$

$$
C(u, v)=u \cdot v .
$$

378 A copula of the Archimedean family takes the following 379 form:

$$
C(u, v)=\phi^{-1}(\phi(u)+\phi(v))
$$

380 where $\phi$ is the generator function that goes from $[0,1]$ to $381(0, \infty)$. It satisfies three conditions: $\phi(1)=0, \phi$ strictly de382 creasing, and $\phi$ convex.

383 Elliptical copulas have distributions with elliptic contours. 384 The main advantage of elliptical distributions is that the level of correlation between the variables $U$ and $V$ can be specified. 385 The disadvantages are that elliptical copulas do not have closed- 386 form expressions and are restricted to have radial symmetry. 387

In this paper, nine copulas were used: the product cop- 388 ula, Clayton, Frank, Gumbel, Farlie-Gumbel-Moregenstern 389 (FGM), Ali-Mikhail-Haq, Arch12 (the 12th copula presented 390 in [21]), Arch14 (the 14th copula presented in [21]), and the 391 Gaussian copula. The nine copulas are described in Table III 392 and Fig. 4 and have their own characteristics.

1) Clayton: Strong left tail dependence and relatively weak 394 right tail dependence (i.e., $u$ and $v$ are strongly linked for 395 low values, whereas they are not for high values). 396

2) Frank: Dependence is symmetric in both tails, weak in 397 both tails, and stronger in the center of the distribution. 398

3) Gumbel: Strong right tail dependence and relatively weak 399 left tail dependence (the opposite of Clayton).

400

4) FGM: Useful when the dependence between $U$ and $V$ is 401 modest in amplitude.

5) Gaussian: Flexible as it allows for positive and negative 403 dependences.

Hafner and Reznikova [23] and Wang and Pham [49] 405 developed a method that includes the time into the copula 406 formula to create a dynamic copula evolving with time. In 407 this paper, time was not included, but the year 2010 was 408 divided into four seasons as different statistical behaviors were 409 expected: December-January-February, March-April-May 410 (MAM), June-July-August (JJA), and September-October- 411 November (SON).

3) How to Select a Family: Since copulas separate marginal 413 distributions from dependence structures, the appropriate cop- 414 ula for a particular application is the one that best captures the 415 dependence features of the data [22]. Dupuis [27] examined the 416 effects of model misspecification and highlighted the dangers 417 of improper copula selection. Genest and Rivest [50] proposed 418 a method to select the most appropriate copula, but this method 419 is only relevant for Archimedean copulas. Other methods 420 were developed to compare any type of copulas [51]-[54]. 421 Genest et al. [55] and Berg [54] compared some of them 422 and concluded that there was no universal test and that some 423 procedures performed better in some situations but never in all 424 the situations. 
426 The method proposed by Huard et al. [56] is based on a 427 Bayesian approach where any type of copula can be tested. It 428 does not perform perfectly well in all the situations (with small 429 correlation coefficients or with small sample size) but has the 430 advantage to be a very fast method. This method was chosen 431 in this study to select the copula that provides the best fit to the 432 data.

433 4) Method Used for Simulations: The key to generating 434 simulations from a copula is to understand that a copula is a 435 joint distribution and that it obeys to the same rules. A con436 ditional copula $C_{V \mid U}(u, v)$ is the probability that the random 437 variable $V$ is less than or equal to a value $v$ knowing that the 438 random variable $U$ is equal to a value $u$

$$
C_{V \mid U}(u, v)=\operatorname{Pr}[V \leq v \mid U=u]=t \sim \mathcal{U}(0,1) .
$$

439 Simulating a uniform variable $t$ is necessary in order to 440 generate simulations from a copula. To retrieve $V \mid U$, the func441 tion $C_{V \mid U}$ needs to be inverted such that $v=C_{V \mid U}^{-1}(t)$, or the 442 equation $C_{V \mid U}(v)=t$ needs to be solved numerically. For each 443 value of $t$, a value for $v$ is retrieved. The following approach 444 was used here to simulate data with the copulas.

445 1) Compute $F_{X}$ and $G_{Y}$ from the two original data sets $X$ 446 and $Y$ with (1).

447 2) Choose the appropriate copula $C$ by applying Huard's 448 method and fitting the parameter $\theta$ to the original data.

4493 ) Derive the conditional copula $C_{V \mid U}$ with (3).

450 4) Generate 1000 simulations $t \sim \mathcal{U}(0,1)$.

451 5) Compute $v$ with $v=C_{V \mid U}^{-1}(t)$ and $y$ with $y=G_{Y}^{-1}(v)$.

452 6) The mean and standard deviation from the 1000 simula453 tions can be computed.

\section{Methodology}

455 For the CDF matching and the copula methods, 2010 data 456 were used for calibration. The CDFs of SMOS and LPRM were 457 calculated for the 2010 data sets. The two algorithms were then 458 applied to the data from previous years. It should be noted that 459 the consequence of using 2010 as a calibration year is that only 460 the soil moisture range from 2010 is taken into account. If an 461 extreme event occurred in the previous years, it might not be 462 well described with these methods as they are only based on 463 statistics and not on physical models. By looking at the in situ 464 soil moisture time series in Fig. 7, 2010 did not have enough 465 wet values over LR to estimate correctly the strong rainfalls 466 of 2004, 2005, and 2009, not enough wet values over LW for 467 rainfalls in 2007 and not enough dry values as well for 2003 468 and 2006, and again not enough dry values over RC for all the AQ23 469 previous years.

470 The two methods were applied to data contained in a $1^{\circ} \times 1^{\circ}$ 471 box around each watershed in order to have enough points for 472 computing reliable statistics. The coordinates of each box are 473 indicated in Table I. Only the satellite morning overpasses were 474 selected for this study (6:00 am for SMOS and 1:30 am for 475 AMSR-E, LST) since LPRM retrievals were only available for 476 this overpass.

477 The 2010 calibration year was divided into four seasons: 478 December-January-February, MAM, JJA, and SON. This
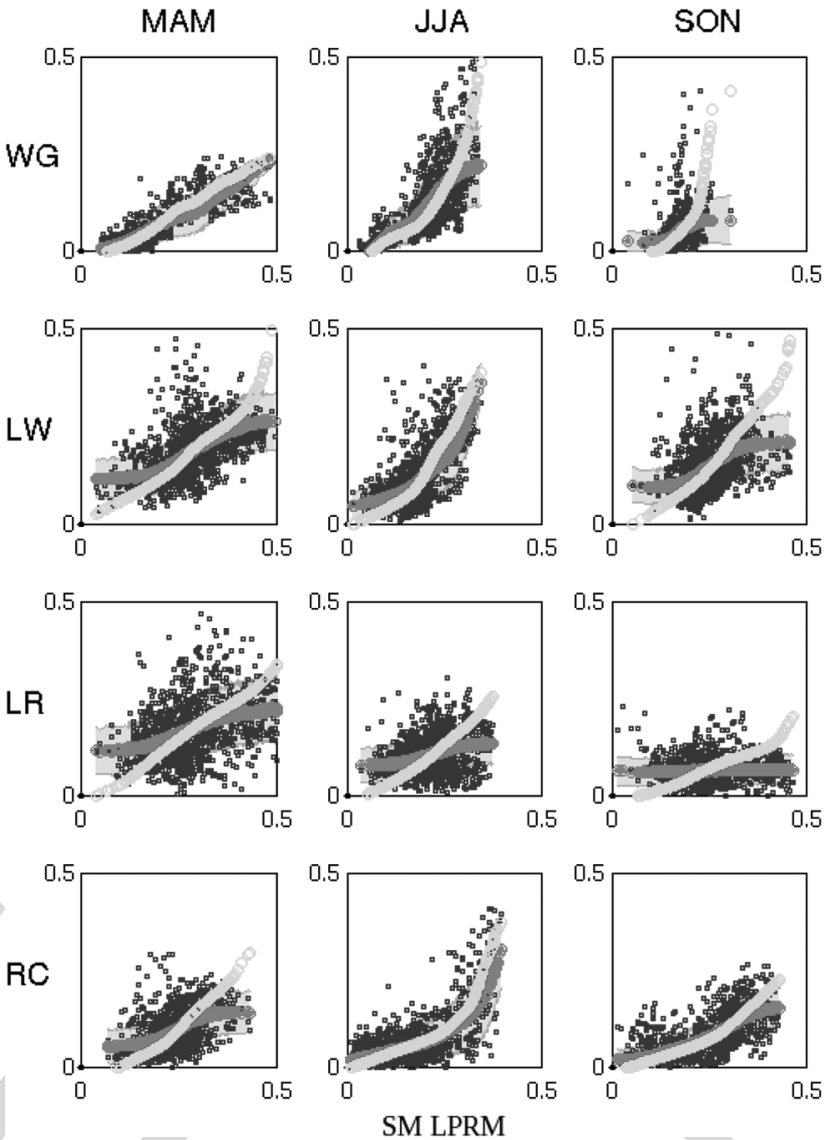

Fig. 5. Discrepancies in the simulations of soil moisture between CDF matching and copulas in 2010. Original soil moisture LPRM data are represented by blue points, and simulated data with CDF matching and copulas are in green and red, respectively. The standard deviation of the copula simulations is represented in shadowed red. Each row corresponds to a site, and each column corresponds to a season. $x$-axis: LPRM soil moisture. $y$-axis: SMOS soil moisture.

subdivision was done in order to better capture the sea- 479 sonal dynamic that can be very different depending on the 480 time of the year, particularly in vegetated areas. However, 481 not enough points were available during the winter period 482 (December-January-February) to compute reliable statistics, 483 so no estimation was performed for this season.

484

When comparing either two different remote sensing prod- 485 ucts or in situ data with remote sensing products, there is the 486 issue of the scale effect, as the products may have significantly 487 different spatial resolutions. Moreover, the spatial variability 488 varies with the seasons and the heterogeneity. So as to reduce 489 the problem, we used in this study averaged in situ data sets 490 ( 8 to 15 stations that were several miles away) which were 491 especially produced to be representative of 50-km spatial res- 492 olution or so [47]. Also, statistics were applied to all the points 493 contained in a $1^{\circ} \times 1^{\circ}$ box (more than 50 grid points).

\section{Generated Homogeneous Time Series}

The year 2010 was used to compute the CDFs of each 496 data set (SMOS and LPRM) for both methods and the joint 497 CDF based on fitting and selecting copula functions as de- 498 scribed previously. The soil moisture data were estimated using 499 
TABLE IV

Statistical Results of the Simulations From Copulas and CDF Matching. The Simulations Were Compared to Ground Measurements Over 2010 Divided Into Four Seasons: MAM, JJA, SON, but Not Enough Data Available for Winter Season. The Best Results Are Written in Bold, AND RMSES ARE IN $\mathrm{m}^{3} / \mathrm{m}^{3}$

\begin{tabular}{cc|cc|cc|ccc|cc|c}
\hline & & \multicolumn{2}{|c|}{ SMOS } & \multicolumn{2}{c|}{ LPRM } & \multicolumn{2}{|c|}{ Copula method } & \multicolumn{2}{c}{ CDF matching } & \# points \\
& & R & RMSE & R & RMSE & Fam $(\theta)$ & R & RMSE & R & RMSE & \\
\hline \multirow{4}{*}{ WG } & MAM & 0.80 & 0.032 & 0.82 & 0.125 & Gumbel $(2.18)$ & $\mathbf{0 . 8 9}$ & $\mathbf{0 . 0 2 0}$ & 0.87 & 0.031 & 43 \\
& JJA & 0.86 & 0.053 & 0.86 & 0.126 & Clayton(2.63) & 0.76 & $\mathbf{0 . 0 7 6}$ & $\mathbf{0 . 8 1}$ & 0.090 & 45 \\
& SON & 0.64 & 0.029 & 0.79 & 0.133 & Frank $(3.13)$ & $\mathbf{0 . 6 4}$ & $\mathbf{0 . 0 1 2}$ & 0.53 & 0.029 & 42 \\
& total & 0.84 & 0.040 & 0.79 & 0.139 & - & 0.79 & $\mathbf{0 . 0 4 3}$ & $\mathbf{0 . 8 2}$ & 0.054 & 159 \\
\hline \multirow{4}{*}{ LW } & MAM & 0.70 & 0.068 & 0.48 & 0.166 & Frank $(4.40)$ & 0.55 & $\mathbf{0 . 0 5 7}$ & $\mathbf{0 . 5 7}$ & 0.075 & 44 \\
& JJA & 0.85 & 0.037 & 0.58 & 0.085 & Gumbel $(1.66)$ & $\mathbf{0 . 7 7}$ & $\mathbf{0 . 0 4 2}$ & 0.76 & 0.050 & 44 \\
& SON & 0.80 & 0.041 & 0.80 & 0.122 & Frank $(3.61)$ & $\mathbf{0 . 7 5}$ & $\mathbf{0 . 0 2 3}$ & 0.72 & 0.048 & 46 \\
& total & 0.78 & 0.049 & 0.59 & 0.148 & - & $\mathbf{0 . 7 1}$ & $\mathbf{0 . 0 4 3}$ & $\mathbf{0 . 7 1}$ & 0.059 & 162 \\
\hline \multirow{4}{*}{ LR } & MAM & 0.77 & 0.080 & 0.54 & 0.175 & Frank $(2.82)$ & $\mathbf{0 . 5 9}$ & $\mathbf{0 . 0 6 3}$ & 0.58 & 0.067 & 39 \\
& JJA & 0.57 & 0.053 & 0.67 & 0.131 & Frank $(2.00)$ & 0.65 & 0.034 & $\mathbf{0 . 6 6}$ & $\mathbf{0 . 0 3 3}$ & 40 \\
& SON & 0.59 & 0.032 & 0.37 & 0.174 & FGM $(0.31)$ & $\mathbf{0 . 1 7}$ & $\mathbf{0 . 0 3 3}$ & 0.16 & 0.037 & 39 \\
& total & 0.74 & 0.060 & 0.65 & 0.178 & - & 0.51 & $\mathbf{0 . 0 4 5}$ & $\mathbf{0 . 5 9}$ & 0.048 & 147 \\
\hline \multirow{4}{*}{ RC } & MAM & 0.14 & 0.097 & 0.11 & 0.096 & Frank $(3.10)$ & 0.26 & $\mathbf{0 . 0 8 9}$ & $\mathbf{0 . 2 7}$ & 0.105 & 47 \\
& JJA & 0.63 & 0.055 & 0.81 & 0.070 & Gumbel $(1.81)$ & $\mathbf{0 . 8 4}$ & $\mathbf{0 . 0 4 7}$ & 0.83 & 0.052 & 42 \\
& SON & 0.14 & 0.070 & 0.52 & 0.144 & Frank $(6.30)$ & $\mathbf{0 . 3 4}$ & $\mathbf{0 . 0 5 6}$ & 0.29 & 0.066 & 39 \\
& total & 0.55 & 0.081 & 0.73 & 0.099 & - & $\mathbf{0 . 8 0}$ & $\mathbf{0 . 0 5 9}$ & 0.70 & 0.067 & 142 \\
\hline
\end{tabular}

500 the conditional distribution (conditional on LPRM retrievals). 501 While the copula procedure has the potential to generate an 502 ensemble of SMOS-like soil moisture estimates, given the 503 LPRM estimated soil moisture, we only use the mean estimate. 504 The ensembles could be used to provide uncertainty estimates. 505 It should be noted that CDF matching can only provide a 506 single SMOS estimate. The resulting time series will result in 507 a statistically homogeneous time series under the assumption 508 that 2010 LPRM retrievals and the underlying AMSR-E bright509 ness temperatures are temporally consistent. The resulting 510 SMOS-like estimated soil moisture is then compared to ground 511 measurements.

\section{A. Calibration Year 2010 and Comparison With 513 Ground Measurements}

5142010 is the year with both SMOS data and LPRM data. $515 \mathrm{CDFs}$ were computed for both variables. CDF matching and 516 copula methods were then applied, and these produced different 517 SMOS-like estimates. In Fig. 5, the original data (SMOS and 518 LPRM) are represented by the blue point cloud, CDF matching 519 and copula estimates are in green and red colors, respectively, 520 and standard deviations from copula simulations are in red AQ26 521 shadows. This standard deviation can be interpreted as the 522 uncertainty associated to the copula simulations, which can be 523 not produced by CDF matching estimation.

524 Over WG in the MAM season, there was no obvious differ525 ence between the two simulation methods. However, in the JJA 526 and SON seasons, there were differences for the high values 527 of soil moisture: The CDF matching method produced higher 528 simulated values than the copula method. Similar behavior can 529 also be seen for all seasons in the other three sites, i.e., LW, LR, 530 and RC. Discrepancies can also be observed for small values 531 of soil moisture over LW, LR, and RC (MAM) where copulas 532 generated higher values of soil moisture.

533 Standard deviations of soil moisture simulations from copu534 las were also computed (see Fig. 5). This standard deviation is 535 directly related to the width of the tail of the chosen copula 536 which is controlled by the $\theta$ parameter. A high value of the 537 standard deviation corresponds to a large tail, meaning that the two variables are weakly linked to each other, whereas a 538 small value corresponds to a strong link. The differences in 539 the simulations can also be observed in the 2010 time series 540 (see Table IV and Fig. 6). Compared to the original LPRM 541 data, the estimated soil moisture was close to the SMOS level 542 and comparable to the ground measurements. The bias between 543 LPRM and SMOS was corrected by both methods.

544

Over WG, CDF matching and copula simulations were not 545 very different except in the summer season when the CDF 546 matching simulations were higher than the copulas. Consid- 547 ering the entire year, both simulation methods improved the 548 original statistics from the LPRM data set. The correlation 549 coefficient did not change significantly ( $R=0.79$ for LPRM 550 and $R=0.79 / 0.82$ for copulas/CDF matching), but the rmse 551 was highly improved going from $0.139 \mathrm{~m}^{3} / \mathrm{m}^{3}$ (original LPRM 552 data) to $0.054 \mathrm{~m}^{3} / \mathrm{m}^{3}$ with CDF matching and $0.043 \mathrm{~m}^{3} / \mathrm{m}^{3} 553$ with copula, which represents an improvement of a factor of 3. 554

Over LW, simulations responded very well to the succes- 555 sive rain events throughout the year and exhibited a pattern 556 of decrease following a rain event. The first two months 557 (March-April) exhibited more noisy simulations, and the statis- 558 tics were impacted by this behavior $(R=0.55 / 0.57$ and 559 rmse $=0.057 / 0.075 \mathrm{~m}^{3} / \mathrm{m}^{3}$ for copulas/CDF matching). The 560 other two seasons gave good results in terms of statistics. For 561 the entire year, the $R$ value was highly improved ( $R=0.59562$ for LPRM and $R=0.71 / 0.71$ for copulas/CDF matching), and 563 the rmse was reduced by a factor of $3\left(\mathrm{rmse}=0.148 \mathrm{~m}^{3} / \mathrm{m}^{3} 564\right.$ for LPRM and rmse $=0.043 / 0.059 \mathrm{~m}^{3} / \mathrm{m}^{3}$ for copulas/CDF 565 matching).

The LR watershed is the site with the highest rainfall fre- 567 quency (events of small amplitude). The successive rainfall 568 events were not well captured by the simulations, particularly 569 during the fall season when both simulations exhibited only 570 small variations, which resulted in very poor statistics $(R=571$ $0.17 / 0.16$ for copulas/CDF matching). Unfortunately, even if 572 the rain events were captured by the original data sets, none 573 was captured by both data sets at the same time, so only the 574 nonraining periods were taken into account by the statistics. 575 Therefore, the simulations can only be representative of the dry 576 periods. It should be noted that the statistics of LPRM were 577 


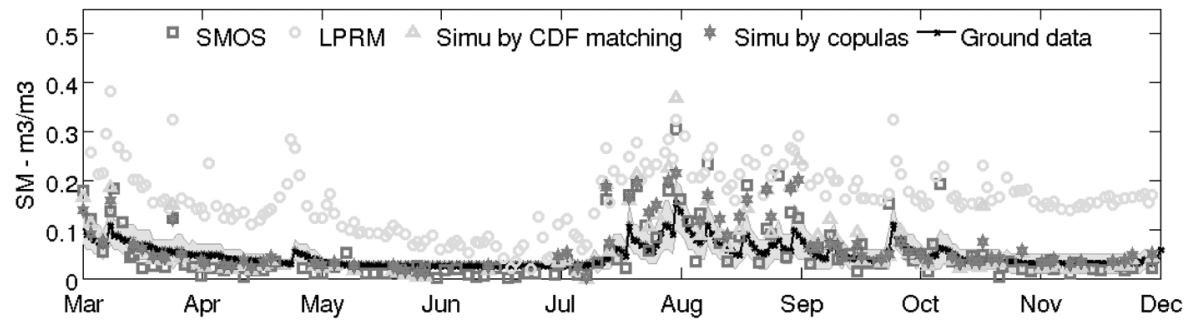

(a)

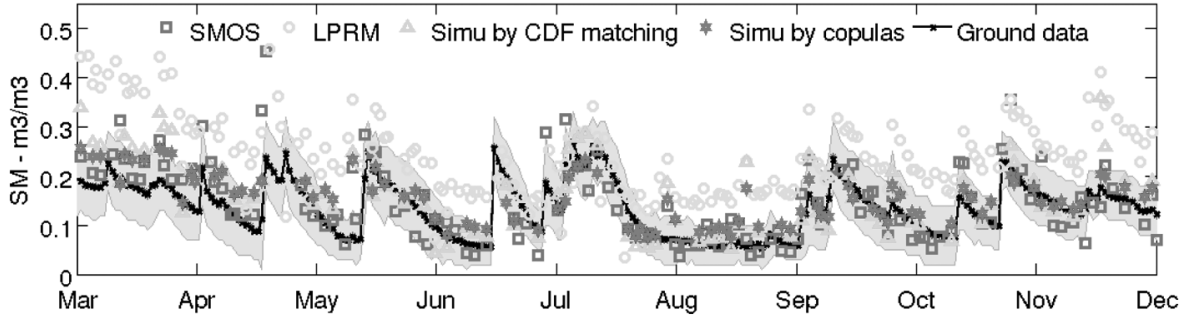

(b)

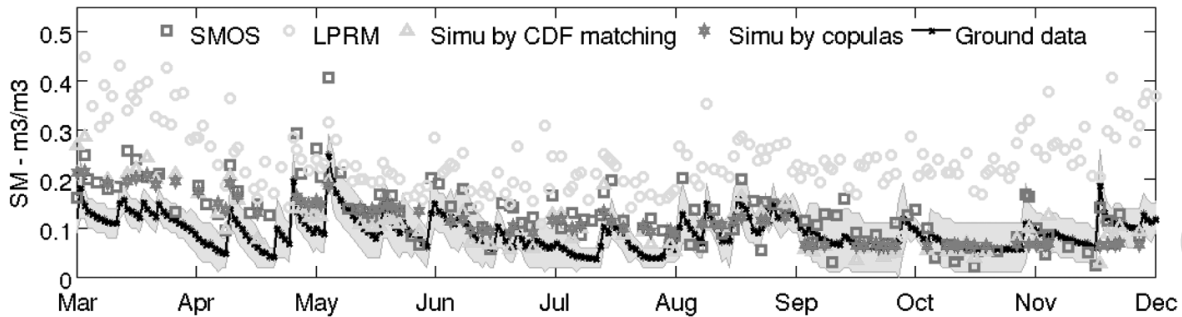

(c)

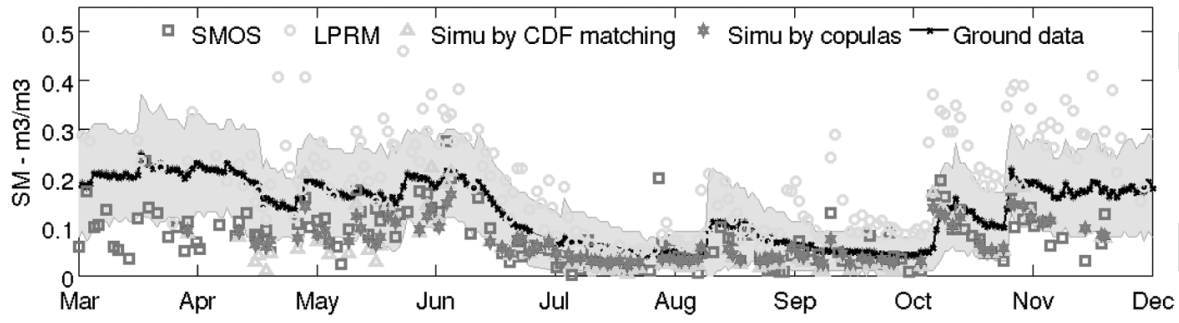

(d)

Fig. 6. Simulations for 2010: SMOS, LPRM, simulated soil moisture data from CDF matching and copulas, and ground measurements over the four watersheds. Since the in situ data are the mean of several ground measurements, their standard deviations are represented in gray shadows showing the spatial variability. (a) WG. (b) LW. (c) LR. (d) RC.

578 already not good during this season $(R=0.37$ and rmse $=$ $\left.5790.174 \mathrm{~m}^{3} / \mathrm{m}^{3}\right)$. During the spring season, SMOS overestimated 580 the in situ soil moisture measurements, so as a result, the 581 copulas and CDF matching estimates overestimated the in situ 582 measurements as well.

$583 \mathrm{RC}$ is located in a mountainous region and is subject to 584 frequent snow and frozen soil events. The satellite-based soil 585 moisture was not comparable to the ground measurements until 586 late May. After this winter period, the simulations captured 587 accurately the soil moisture evolution and improved the original 588 statistics and especially the rmse $\left(0.099 \mathrm{~m}^{3} / \mathrm{m}^{3}\right.$ for LPRM and $5890.059 / 0.067 \mathrm{~m}^{3} / \mathrm{m}^{3}$ for copulas/CDF matching).

\section{B. Times Series 2003-2010 and Comparison With}

\section{Ground Measurements}

592 Soil moisture from 2003 to 2010 was simulated from the 593 LPRM retrievals (2003-2010) using the copulas and CDF matching relationships developed for 2010. Fig. 7 and Table V 594 show the entire time series and the associated statistics ( $R$ and 595 rmse) between the original data, CDF matching simulations, 596 copula simulations, and ground measurements.

WG is the driest site and did not have a lot of rain events. 598 These rain events were well described by the simulated soil 599 moisture even though they were sometimes largely overesti- 600 mated, particularly by CDF matching simulations. Artifacts at 601 the extremities of the seasons can be seen at the beginning 602 of 2006 and 2008. The correlation coefficient was improved 603 using the CDF matching for each year, whereas the errors were 604 reduced by a factor larger than 2 with the copulas.

605

The overestimation of the soil moisture after the rain events 606 with CDF matching can be found as well over LW, but the 607 temporal evolution was well captured by both methods. For this 608 watershed, CDF matching overestimated the high soil moisture 609 values and underestimated the low values. CDF matching pro- 610 duced soil moisture with a higher dynamic range than copulas. 611 


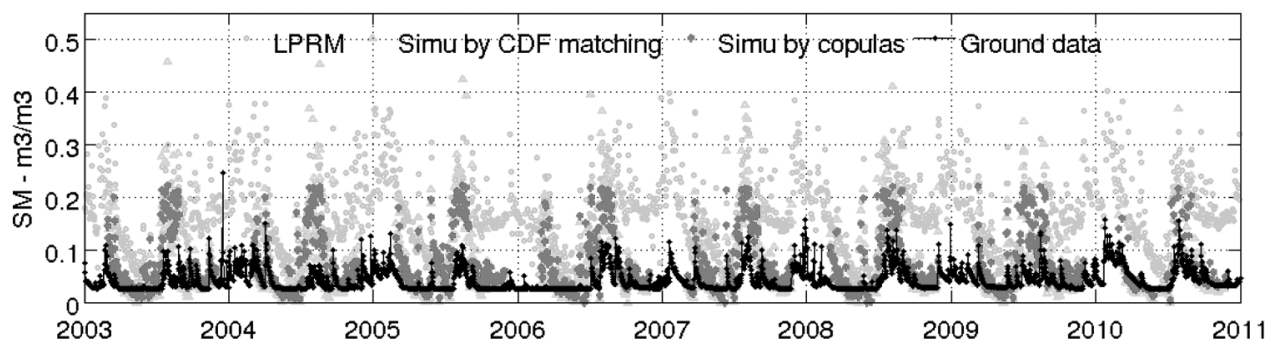

(a)

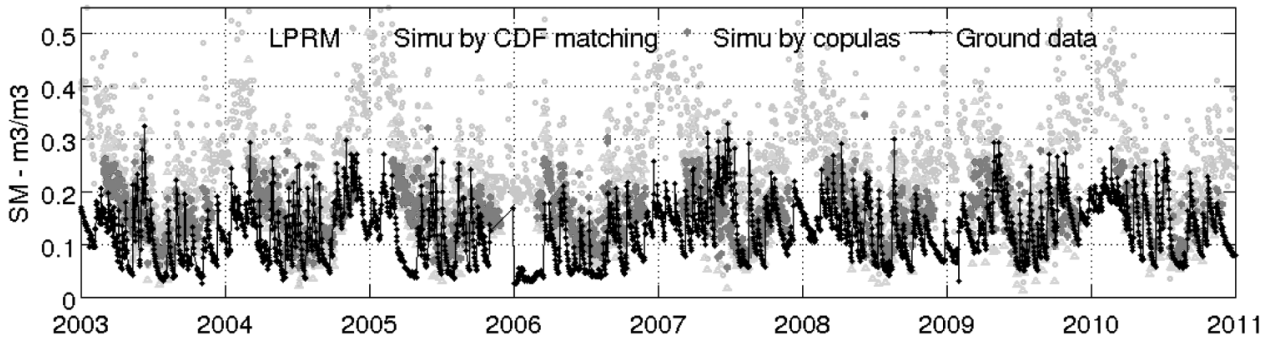

(b)

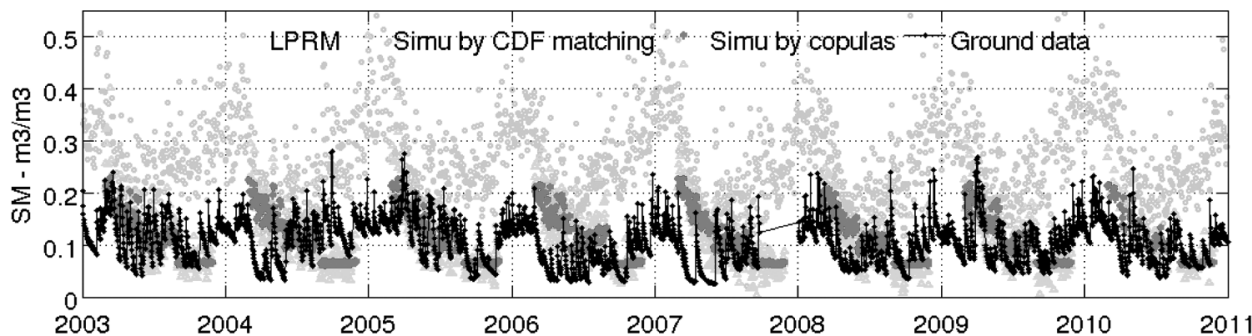

(c)

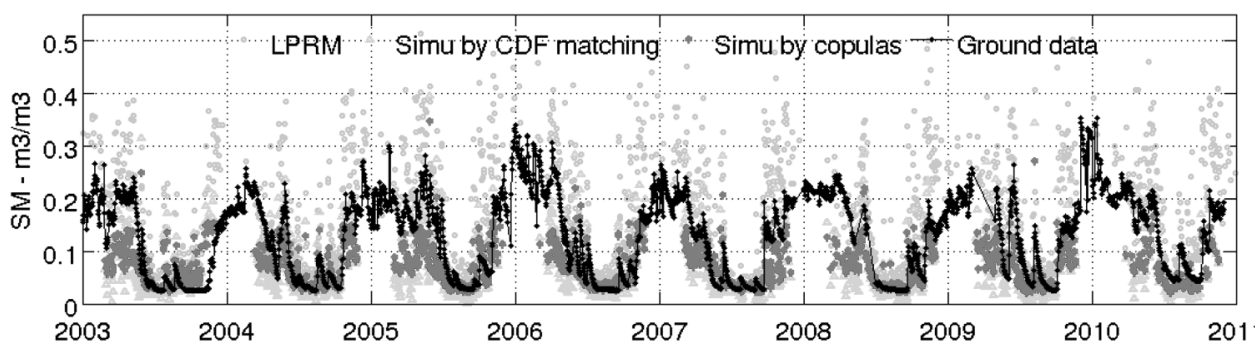

(d)

Fig. 7. Simulated time series from 2003 to 2010 with ground measurements for the four watersheds. (a) WG. (b) LW. (c) LR. (d) RC.

612 This was reflected in the total rmse value $\left(0.079 \mathrm{~m}^{3} / \mathrm{m}^{3}\right)$, 613 whereas the rmse of the copula simulations was of $0.066 \mathrm{~m}^{3} / \mathrm{m}^{3}$ 614 (original LPRM rmse: $0.160 \mathrm{~m}^{3} / \mathrm{m}^{3}$ ).

615 LR is the site with the largest number of rain events, and as 616 mentioned in the previous section, this high rain frequency was 617 not properly captured during the fall season of 2010; this can 618 be seen as well in the entire time series where all the copulas 619 and CDF matching estimates were flat during fall seasons. 620 Moreover, since SMOS was overestimating the soil moisture 621 during the spring season of 2010, both statistical estimates had 622 this behavior. Even though the tendency of the simulations was 623 correct, the dynamic behavior was not well represented, which 624 resulted in a very poor correlation coefficient (negative values 625 in 2004 and 2007).

$626 \mathrm{RC}$ is a very complicated site because of the frequent 627 snow and frozen soil events occurring during half of the year. 628 However, statistical results were improved for the entire year with copula simulations (rmse $=0.099 \mathrm{~m}^{3} / \mathrm{m}^{3}$ for LPRM and 629 rmse $=0.056 / 0.062 \mathrm{~m}^{3} / \mathrm{m}^{3}$ for copulas/CDF matching). $\quad 630$

\section{Conclusion And Perspectives}

The main goal of this study was to propose a new method to 632 generate a long homogeneous time series (2003-2010) of soil 633 moisture from two overlapping time series.

For that purpose, two statistical tools, the CDF matching and 635 the copulas, were tested over four watersheds in the U.S. By us- 636 ing CDF matching, the assumption that the two studied data sets 637 are ranked in the same way is made, which the copulas do not 638 require. The two analyzed data sets (SMOS and LPRM) were 639 jointly available only for 2010 , so data from 2010 were used to 640 estimate the CDFs that are used as references to estimate SMOS 641 soil moisture for previous years. The novelty of the approach is 642 its application: establishing the statistical relationship between 643 
TABLE V

Statistical Results From the Comparison Between the Simulated Time Series of Soil Moisture From 2003 to 2010. Original Soil Moisture Times ARE RePresented by LPRM. The Best Results ARE INDiCATED IN Bold, AND THE RMSE ARE IN $\mathrm{m}^{3} / \mathrm{m}^{3}$. (a) WG. (b) LW. (c) LR. (d) RC

(a)

\begin{tabular}{cc|c|c|c|c|c|c|c|c|c}
\hline & & 2003 & 2004 & 2005 & 2006 & 2007 & 2008 & 2009 & 2010 & Total \\
\hline \multirow{2}{*}{ LPRM } & $\mathrm{R}$ & 0.070 & 0.76 & 0.82 & 0.66 & 0.81 & 0.68 & 0.65 & 0.79 & 0.73 \\
& RMSE & 0.129 & 0.141 & 0.146 & 0.133 & 0.147 & 0.138 & 0.129 & 0.139 & 0.138 \\
\hline \multirow{2}{*}{ Copula } & $\mathrm{R}$ & 0.62 & 0.55 & 0.82 & 0.64 & 0.81 & $\mathbf{0 . 7 5}$ & 0.76 & 0.79 & 0.69 \\
& RMSE & $\mathbf{0 . 0 5 9}$ & $\mathbf{0 . 0 5 9}$ & $\mathbf{0 . 0 5 9}$ & $\mathbf{0 . 0 6 0}$ & $\mathbf{0 . 0 5 4}$ & $\mathbf{0 . 0 5 3}$ & $\mathbf{0 . 0 6 0}$ & $\mathbf{0 . 0 4 3}$ & $\mathbf{0 . 0 5 7}$ \\
\hline \multirow{2}{*}{ CDF m. } & $\mathrm{R}$ & $\mathbf{0 . 7 3}$ & $\mathbf{0 . 6 2}$ & $\mathbf{0 . 8 8}$ & $\mathbf{0 . 7 2}$ & $\mathbf{0 . 8 9}$ & $\mathbf{0 . 7 5}$ & $\mathbf{0 . 7 9}$ & $\mathbf{0 . 8 2}$ & $\mathbf{0 . 7 4}$ \\
& RMSE & 0.070 & 0.074 & 0.071 & 0.073 & 0.067 & 0.067 & 0.077 & 0.054 & 0.071 \\
\hline
\end{tabular}

(b)

\begin{tabular}{cc|c|c|c|c|c|c|c|c|c}
\hline & & 2003 & 2004 & 2005 & 2006 & 2007 & 2008 & 2009 & 2010 & Total \\
\multirow{2}{*}{ LPRM } & $\mathrm{R}$ & 0.56 & 0.71 & 0.48 & 0.67 & 0.32 & 0.42 & 0.52 & 0.58 & 0.55 \\
& RMSE & 0.163 & 0.149 & 0.187 & 0.149 & 0.173 & 0.158 & 0.149 & 0.149 & 0.160 \\
\multirow{2}{*}{ Copula } & $\mathrm{R}$ & 0.56 & 0.47 & 0.19 & 0.62 & 0.41 & $\mathbf{0 . 6 4}$ & $\mathbf{0 . 5 8}$ & $\mathbf{0 . 7 1}$ & 0.47 \\
& RMSE & $\mathbf{0 . 0 7 1}$ & $\mathbf{0 . 0 6 4}$ & $\mathbf{0 . 0 8 8}$ & $\mathbf{0 . 0 7 7}$ & $\mathbf{0 . 0 6 0}$ & $\mathbf{0 . 0 5 6}$ & $\mathbf{0 . 0 5 1}$ & $\mathbf{0 . 0 4 4}$ & $\mathbf{0 . 0 6 6}$ \\
\hline \multirow{2}{*}{ CDF m. } & $\mathrm{R}$ & $\mathbf{0 . 5 9}$ & $\mathbf{0 . 6 0}$ & $\mathbf{0 . 3 4}$ & $\mathbf{0 . 6 3}$ & $\mathbf{0 . 4 9}$ & 0.61 & 0.53 & $\mathbf{0 . 7 1}$ & $\mathbf{0 . 5 1}$ \\
& RMSE & 0.083 & 0.070 & 0.101 & 0.092 & 0.069 & 0.076 & 0.069 & 0.059 & 0.079 \\
\hline
\end{tabular}

(c)

\begin{tabular}{cc|c|c|c|c|c|c|c|c|c}
\hline & & 2003 & 2004 & 2005 & 2006 & 2007 & 2008 & 2009 & 2010 & Total \\
\hline \multirow{2}{*}{ LPRM } & $\mathrm{R}$ & 0.51 & 0.60 & 0.46 & 0.75 & 0.64 & 0.70 & 0.49 & 0.65 & 0.58 \\
& RMSE & 0.171 & 0.148 & 0.181 & 0.185 & 0.180 & 0.166 & 0.187 & 0.178 & 0.174 \\
\hline \multirow{2}{*}{ Copula } & $\mathrm{R}$ & 0.54 & -0.48 & $\mathbf{0 . 7 3}$ & 0.01 & -0.14 & 0.20 & 0.43 & 0.51 & 0.19 \\
& RMSE & $\mathbf{0 . 0 4 2}$ & $\mathbf{0 . 0 7 9}$ & $\mathbf{0 . 0 3 6}$ & $\mathbf{0 . 0 6 9}$ & $\mathbf{0 . 0 8 1}$ & 0.054 & $\mathbf{0 . 0 4 7}$ & $\mathbf{0 . 0 4 5}$ & $\mathbf{0 . 0 5 9}$ \\
\hline \multirow{2}{*}{ CDF m. } & $\mathrm{R}$ & $\mathbf{0 . 6 8}$ & $\mathbf{- 0 . 1 6}$ & 0.72 & $\mathbf{0 . 2 8}$ & $\mathbf{0 . 1 8}$ & $\mathbf{0 . 5 0}$ & $\mathbf{0 . 5 5}$ & $\mathbf{0 . 5 9}$ & $\mathbf{0 . 3 7}$ \\
& RMSE & 0.044 & 0.080 & 0.042 & 0.070 & 0.085 & $\mathbf{0 . 0 5 0}$ & 0.048 & 0.048 & 0.061 \\
\hline
\end{tabular}

(d)

\begin{tabular}{cc|c|c|c|c|c|c|c|c|c}
\hline & & 2003 & 2004 & 2005 & 2006 & 2007 & 2008 & 2009 & 2010 & Total \\
\hline \multirow{2}{*}{ LPRM } & $\mathrm{R}$ & 0.78 & 0.76 & 0.74 & 0.80 & 0.84 & 0.69 & 0.78 & 0.73 & 0.77 \\
& RMSE & 0.093 & 0.085 & 0.110 & 0.099 & 0.102 & 0.106 & 0.099 & 0.099 & 0.099 \\
\hline \multirow{2}{*}{ Copula } & $\mathrm{R}$ & $\mathbf{0 . 5 3}$ & $\mathbf{0 . 7 8}$ & $\mathbf{0 . 7 0}$ & $\mathbf{0 . 6 8}$ & $\mathbf{0 . 7 2}$ & 0.75 & $\mathbf{0 . 7 2}$ & $\mathbf{0 . 8 0}$ & $\mathbf{0 . 6 9}$ \\
& RMSE & $\mathbf{0 . 0 6 5}$ & $\mathbf{0 . 0 4 5}$ & $\mathbf{0 . 0 6 5}$ & $\mathbf{0 . 0 6 0}$ & $\mathbf{0 . 0 5 1}$ & $\mathbf{0 . 0 4 7}$ & $\mathbf{0 . 0 5 2}$ & $\mathbf{0 . 0 5 9}$ & $\mathbf{0 . 0 5 6}$ \\
\hline \multirow{2}{*}{ LDF m. } & $\mathrm{R}$ & 0.42 & 0.69 & 0.65 & 0.63 & 0.70 & $\mathbf{0 . 6 5}$ & 0.71 & 0.70 & 0.63 \\
& RMSE & 0.073 & 0.051 & 0.070 & 0.063 & 0.055 & 0.056 & 0.056 & 0.067 & 0.062 \\
\hline
\end{tabular}

644 AMSR-E and SMOS retrieved soil moisture values and using 645 this relationship to estimate the equivalent SMOS value for the 646 AMSR-E period prior to the SMOS launch.

647 The first analysis of these simulations over 2010 showed that 648 the simulated data sets were very similar to the SMOS estimates 649 and reproduced SMOS behavior accurately except over the LR 650 watershed where numerous rain events occurred. This high 651 rainfall frequency was interpreted statistically as noise, and 652 hence, the simulations did not describe the soil moisture evolu653 tion over this site very well. RC was also a very complicated site 654 due to the local topography and seasonal climate conditions. 655 Soil moisture derived from satellite observations was not able 656 to accurately reproduce the dynamics as found in the in situ 657 data, and as a result, the simulated soil moisture did not either. 658 However, the total rmse for the simulated soil moisture from 659 copulas was reduced by a factor of almost 2. The WG and $660 \mathrm{LW}$ sites were well represented by the simulations, and copulas 661 improved the error by a factor of 3, whereas CDF matching 662 improved the correlation.

663 The time series of soil moisture were estimated from 2003 to 6642010 and were compared to in situ measurements at all four 665 watersheds. Since simulated soil moisture data in 2010 over 666 the LR watershed had very little dynamic range, they remained 667 the same for the entire time series and showed very poor 668 statistical results. Even though the rmse values were improved by a factor of 3, the total correlation was not good. For the 669 three other sites, the correlation coefficient was a bit degraded 670 compared to the original LPRM data, but the rmse was highly 671 improved with copulas by a factor of 2 to 3. In general, CDF 672 matching gave better results in terms of correlation, and copulas 673 gave better results in terms of errors compared to the ground 674 measurements.

As a more general conclusion, CDF matching gives good 676 results but does not take into account the structure of the 677 dependence between the two data sets, whereas the copulas 678 allow to model this structure. Through the choice of the family 679 and the parameter $\theta$ (which controls the width of the tail of the 680 scatter), it is possible to model all kinds of structures, from the 681 perfect dependence (CDF matching), right or left dependence, 682 to complete independence. This is why copulas produce better 683 results for the extreme values (very low and very high values) 684 than CDF matching. Copulas can also estimate the uncertainty 685 of the soil moisture simulations given the LPRM value and 686 can be seen as a quality information in the simulation process. 687 However, the copula method is time consuming. It is quick 688 to choose the copula family and its associated parameter as 689 it is based on a Bayesian approach; however, it is very time 690 consuming to generate the 1000 simulations, particularly if the 691 chosen copula does not have an analytic inversion form. In the 692 latter case, 1000 equations need to be resolved numerically. 693 
694 Nevertheless, these simulations represent an advantage since it 695 is possible to compute a mean and a standard deviation. The 696 limitations are the same for both methods and even for any 697 general statistical methods using a specific year as a reference: 698 Only the variable range of this particular year can be well 699 represented. Therefore, if an event in a previous year occurs 700 and is out of the range found in the specific year of reference 701 (such as drought or flood events), then that event will not be 702 well represented in the simulated results.

703 In order to improve this methodology, applying a moving 704 window of three months would provide more accurate results 705 instead of dividing the year into four seasons. This would also 706 avoid the artifacts and gaps generally noticed at the transition 707 between the seasons. Another solution would be to introduce 708 the time in the copulas, but the level of complexity in the copula 709 manipulation would increase as well.

710 In this paper, the attempt to build a homogeneous soil mois711 ture time series has been based on statistical methods only. Of 712 course, other methods exist to reconcile different sensor ac713 quisitions, and because SMOS and AMSR-E do not operate at 714 the same frequencies and not at the same crossing times, using 715 physical models to tackle these discrepancies is an alternative to 716 statistical methods. Moreover, matching observations acquired 717 at 130 am and 600 am can trigger some questions, particularly 718 regarding the precipitations that could occur in between. The 719 present study is a first step toward a unified and homogeneous 720 soil moisture time series, and mixing physical and statisti721 cal models to do so would be a breakthrough for climate 722 studies.

723 The next step of this study is to build a homogeneous time 724 series of soil moisture at the global scale. Hence, the results of 725 this study will be extended in the future to build a global map 726 of the copula family choice and to study if there exists any rela727 tionship between the chosen copulas and the soil characteristics 728 or land use data. This would allow us to derive soil moisture 729 time series from LPRM data within SMOS soil moisture range 730 over the entire globe.

\section{ACKNOWLEDGMENT}

732 The authors would like to thank the USDA research team for 733 providing the in situ data and D. Huard from McGill University 734 for the helpful inputs on the copula method. USDA is an Equal 735 Employment Opportunity employer.

\section{REFERENCES}

1] "Implementation Plan for the Global Observing System for Climate in Support of the UNFCCC," World Meteorological Org., Geneva, Switzerland, Tech. Rep., 2010.

2] M. Drusch, "Initializing numerical weather predictions models with satellite derived surface soil moisture: Data assimilation experiments with ECMWF's integrated forecast system and the TMI soil moisture data set," J. Geophys. Res., vol. 113, no. D3, p. D03 102, Feb. 2007.

[3] H. Douville and F. Chauvin, "Relevance of soil moisture for seasonal climate predictions: A preliminary study," Climate Dyn., vol. 16, no. 10/11, pp. 719-736, Oct. 2000.

[4] Y. Kerr, P. Waldteufel, J. Wigneron, S. Delwart, F. Cabot, J. Boutin, M. Escorihuela, J. Font, N. Reul, C. Gruhier, S. Juglea, M. Drinkwater, A. Hahne, M. Martin-Neira, and S. Mecklenburg, "The SMOS mission: New tool for monitoring key elements of the global water cycle," Proc. IEEE, vol. 98, no. 5, pp. 666-687, May 2010.
[5] D. Entekhabi, E. Njoku, P. O’Neill, K. Kellogg, W. Crow, W. Edelstein, 752 J. Entin, S. Goodman, T. Jackson, J. Johnson, J. Kimball, J. Piepmeier, 753 R. Koster, N. Martin, K. McDonald, M. Moghaddam, S. Moran, 754 R. Reichle, J. Shi, M. Spencer, S. Thurman, L. Tsang, and J. Zyl, "The 755 soil moisture active passive (SMAP) mission," Proc. IEEE, vol. 98, no. 5, 756 pp. 704-716, May 2010.

[6] Y. Kerr, P. Waldteufel, J. Wigneron, J. Martinuzzi, J. Font, and M. Berger, 758 "Soil moisture retrieval from space: The soil moisture and ocean salinity 759 (SMOS) mission," IEEE Trans. Geosci. Remote Sens., vol. 39, no. 8, 760 pp. 1729-1735, Aug. 2001.

[7] M. Owe, R. de Jeu, and J. Walker, "A methodology for surface soil 762 moisture and vegetation optical depth retrieval using the microwave po- 763 larization difference index," IEEE Trans. Geosci. Remote Sens., vol. 39, 764 no. 8, pp. 1643-1654, Aug. 2001.

[8] E. Njoku, T. Jackson, V. Lakshmi, T. Chan, and S. Nghiem, "Soil moisture 766 retrieval from AMSR-E," IEEE Trans. Geosci. Remote Sens., vol. 41, 767 no. 2, pp. 215-229, Feb. 2003.

[9] L. Li, P. Gaiser, B. Gao, R. Bevilacqua, T. Jackson, E. Njoku, C. Rüdiger, 769 J. Calvet, and R. Bindlish, "Windsat global soil moisture retrieval and 770 validation," IEEE Trans. Geosci. Remote Sens., vol. 48, no. 5, pp. 2224- 771 2241, May 2010.

[10] V. Naeimi, K. Scipal, Z. Bartalis, and S. H. W. Wagner, "An improved soil 773 moisture retrieval algorithm for ERS and METOP scatterometer observa- 774 tions," IEEE Trans. Geosci. Remote Sens., vol. 47, no. 7, pp. 1999-2013, 775 Jul. 2009.

[11] L. Vincent, X. Zhang, B. Bonsal, and W. Hogg, "Homogeneization of 777 daily temperatures over Canada," J. Climate, vol. 15, no. 11, pp. 1322- 778 1334, Jun. 2002.

[12] M. Begert, T. Schlegel, and W. Kirchhofer, "Homogeneous temperature 780 and precipitation series of Switzerland from 1864 to 2000," Int. J. Clima- 781 tol., vol. 25, no. 1, pp. 65-80, Jan. 2005.

[13] G. Picard and M. Fily, "Surface melting observations in Antarctica by 783 microwave radiometers: Correcting 26-year time series from changes in 784 acquisition hours," Remote Sens. Environ., vol. 104, no. 3, pp. 325-336, 785 Oct. 2006.

[14] R. Reichle and R. Koster, "Bias reduction in short records of satellite soil 787 moisture," Geophys. Res. Lett., vol. 31, no. 19, p. L19501, Oct. 2004.788

[15] M. Choi and J. Jacobs, "Temporal variability corrections for advanced 789 microwave scanning radiometer E (AMSR-E) surface soil moisture: 790 Case study in little river region, Georgia, U.S.," Sensors, vol. 8, no. 4, 791 pp. 2617-2627, Apr. 2008.

[16] H. Li, J. Sheffield, and E. Wood, "Bias correction of monthly precipitation 793 and temperature fields from IPCC AR4 models using equidistant quantile 794 matching," J. Geophys. Res., Atmosp., vol. 115, no. D10, p. D10 101, 795 May 2010.

[17] M. Drusch, E. Wood, and H. Gao, "Observation operators for the di- 797 rect assimilation of TRMM microwave imager retrieved soil moisture," 798 Geophys. Res. Lett., vol. 32, no. 15, p. L15 403, Aug. 2005.

[18] Y. Liu, A. van Dijk, R. de Jeu, and T. Holmes, "An analysis of spatiotem- 800 poral variations of soil and vegetation moisture from a 29-year satellite- 801 derived data set over mainland Australia," Water Resour. Res., vol. 45, 802 no. 7, p. W07 405, Jul. 2009.

[19] Y. Liu, R. Parinussa, W. Dorigo, R. D. Jeu, W. Wagner, A. V. Dijk, 804 M. McCabe, and J. Evans, "Developing an improved soil moisture dataset 805 by blending passive and active microwave satellite-based retrievals," 806 Hydrol. Earth Syst. Sci., vol. 15, no. 2, pp. 425-436, Feb. 2011.

[20] V. Singh and W. Strupczewski, "Editorial," J. Hydrol. Eng., vol. 12, no. 4, 808 p. 345 , Jul. 2007.

[21] R. Nelsen, "An introduction to copulas," in Springer Series in Statistics. 810 New York, NY, USA: Springer-Verlag, 1998.

[22] P. Trivedi and D. Zimmer, Copula Modeling: An Introduction for Practi- 812 tioners, vol. 1, Foundations and Trends in Econometrics. Hanover, MA, 813 USA: Now Publ. Inc., 2005, pp. 1-111.

[23] C. Hafner and O. Reznikova, "Efficient estimation of a semiparamet- 815 ric synamic copula model," Comput. Stat. Data Anal., vol. 54, no. 11, 816 pp. 2609-2627, Nov. 2010.

[24] C. Genest and A. Favre, "Everything you always wanted to know about 818 copula modeling but were afraid to ask," J. Hydrol. Eng., vol. 12, no. 4, 819 pp. 347-368, Jul./Aug. 2007.

[25] A. Favre, S. E. Adlouni, L. Perreault, N. Thiémonge, and B. Bobée, "Mul- 821 tivariate hydrological frequency analysis using copulas," Water Resour. 822 Res., vol. 40, no. 1, p. W01 101, Jan. 2004.

[26] G. Salvadori and C. de Michele, "On the use of copulas in hydrology: 824 Theory and practice," J. Hydrol. Eng., vol. 12, no. 4, pp. 369-380, 825 Jul. 2007.

[27] D. Dupuis, "Using Copulas in hydrology: Benefits, cautions and issues," 827 J. Hydrol. Eng., vol. 12, no. 4, pp. 381-393, Jul. 2007. 
28] L. Zhang and V. Singh, "Trivariate flood frequency analysis using the Gumbel-Hougaard copula," J. Hydrol. Eng., vol. 12, no. 4, pp. 431-439, Jul. 2007.

29] F. Serinaldi and S. Grimaldi, "Fully nested 3-copula: Procedure and application on hydrological data," J. Hydrol. Eng., vol. 12, no. 4, pp. 420-430, Jul. 2007.

30] P. Laux, S. Vog1, W. Qiu, H. Knoche, and H. Kunstmann, "Copula-based statistical refinement of precipitation in RCM simulations over complex terrain," Hydrol. Earth Syst. Sci., vol. 15, no. 7, pp. 2401-2419, Jul. 2011. 1] H. Gao, E. Wood, M. Drusch, and M. McCabe, "Copula-derived observation operators for assimilating TMI and AMSR-E retrieved soil moisture into land surface models," J. Hydrometreol., vol. 8, no. 3, pp. 413-429, Jun. 2007.

32] C. de Michele and G. Salvadori, "A generalized pareto intensity-duration model of storm rainfall exploiting 2-copulas," J. Geophys. Res., vol. 108, no. D2, p. 4067, Jan. 2003.

3] J. Wigneron, Y. Kerr, P. Waldteufel, K. Saleh, M. Escorihuela, P. Richaume, P. Ferrazzoli, P. de Rosnay, R. Gurney, J. Calvet, J. Grant, M. Guglielmetti, B. Hornbuckle, C. Mätzler, T. Pellarin, and M. Schwank, "L-band microwave emission of the biosphere (L-MEB) model: Description and calibration against experimental data sets over crop fields," Remote Sens. Environ., vol. 107, no. 4, pp. 639-655, Apr. 2007.

34] Y. Kerr, P. Waldteufel, P. Richaume, J. Wigneron, P. Ferrazzoli, A. Mahmoodi, A. A. Bitar, F. Cabot, C. Gruhier, S. Juglea, D. Leroux, A. Mialon, and S. Delwart, "The SMOS soil moisture retrieval algorithm," IEEE Trans. Geosci. Remote Sens., vol. 50, no. 5, pp. 1384-1403, May 2012

35] D. Carr, R. Kahn, K. Sahr, and T. Olsen, "ISEA discrete global grids," Stat. Comput. Stat. Graph. Newl., vol. 8, no. 2/3, pp. 31-39, 1997.

36] A. A. Bitar, D. Leroux, Y. Kerr, O. Merlin, P. Richaume, A. Sahoo, and E. Wood, "Evaluation of SMOS soil moisture products over continental US using SCAN/SNOTEL network," IEEE Trans. Geosci. Remote Sens., vol. 50, no. 5, pp. 1572-1586, May 2012.

37] G. Schaefer, M. Cosh, and T. Jackson, "The USDA natural resources conservation service soil climate analysis network (SCAN)," J. Atmosp. Ocean. Technol., vol. 24, no. 12, pp. 2073-2077, Dec. 2007.

8] T. Jackson, R. Bindlish, M. Cosh, T. Zhao, P. Starks, D. Bosch, M. Seyfried, S. Moran, Y. Kerr, and D. Leroux, "Validation of soil moisture and ocean salinity (SMOS) soil moisture over watershed networks in the U.S.," IEEE Trans. Geosci. Remote Sens., vol. 50, no. 5, pp. 15301543, May 2012.

9] D. Leroux, Y. Kerr, A. A. Bitar, C. Gruhier, R. Bindlish, T. Jackson, B. Berthelot, and G. Portet, "Comparison between SMOS, VUA, ASCAT and ECMWF soil moisture products over four watersheds in the U.S.," IEEE Trans. Geosci. Remote Sens., submitted for publication.

40] J. Sabatier, A. Fouilloux, and P. de Rosnay, "Technical implementation of SMOS data in the ECMWF integrated forecast system," IEEE Geosci. Remote Sens. Lett., vol. 9, no. 2, pp. 252-256, Mar. 2012.

11] [Online]. Available: ftp://n4ftl01u.ecs.nasa.gov/SAN/AMSA/

42] C. Gruhier, P. de Rosnay, Y. Kerr, E. Mougin, E. Ceschia, J. Calvet, and P. Richaume, "Evaluation of AMSR-E soil moisture product based on ground measurements over temperate and semi-arid regions," Geophys. Res. Lett., vol. 35, no. 10, p. L10 405, May 2008.

43] C. Rudiger, J. C. Calvet, C. Gruhier, T. Holmes, R. de Jeu, and W. Wagner, "An intercomparison of ERS-SCAT and AMSR-E soil moisture observations with model simulations over France," Amer. Meteorol. Soc., vol. 10, no. 2, pp. 431-447, Apr. 2009.

44] C. Draper, J. Walker, P. Steinle, R. de Jeu, and T. Holmes, "An evaluation of AMSR-E derived soil moisture over Australia," Remote Sens. Environ., vol. 113, no. 4, pp. 703-710, Apr. 2009.

45] C. Gruhier, P. de Rosnay, S. Hasenauer, T. Holmes, R. de Jeu, Y. Kerr, E. Mougin, E. Njoku, F. Timouk, W. Wagner, and M. Zribi, "Soil moisture active and passive microwave products: Intercomparison and evaluation over a Sahelian site," Hydrol. Earth Syst. Sci., vol. 14, no. 1, pp. 141-156, Jan. 2010.

46] S. Chaurasia, D. Tung, P. Thapliyal, and P. Joshi, "Assessment of AMSRE soil moisture product over India," Int. J. Remote Sens., vol. 32, no. 23, pp. 7955-7970, Dec. 2011.

47] T. Jackson, M. Cosh, R. Bindlish, P. Starks, D. Bosch, M. Seyfried, D. Goodrich, M. Moran, and J. Du, "Validation of advanced microwave scanning radiometer soil moisture products," IEEE Trans. Geosci. Remote Sens., vol. 48, no. 12, pp. 4256-4272, Dec. 2010.

8] B. Schweizer and E. Wolff, "On nonparametric measures of dependence for random variables," Ann. Stat., vol. 9, no. 4, pp. 879-885, Jul. 1981. multiple degradation processes and random shock using time-varying copulas," IEEE Trans. Rel., vol. 61, no. 1, pp. 13-22, Mar. 2012

[50] C. Genest and L.-P. Rivest, "Statistical inference procedures for bivariate 906 Archimedean copulas," J. Amer. Stat. Assoc., vol. 88, no. 423, pp. 1034- 907 1043, Sep. 1993.

[51] J. Fermanian, "Goodness of fit tests for copulas," J. Multivariate Anal., 909 vol. 95, no. 1, pp. 119-152, Jul. 2005.

[52] C. Genest, J.-F. Quessy, and B. Rémillard, "Goodness-of-fit procedures 911 for copula models based on the probability integral transform," Scand. J. 912 Stat., vol. 33, no. 2, pp. 337-366, Jun. 2006.

[53] C. Genest and B. Rémillard, "Validity of the parametric bootstrap 914 for goodness-of-fit testing in semiparametric models," Annales Henri 915 Poincaré, vol. 44, no. 6, pp. 1096-1127, 2008.

[54] D. Berg, "Copula goodness-of-fit testing: An overview and power com- 917 parison," Eur. J. Finance, vol. 15, no. 7/8, pp. 675-701, 2009.

[55] C. Genest, B. Rémillard, and D. Beaudoin, "Goodness-of-fit tests for 919 copulas: A review and a power study," Insurance: Math. Econom., vol. 44, 920 no. 2, pp. 199-213, Apr. 2009.

[56] D. Huard, G. Evin, and A. Favre, "Bayesian copula selection," Comput. 922 Stat. Data Anal., vol. 51, no. 2, pp. 809-822, Nov. 2006.

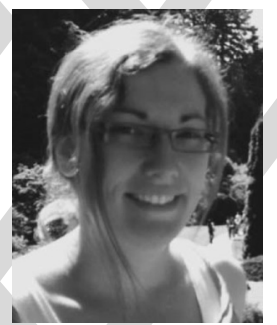

Delphine J. Leroux received the M.S. degree in 924 applied mathematics from Institut National des Sci- 925 ences Appliquees, Toulouse, France, in 2009 and the 926 $\mathrm{Ph} . \mathrm{D}$. degree in spatial hydrology from Universite 927 Paul Sabatier, Toulouse, in 2012.

From 2009 to 2012, she was with the Centre 929 d'Etudes Spatiales de la Biosphere, Toulouse, where 930 she worked on the validation of the Soil Moisture 931 and Ocean Salinity soil moisture product at the local 932 and global scales by using statistical and physical 933 methods. She is currently with the Jet Propulsion 934 Laboratory (JPL), Pasadena, CA, USA, on the Soil Moisture Active Passive 935 mission.
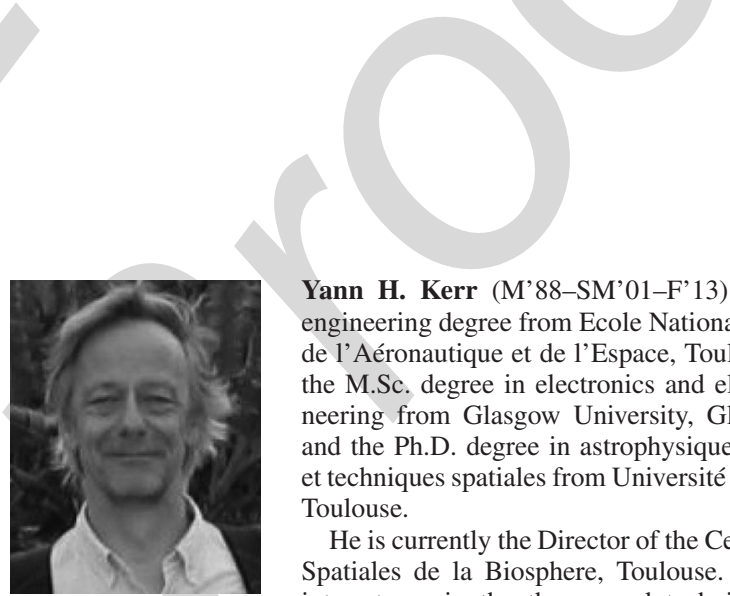

Yann H. Kerr (M'88-SM'01-F'13) received the 937 engineering degree from Ecole Nationale Supérieure 938 de l'Aéronautique et de l'Espace, Toulouse, France, 939 the M.Sc. degree in electronics and electrical engi- 940 neering from Glasgow University, Glasgow, U.K., 941 and the Ph.D. degree in astrophysique geophysique 942 et techniques spatiales from Université Paul Sabatier, 943 Toulouse.

He is currently the Director of the Centre d'Etudes 945 Spatiales de la Biosphere, Toulouse. His fields of 946 interest are in the theory and techniques for mi- 947 crowave and thermal infrared remote sensing of the Earth, with emphasis 948 on hydrology and water resource management. He was an EOS Principal 949 Investigator (interdisciplinary investigations) and PI and precursor of the use 950 of the SCAT over land. In 1990, he started to work on the interferometric 951 concept applied to passive microwave Earth observation and was subsequently 952 the Science Lead on the MIRAS project for ESA. In 1997, he proposed the 953 Soil Moisture and Ocean Salinity (SMOS) mission, the natural outcome of the 954 previous MIRAS work. He is currently involved in the exploitation of SMOS 955 data, in the Cal Val activities and related level 2 soil moisture and level 3 and 4956 developments. He is also working on the SMOS next concept.

Dr. Kerr received the World Meteorological Organization 1st prize (Norbert 958 Gerbier), the USDA Secretary's team award for excellence (Salsa Program), 959 and the GRSS certificate of recognition for leadership in the development of 960 the first synthetic aperture microwave radiometer in space and success of the 961 SMOS mission and is a Distinguished Lecturer for GRSS.
962 


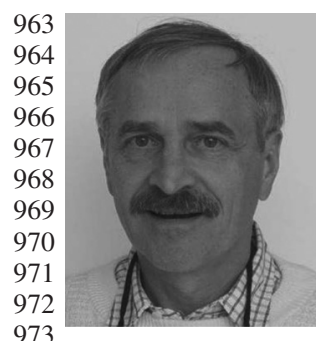

Eric F. Wood received the B.A.Sc. degree in civil engineering from the University of British Columbia, Vancouver, BC, Canada, in 1970 and the S.M., C.E., and Sc.D. degrees in civil engineering from the Massachusetts Institute of Technology, Cambridge, MA, USA, in 1972, 1973, and 1974, respectively.

$\mathrm{He}$ is currently a Professor in the Department of Civil and Environmental Engineering, Princeton University, NJ, USA. His recent contributions include the macroscale hydrologic prediction of the coupled water and energy balances of the land sur974 face, remote sensing as an integral tool for observation and modeling of 975 the hydrologic cycle, and developing and evaluating seasonal hydrological 976 forecasts based on coupled seasonal climate forecasts.

977 Dr. Wood is a fellow of the American Geophysical Union and the American 978 Meteorological Society. He received, among other honors, the Robert E. Horton 979 Award from the Hydrology Section of the American Geophysical Union (1977), 980 the John Dalton Medal from the European Geophysical Union (2007), and the 981 Jules G. Charney Award from the American Meteorological Society (2010).

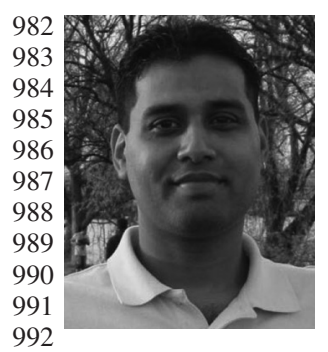

Alok K. Sahoo received the Ph.D. degree in computational sciences from George Mason University, Fairfax, VA, USA, in 2008.

After finishing his Ph.D., he worked as a Research Associate at the Institute of Global Environment and Society, Beltsville, MD, USA, from 2008 to 2009. $\mathrm{He}$ is currently an Associate Research Hydrologist with the Department of Civil and Environmental Engineering, Princeton University, Princeton, NJ, USA. His research interests involve the application of microwave remote sensing in hydrologic applications. 993 His current research projects include soil moisture estimation from microwave 994 sensors and checking consistency among hydrologic cycle variables for drought 995 monitoring.

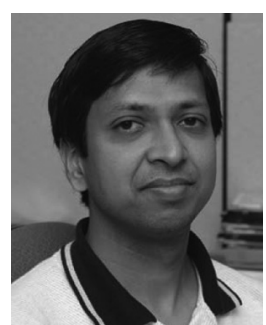

Rajat Bindlish (S'98-AM'99-M'03-SM'05) re- 996 ceived the B.S. degree in civil engineering from the 997 Indian Institute of Technology, Bombay in 1993 and 998 AQ40 the M.S. and Ph.D. degrees in civil engineering from 999 The Pennsylvania State University in 1996 and 2000, 1000 AQ41 respectively.

He is currently with SSAI, working at USDA 1002 AQ42 Agricultural Research Service, Hydrology and Re- 1003 mote Sensing Laboratory, Beltsville, MD, USA. His 1004 research interests involve the application of mi- 1005 crowave remote sensing in hydrology. He is currently 1006 working on soil moisture estimation from microwave sensors and their subse- 1007 quent application in land surface hydrology.

1008

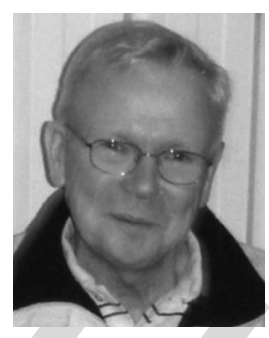

Thomas J.Jackson (SM'96-F'02) received the 1009 $\mathrm{Ph} . \mathrm{D}$. degree from the University of Maryland, 1010 College Park, MD, USA, in 1976.

1011

$\mathrm{He}$ is a Research Hydrologist with the U.S. De- 1012 partment of Agriculture, Agricultural Research Ser- 1013 vice, Hydrology and Remote Sensing Laboratory, 1014 Beltsville, MD, USA. His research involves the ap- 1015 plication and development of remote sensing tech- 1016 nology in hydrology and agriculture, primarily the 1017 microwave measurement of soil moisture.

1018

Dr. Jackson is or has been a member of the science 1019 and validation teams of the Aqua, ADEOS-II, Radarsat, Oceansat-1, Envisat, 1020 AQ43 ALOS, Soil Moisture and Ocean Salinity, Aquarius, GCOM-W, and Soil 1021 AO44 Moisture Active Passive remote sensing satellites. He is a fellow of the Society 1022 of Photo-Optical Instrumentation Engineers, the American Meteorological 1023 Society, and the American Geophysical Union. In 2003, he received the 1024 William T. Pecora Award (NASA and Department of Interior) for outstanding 1025 contributions toward understanding the Earth by means of remote sensing 1026 and the AGU Hydrologic Sciences Award for outstanding contributions to the $1027 \mathrm{AQ4}$ science of hydrology. He received the IEEE Geoscience and Remote Sensing 1028 Society Distinguished Achievement Award in 2011. 


\section{AUTHOR QUERIES}

\section{AUTHOR PLEASE ANSWER ALL QUERIES}

Please be aware that the authors are required to pay overlength page charges ( $\$ 200$ per page) if the paper is longer than 6 pages. If you cannot pay any or all of these charges please let us know.

This pdf contains 2 proofs. The first half is the version that will appear on Xplore. The second half is the version that will appear in print. If you have any figures to print in color, they will be in color in both proofs.

AQ1 = The sentence was restructured for clarity. Please check if the original thought was retained, and correct if necessary.

AQ2 = Please provide the expanded form of "USDA."

AQ3 = Please provide the expanded form of "ARS."

AQ4 = The sentence was restructured for clarity. Please check if the original thought was retained, and correct if necessary.

AQ5 = The sentence was restructured for clarity. Please check if the original thought was retained, and correct if necessary.

AQ6 = "AMSR-E" is defined as "Advanced Microwave Scanning Radiometer-Earth Observing System" for consistency. Please check if appropriate, and correct if necessary.

AQ7 = The sentence was restructured for clarity. Please check if the original thought was retained, and correct if necessary.

AQ8 = "Picard et al." was changed to "Picard and Fily." Please check if appropriate, and correct if necessary."

AQ9 = The sentence was rephrased for clarity. Please check if the original thought was retained, and correct if necessary.

AQ10 = The sentence was rephrased for clarity. Please check if the original thought was retained, and correct if necessary.

AQ11 = The sentence was rephrased for clarity. Please check if the original thought was retained, and correct if necessary.

AQ12 = The sentence was restructured for clarity. Please check if the original thought was retained, and correct if necessary.

AQ13 = "rmse" is defined as "root-mean-square error." Please check if appropriate, and correct if necessary."

AQ14 = The sentence was rephrased. Please check if the original thought was retained, and correct if necessary."

AQ15 = Please provide the expanded form of "NASA."

AQ16 = The sentence was rephrased for clarity. Please check if the original thought was retained, and correct if necessary.

AQ17 = The sentence was rephrased for clarity. Please check if the original thought was retained, and correct if necessary.

AQ18 = The caption was rephrased for clarity. Please check if the original thought was retained, and correct if necessary.

AQ19 = The sentence was rephrased for clarity. Please check if the original thought was retained, and correct if necessary.

AQ20 = "CDF" is defined as "cumulative density function" for consistency. Please check if appropriate, and correct if necessary.

AQ21 = The sentence was rephrased for clarity. Please check if the original thought was retained, and correct if necessary. 
AQ22 = The sentence was rephrased for clarity. Please check if the original thought was retained, and correct if necessary.

AQ23 = The sentence was rephrased for clarity. Please check if the original thought was retained, and correct if necessary.

AQ24 = The sentence was rephrased for clarity. Please check if the original thought was retained, and correct if necessary.

AQ25 = The sentence was rephrased for clarity. Please check if the original thought was retained, and correct if necessary.

AQ26 = The sentence was rephrased for clarity. Please check if the original thought was retained, and correct if necessary.

AQ27 = Please provide publication update in Ref. [39].

AQ28 = The author's current affiliation indicated in the footnote did not correspond to the current affiliation provided in the curriculum vitae. Please check.

AQ29 = The sentence was rephrased for clarity. Please check if the original thought was retained, and correct if necessary.

AQ30 = The sentence was rephrased for clarity. Please check if the original thought was retained, and correct if necessary.

AQ31 = Please provide the expanded form of "EOS."

AQ32 = Please provide the expanded form of "PI."

AQ33 = Please provide the expanded form of "SCAT."

AQ34 = Please provide the expanded form of "MIRAS."

AQ35 = Please provide the expanded form of "ESA."

AQ36 = Please provide the expanded form of "Cal Val."

AQ37 = "Dr." was inserted as the title for author Yann H. Kerr. Please check if appropriate, and correct if necessary.

AQ38 = Please provide the expanded form of "GRSS."

AQ39 = The sentence was rephrased for clarity. Please check if the original thought was retained, and correct if necessary.

AQ40 = Please provide the specific location of the Indian Institute of Technology, Bombay.

AQ41 = Please provide the specific location of The Pennsylvania State University.

AQ42 = Please provide the expanded form of "SSAI."

AQ43 = Please provide the expanded form of "ADEOS-II."

AQ44 = Please provide the expanded form of "ALOS."

AQ45 = Please provide the expanded form of "GCOM-W."

AQ46 = Please provide the expanded form of "AGU." 